\title{
Travel in Britain in 2035
}

Future scenarios and their implications for technology innovation

Charlene Rohr, Liisa Ecola, Johanna Zmud, Fay Dunkerley, James Black, Eleanor Baker

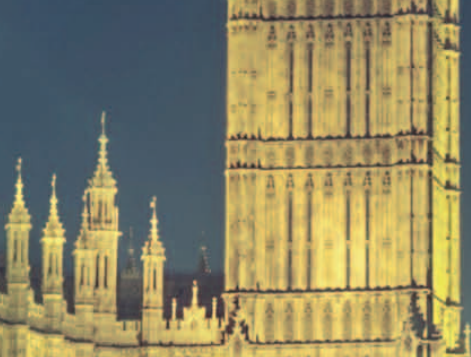

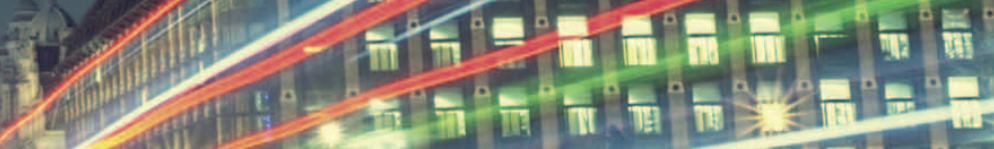

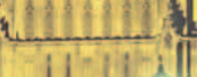


For more information on this publication, visit www.rand.org/t/RR1377

Published by the RAND Corporation, Santa Monica, Calif., and Cambridge, UK

RAND $^{\circledR}$ is a registered trademark.

\title{
Innovate UK
}

\author{
(C) 2016 Innovate UK
}

RAND Europe is a not-for-profit organisation whose mission is to help improve policy and decisionmaking through research and analysis. RAND's publications do not necessarily reflect the opinions of its research clients and sponsors.

All rights reserved. No part of this book may be reproduced in any form by any electronic or mechanical means (including photocopying, recording, or information storage and retrieval) without permission in writing from the sponsor.

\section{Support RAND}

Make a tax-deductible charitable contribution at www.rand.org/giving/contribute

www.rand.org

www.randeurope.org 


\section{Preface}

RAND Europe, in collaboration with Risk Solutions and Dr Johanna Zmud from the Texas A\&M Transportation Institute, was commissioned by Innovate UK to develop future travel scenarios for 2035 , considering possible social and economic changes and exploiting key technologies and innovation in ways that could reduce congestion. The purpose of this independent research is to explore and examine how new technologies may influence travel and to facilitate discussion about how transport can be more efficient in future. In no way are the findings intended to reflect the views, opinions or policy of Innovate UK or the UK Government.

The scenario methodology focuses on identifying the potential impact of critical factors and technologies on five activities and the travel associated with them - undertaking work and business, shopping, seeking healthcare, making long-distance journeys for work or leisure, and freight activity. It combines expert opinion, gathered via in-person workshops, with crossimpact analysis, consistency analysis and cluster analysis. The scenarios are then used to identify innovation investments and policies that provide benefits across the range of possible futures.
This report describes the main aspects of the study: the identification of key future technologies, the development of the scenarios, and the findings from interviews with experts about what the scenarios may mean for innovation and policy priorities. It may be of use to policymakers or researchers who are interested in future travel and the influence of technology.

RAND Europe is a not-for-profit organisation whose mission is to help improve policy and decisionmaking through research and analysis. RAND Europe's clients include European governments, institutions, NGOs and firms with a need for rigorous, independent, multidisciplinary analysis.

For more information about RAND Europe or this document, please contact:

Charlene Rohr

RAND Europe

Westbrook Centre

Milton Road

Cambridge, United Kingdom

CB4 1YG

Tel. +44 (1223) 353329

crohr@rand.org 



\section{Table of contents}

$\begin{array}{lll}\text { Preface } & \text { iii }\end{array}$

Table of contents $\quad v$

Figures and tables $\quad$ vii

Summary $\quad$ ix

Acknowledgements $\quad$ xiii

Abbreviations $\quad$ xv

Chapter One. Using future transport scenarios to identify future policy and investment needs 1

1.1. Study background, scope and objectives

1.2. Our study methodology 3

1.2.1. Technology review 3

1.2.2. Creating the scenarios 3

1.2.3. Draw policy and innovation implications 6

Chapter Two. Key technologies that could influence transport efficiency in $2035 \quad 7$

2.1. Autonomous vehicles 8

2.2. Next-generation connectivity 10

2.3. User apps and Big Data 12

2.4. Advanced manufacturing 13

2.5. Internet of Things 14

2.6. Novel materials and embedded sensors in infrastructure 15

$\begin{array}{ll}\text { Chapter Three. Three future transport scenarios } & 17\end{array}$

3.1. Driving Ahead 20

3.1.1. A day in the life of Driving Ahead: The Borowskis 24

3.2. Live Local $\quad 25$

3.2.1. A day in the life of Live Local: Mia

3.3. Digital Divide 30

3.3.1. A day in the life of Digital Divide: Max and Jules 34

Chapter Four. What do these scenarios mean for policy and innovation investment? $\quad 35$

4.1. Barriers and enablers for key technologies 36

4.1.1. Public acceptability and consumer demand $\quad 36$

4.1.2. Data security and privacy 38

4.1.3. Interaction with legacy systems 38

4.1.4. Legal and regulatory frameworks 38

4.1.5. Standardisation and interoperability 39 
4.1.6. Nature of the market $\quad 40$

4.2. The implications of the scenarios for policymaking 40

4.3. Identifying robust innovation investments $\quad 43$

4.3.1. Investment in next-generation ICT 44

4.3.2. Investment in Big Data / user apps 44

4.3.3. Investment in pilot/real-world testing $\quad 45$

4.4. Need for new business models $\quad 45$

4.5. Strategic roadmap of policy and innovation investment 46

$\begin{array}{ll}\text { 4.5.1. Next steps } & 47\end{array}$

$\begin{array}{ll}\text { References } & 49\end{array}$

Appendix A: Methodology for shortlisting key technologies $\quad 55$

Developing the assessment criteria to identify key technologies $\quad 55$

Identifying and assessing potential technologies of interest $\quad 57$

Characterisation of technologies against framing criteria $\quad 58$

Comparison of technologies across key criteria $\quad 58$

Selecting key technologies $\quad 59$

Appendix B: Scenario methodology

Step 1: Select activities $\quad 63$

Step 2: Identify critical factors $\quad 65$

$\begin{array}{ll}\text { Step 3: Elicit projections on critical factors } & 67\end{array}$

Step 4: Integrate into scenario frameworks $\quad 69$

Step 5: Produce scenario narratives $\quad 72$ 


\section{Figures and tables}

Figure 1.1. Study tasks and methodologies 3

Figure 1.2. The STREAM methodology for technology assessment 4

Figure 1.3. The range of future scenarios $\quad 5$

Figure 1.4. Scenario methodology $\quad 5$

Figure 3.1. The Driving Ahead, Live Local and Digital Divide scenarios 19

Figure A.1. Overview of UK transport stakeholders examined 55

Figure A.2. Longlist of potential technologies $\quad 57$

Figure A.3. Scenario methodology $\quad 64$

Figure A.4. Factor impact measured through cross impact analysis $\quad 66$

$\begin{array}{ll}\text { Figure A.5. Extract from the consistency matrix } & 69\end{array}$

Table 2.1. NHTSA taxonomy of autonomy levels $\quad 8$

Table 4.2. Implications of scenarios for society, businesses and government 42

Table A.1. Key assessment criteria for technologies 56

Table A.2. Barriers affecting probability of successful implementation (POSI) 57

Table A.3. Shortlist of candidate technologies for assessment 58

Table A.4. Assessment scores for shortlisted technologies $\quad 59$

Table A.5. Outcome of selection process 60

Table A.6. Recommended technologies to be considered in scenarios 61

$\begin{array}{ll}\text { Table A.7. Activities and critical factors } & 65\end{array}$

$\begin{array}{ll}\text { Table A.8. Projections for common factors } & 67\end{array}$

Table A.9. Projections for activity-specific factors $\quad 68$

$\begin{array}{ll}\text { Table A.10. High GDP clusters, by technology type } & 71\end{array}$ 


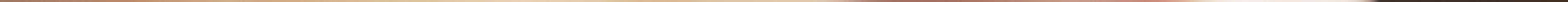




\section{Summary}

The UK's roads, railways and airports are some of the most congested in the world (Mills et al. 2011). In the past, countries including the UK have addressed such problems with additional infrastructure investment. But this strategy has its limits: land is finite and subject to competing uses, government resources are constrained, and study after study has shown that it is not possible to build one's way out of congestion, because improved transport services entice more people to use those services. Innovate UK is looking at other strategies to alleviate congestion, such as managing demand, making better use of existing capacity, and encouraging shifts away from congested modes of travel. Essentially, the goal is to make the existing transport system more efficient and effective.

One way to approach this problem is through technology. Technologies could help address all three of these possible strategies. For example, virtual presence may be an appropriate substitute for some types of journey, thus reducing overall travel demand. Advanced manufacturing methods, like 3D printing, could create consumer products closer to their potential markets, thus reducing shipping distances. With regard to capacity, ride- or loadsharing apps could help fill empty passenger seats in cars or unutilised space in lorries. And to encourage mode shifts, instead of trying to push people away from already crowded modes, we need to lure them away with innovative strategies and ensure that transfers across modes are seamless.

\section{Key technologies}

This study was commissioned to explore how different technologies might address travel demand in the future. The focus is on travel in 2035. Any technology that will be widely available in 2035 is most likely to already be under development. Consequently, radically new technologies are not considered, but rather we focus on technologies that are in development currently, but that are not yet commercially viable, or that may combined with other technologies to create new uses, or those that are currently prohibitively expensive but may become more affordable in the future.

From a long-list of over 60 technologies, six were identified that could have a substantial impact on the efficiency and effectiveness of the transport network, by influencing travel demand, increasing the capacity of the transport network, or by improving the productivity of travellers.

These are:

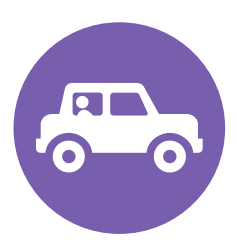

Autonomous vehicles (AVs):

a field of technologies that, in their fullest expression, will allow vehicles to sense their environment and navigate without human input. There may also be more limited options in which vehicles could self-navigate only in certain environments or certain circumstances; such vehicles would still occasionally require human drivers.

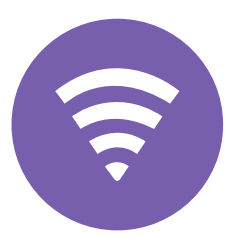

\section{Next-generation ICT} connectivity / telecommuting / telehealth: These three initially separate technologies were merged and considered as one broad group. Next-generation connectivity denotes a range of telecommunications technologies that improve bandwidth, network availability and download/upload speeds for wireless communication. Telecommuting is the ability of an employee to work remotely without needing to be physically present at a workplace. 
Telehealth is the remote delivery of healthrelated services, ranging from a simple GP consultation over the phone through to remotecontrolled robotic surgery.

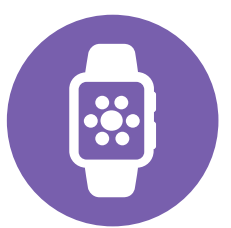

\section{User apps / Big Data /} intelligent processing: These technologies were merged and considered as one broad group. User apps include personalisation (such as voice and facial recognition) that provides individuals with new ways to access and visualise data to inform transport decisions. This could also include wearable technology, such as 'smart' watches. Big Data refers to the growing generation and collation of vast amounts of data, with the sheer volume presenting novel challenges and opportunities in terms of analysis, storage and visualisation. Intelligent processing includes new, 'smart' ways of processing and leveraging this data in future.

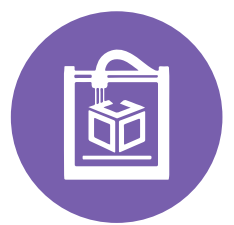

\section{Advanced manufacturing} (including 3D printing): Advanced manufacturing comprises a range of novel technologies to improve manufacturing processes. These include the use of additive manufacturing (also known as 3D printing), robotics, novel materials (e.g. bio, nano, composite, smart), and other advanced equipment (e.g. lasers, plasma, waterjet). It also includes novel methods, digital tools, rapid prototyping and synthetic environments (e.g. virtual or augmented reality) to aid design and production processes.

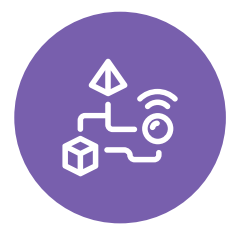

Internet of Things: The Internet of Things (IOT) is a network of physical objects capable of detecting and communicating information between each other through the use of embedded chips, sensors and connectivity. It creates a pervasive and self-organising network of identifiable physical objects, such as 'smart' meters, wearable technology or domestic appliances, which can then transfer data between each other.

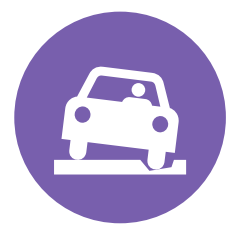

Novel materials and embedded sensors in infrastructure: This refers to a range of advances in materials science and production techniques. Self-healing

materials, for example, could automatically repair ruptures or abrasions in road surfaces, and embedded sensors in roads, rails or runways could provide continuous self-monitoring of the need for maintenance.

We deliberately excluded fuel and vehicle technologies whose main purpose is to reduce emissions or fuel consumption. This is not to say they are not important - they obviously are, given the sizable contributions of the transport sector to environmental concerns including climate change - but simply that these technologies do not directly influence the effectiveness and efficiency of the network. 


\section{Three future scenarios}

We used a scenario approach to explore plausible visions of the future. The aim was not to attempt to predict the future, but to explore a broad spectrum of future possibilities.

Our futures methodology combines expert opinion, gathered via in-person workshops, with cross-impact analysis, consistency analysis and cluster analysis using specialised computer support. Even though it relies more on substantive expertise than on formal research and modelling, the approach was highly empirical.

We developed three future travel scenarios, incorporating the technologies described above, as well as social and economic factors that may influence future travel. These scenarios vary by GDP growth assumptions, technology development, cost of travel and total travel.

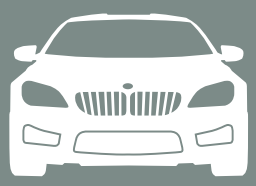

Driving Ahead: A scenario where gross domestic product (GDP) and per capita travel have grown at rates higher than anticipated. Stimulating growth in both is the rise of autonomous vehicles (AVs), which are changing the face of not only transport, but also healthcare and retail. Many of these are shared vehicles, reducing costs for those who no longer have to own cars. The ease of use has led to growth in vehicle travel and congestion, as being stuck in traffic no longer means being unproductive. As the population has grown, the large proportion of older people who live on their own have greater flexibility to travel, especially for medical visits, and the freight and retail sectors make heavy use of AVs for both long-haul freight as well as delivery to customers.

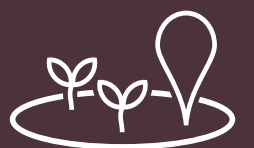

Live Local: This scenario is distinguished by more use of digital substitution for travel and lower per capita travel. The most advanced technologies developed by 2035 are more powerful ICT, user apps and the Internet of Things. They have led to some profound changes in travel demand, because their ease of use has led to far greater use of telepresence. At the same time there has been an evolution in environmental attitudes, with a robust 'Live Local' movement that frowns on excess travel, as well as greater decentralisation of both population and employment away from London. Two other factors have contributed to the decline in per capita travel: first, AVs have not been widely adopted by the public, and second, road pricing has become sophisticated and effective.

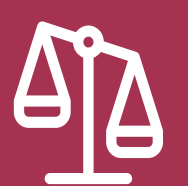

Digital Divide: In this scenario, the economy and the overall population are growing at slower-than-anticipated rates. Income inequality is increasing and, while advanced technologies have been commercialised, many remain financially out of reach for much of the population. Lower GDP growth combined with increased travel costs has led to lower levels of travel per capita. Advanced ICT has contributed to businesses moving away from London, which has remained very expensive. AVs and 3D printing are used fairly extensively in the freight sector, with warehouses around the country serving as devolved 3D printing locations. An extensive peer-to-peer and sharing-based economy has developed, because many people cannot afford to buy everything new. 


\section{Strategic roadmap of policy and investment}

In order to encourage efficient and effective transport in future, government agencies should:

As a priority, invest in and monitor technological interventions that are robust across a range of future scenarios:

- Be aware of what quality of ICT services are needed to support future technologies and services, such as next-generation telecommuting and telehealth, user apps, Big Data, V2V and V2I communication, and ensure that these services are available, across all geographies.

- Support the development of frameworks and systems necessary for addressing issues of data governance, transparency, value, privacy and security, ensuring balance in regulation between the beneficial uses of data and consumer protection. Contribute to brokering on issues related to data ownership and data sharing. Support Open Data initiatives that lead to social, environmental and economic benefits for society.

- Support pilot testing of new technologies and services, particularly those that will bring substantial societal benefits.

Develop policies to ensure that new technologies lead to the best outcomes for society:

- Monitor road congestion and introduce road-pricing policies to manage travel demand, if required.

- Support training and up-skilling of workers to ensure they have the skills needed for future jobs.

- Ensure equity of access to technologies that have the possibility of bringing substantial societal benefits, across geographies and society.

Address key barriers to innovation for AVs, next-generation ICT and Big Data / user apps / intelligent processing:

- Monitor and, if necessary, address future liability and safety regulatory issues for AVs.

- Monitor and, if necessary, support the development of standards supporting interoperability of systems, ensuring that such standards are developed in consultation with all relevant stakeholders.

- $\quad$ Provide education to ensure that all those with access to new services are able to benefit from them, particularly monitoring the use and take up of new technology by the elderly.

These scenarios are then used to identify innovation investment and policies that are robust across all scenarios or that ensure positive societal outcomes for the different scenarios or that support development of key technologies. To this end we undertook interviews with experts from government, academia and industry.

The resulting recommendations reflect highlevel observations on policy and innovation investments, based on consideration of the potential future landscape for transport, across the range of technologies discussed. When thinking about the likely development pathway for any one technology, further in-depth studies will be necessary to consider the impact of policies or innovation investments on how that technology may develop.

This study has identified three technologies that are likely to have a substantial impact on future travel: AVs, next-generation ICT and user apps / Big Data. Further work is now required to envisage roadmaps of implementation for each, thinking through how policy may have an impact on their development and use in society. For without thoughtful facilitation, these technology areas are unlikely to develop in ways that will provide the maximum societal benefit. 


\section{Acknowledgements}

We have been able to deliver this study because of the input and support of a number of people. First, we thank Innovate UK for sponsoring the project, and Karla Jakeman, the Portfolio Manager, who provided invaluable support and feedback throughout. We are also grateful for the support of the Knowledge Transfer Network, and particularly the assistance of Rob Furlong and Tessa Darley, who helped pull together the workshops and link us to excellent subject experts. We also wish to thank Dr Peter Phleps for his input on the scenario design and for running the RAHS software for us. We also acknowledge the contribution of other RAND staff who supported this research project: Dr Jon Freeman, Dr Richard Silberglitt, Dr Nicole van der Meulen and Bryn Garrod, who contributed to the technology review task; $\mathrm{Dr}$ Catherine Saunders, who wrote the background paper on health; Dr Stuart Parris, who advised on innovation policy; Dr Joanna Chataway and Alex Hall for their helpful feedback and independent review of this report; and Peter Burge, who reviewed the background papers. We also wish to acknowledge the design support for this report and other project materials provided by Jessica Plumridge. We also thank Dr Helen Wilkinson and Mike Robertson from Risk Solutions for their helpful advice on this report.

Most importantly, however, we are indebted to the host of external experts who gave us their time, enthusiasm and expertise to help us identify the key technologies that influence the effectiveness and efficiency of the transport network, to explore how the future may develop and the implications for innovation investment and policy. They have allowed us to push forward thinking about how the future of transport may unfold.

We emphasise that the views reflected in the report are those of the project team, who remain responsible for any errors or omissions herein. 
We would like to thank all of the people and agencies who made valuable contributions to the workshops, including the following:

Jeremy Baker, ESCP Europe Business School

Dr Ralph Barthel, University of Greenwich

Brian Bolam, Omprompt

Andrew Bolitho, British Retail Consortium

Alan Braithwaite, LCP Consulting

Dr V Paul Brand, Risk Solutions

David Calder, Knowledge Transfer Network

Phil Carey, Phil Carey Consulting

Paul Clitheroe, Liverpool Clinical Commissioning Group

Bert Craven, Travel Technology Research Ltd.

Tessa Darley, Knowledge Transfer Network

Professor Janine Dermody, Oxford Brookes

University

Jolyon Drury, CILT, Surge Logistics Consultants

Rob Furlong, Knowledge Transfer Network

Carl Freeman, Guide Dogs

Evelyne Freiermuth, World Travel \& Tourism

Council

Damian Grantham, Cell Therapy Catapult

Lorna Green, North West Coast Academic

Health Science Network

Mark Grimshaw-Smith, Cemex

Mostafa Gulam, Association of Train Operating

Companies

Dave Horsefield, Liverpool Clinical

Commissioning Group

Dr Nick Knorr, Transport Systems Catapult

Dr Bjorn Madsen, Multi Agent Technology Ltd.

Dr Keith Mason, Cranfield University
Dr Mitra Memarzia, Knowledge Transfer Network, Seeper

Richard Miller, Innovate UK

Eliot Minn, e2E Services Ltd

Alan Nettleton, Transport Systems Catapult

Alan Peters, Transport Systems Catapult

Dr Nikos Pronios, Innovate UK

Dr Robert Quarshie, Knowledge Transfer Network

Dr Arthur Richards, University of Bristol

Mike Robertson, Risk Solutions

Philipp Rode, LSE Cities

Richard Saady, Ricardo

Richard Savage, Future Work Forum

Rebeka Sellick, Interfleet

Maggie Simpson, Rail Freight Group

Freddie Talberg, Pie Mapping

Michael Talbot, Department of Business, Innovation and Skills

James Taplin, Innovate UK

Chris Thompson, Enable iD

Peter Thomson, Future Work Forum

Andrew Traill, Transport Systems Catapult

Robert Turpin, BSI

Sukhvinder Ubhi, Highways England

Barbara Walker, IORMA

Michael Weedon, British Independent Retailers

Association

Professor Peter White, University of Westminster

Scott Wilson, LeighFisher 


\section{Abbreviations}

\begin{tabular}{|c|c|}
\hline $\mathrm{Al}$ & Artificial Intelligence \\
\hline AV & Autonomous vehicle \\
\hline CEN & European Committee for Standardization \\
\hline C-ITS & Cooperative Intelligence Transport Systems \\
\hline ETSI & European Telecommunications Standards Institute \\
\hline FAV & Fully autonomous vehicle \\
\hline GDP & Gross domestic product \\
\hline GP & General practitioner (medical doctor) \\
\hline HALE & High-altitude long-endurance \\
\hline ICT & Information and communications technology \\
\hline loT & Internet of Things \\
\hline IP & Internet Protocol \\
\hline LED & Light-emitting diode \\
\hline $\mathrm{Li}-\mathrm{Fi}$ & Light-enabled Wi-Fi \\
\hline NHTSA & US National Highway Traffic Safety Administration \\
\hline UAV & Unmanned aerial vehicle, e.g. drone \\
\hline V2I & Vehicle-to-infrastructure \\
\hline V2V & Vehicle-to-vehicle \\
\hline Wi-Fi & Wireless computing technology \\
\hline
\end{tabular}





\section{Chapter One.}

Using future transport

scenarios to identify future

policy and investment needs

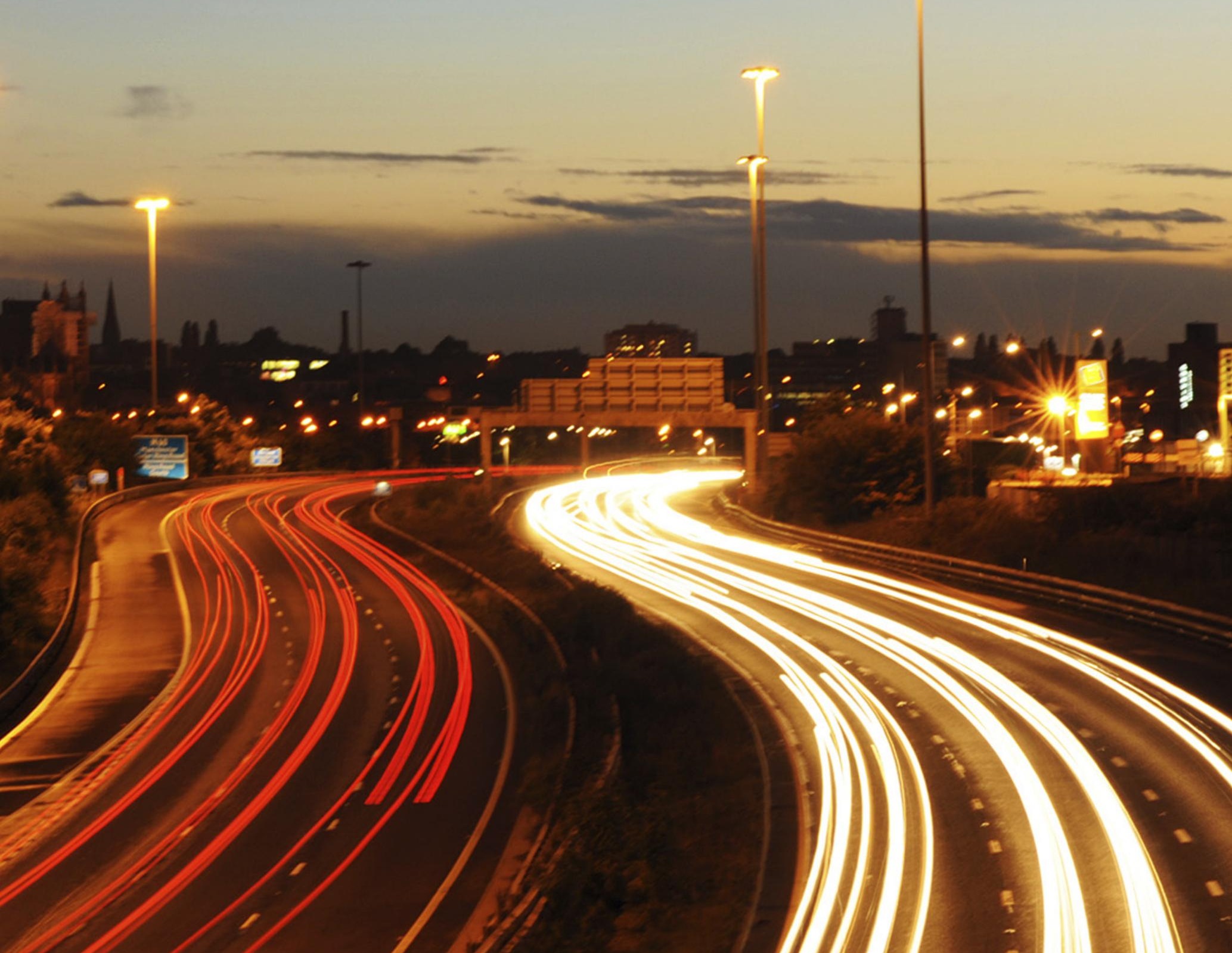




\subsection{Study background, scope and objectives}

The UK, like many other countries, faces an increasing congestion problem. Demand for both passenger travel and goods movement continues to grow and with it a host of problems, including: travel delays and additional costs for motorists, shippers and emergency services; decreasing quality of life; overconsumption of petrol and diesel; greenhouse gas and particulate emissions; and impacts on economic growth.

In the past, most countries have addressed such problems with additional infrastructure investment. But this strategy has its limits. Land is finite and subject to competing uses, government resources are constrained, and most importantly study after study has shown that it is impossible to build one's way out of congestion (Goodwin 1996; Cervero \& Hansen 2002; Noland \& Lem 2002; Rohr et al. 2013b).

When infrastructure supply is constrained, other approaches are needed to ensure that the existing system is used with maximum efficiency. While a variety of strategies could be pursued, this project focuses on how key technologies and innovation can help. The goal is to envision plausible futures that exploit key technologies and innovation to increase the effectiveness and efficiency of the transport network. We then use these to determine which technologies and innovations may be most valuable across a wide range of future scenarios.

Technologies and innovations could be useful for improving effectiveness and efficiency in a variety of ways. First, instead of trying to supply more capacity, we can make the most of the capacity we already have: moving more vehicles on existing roads and more people on existing public transport service, using unused capacity in singleoccupant vehicles or part-filled heavy goods vehicles, as well as making better use of the total capacity, both day and night. Second, instead of trying to push people away from already crowded modes of transport, we need to lure them away with innovative strategies and ensure that transfers across modes are seamless. And finally, instead of assuming that all travel demand can be satisfied only with travel, we need to take advantage of new technologies and innovations that can substitute for travel.

Technologies can help to address all three of these strategies. For example, in relation to capacity, ride-sharing apps can let drivers with empty seats find passengers, or allow haulage companies to better match partial loads with available capacity; automated vehicles can platoon, allowing more vehicles to use the same roads; and real-time information for parking can help drivers avoid excess driving by guiding them directly to available parking spaces. With regard to mode shift, innovations that make car-sharing convenient may discourage car ownership and depress demand for driving; smart braking on cars might reduce collisions with pedestrians and cyclists, encouraging use of those modes; faster broadband and higher-quality connections could enable greater use of telehealth and telework, meaning that less travel may be necessary; and advances in $3 \mathrm{D}$ printing might mean that goods can be produced closer to where they are needed, reducing the need for transport. In this report we focus on technologies that may affect the effectiveness and efficiency of the transport network; we have deliberately excluded fuel and vehicle technologies whose main purpose is to reduce emissions or petrol consumption. This is not to say they are not important - they are, given the sizable contributions of the transport sector to environmental concerns including climate change - but simply that these technologies do not directly influence the effectiveness and efficiency of the network.

We use a futures methodology that takes a systematic view of travel activity, looking at scenarios that incorporate insights from key activities that generate travel: work/business, health, retail, long-distance travel for work and leisure, and freight movement. We focus on 2035: a timeframe that could realistically be influenced 
by decisions taken today. Looking at a future 20 years away strikes a good balance between the possibility of major change - to use an example that has revolutionised our own world, the first device called a 'smartphone' became commercially available in 2000 - yet grounds us in technologies that are almost certainly already under development. However, these technologies may not be commercially viable (yet), they may be improved exponentially, they may fall in price so significantly that far more people can afford them, or they might be combined with existing technologies in ways that create new products and uses. Our focus is on technologies at this stage of development, where experts in the field can realistically assess their future prospects and the changes they may bring.

\subsection{Our study methodology}

Our study methodology involved three main tasks, as illustrated in Figure 1.1 below. First, we undertook a review to identify future technologies that would have an influence on the effectiveness and efficiency of the transport network, recognising that we could not meaningfully compare potential future impacts of more than half a dozen key technologies. Second, we developed scenarios that illustrate how these technologies might play out in 20 years' time. Finally we interviewed experts about what these scenarios may mean in terms of innovation investment and policy priorities.
The results of the technology review process are presented in Chapter 2, the completed scenarios are in Chapter 3, and the results of the interviews are in Chapter 4.

\subsubsection{Technology review}

The aim of this task was to identify technologies that could influence the efficiency and effectiveness of the transport network to be considered in the development of the future scenarios. To this end we used a methodology developed by RAND called STREAM Systematic Technology Reconnaissance, Evaluation and Adoption Methodology (Popper et al. 2013). The STREAM system relies on desktop research and expert interviews to assess the benefits of future technologies, across a range of criteria developed for the project, and the possibility of their successful implementation. The steps of the STREAM methodology are summarised in Figure 1.2 (further details are also provided in Appendix A).

\subsubsection{Creating the scenarios}

The aim of this task was to produce a range of plausible scenarios, reflecting differing views of technology, social and economic change, and the influence of these on future transport. The scenarios are not forecasts but represent a spectrum of future possibilities, as illustrated in Figure 1.2.

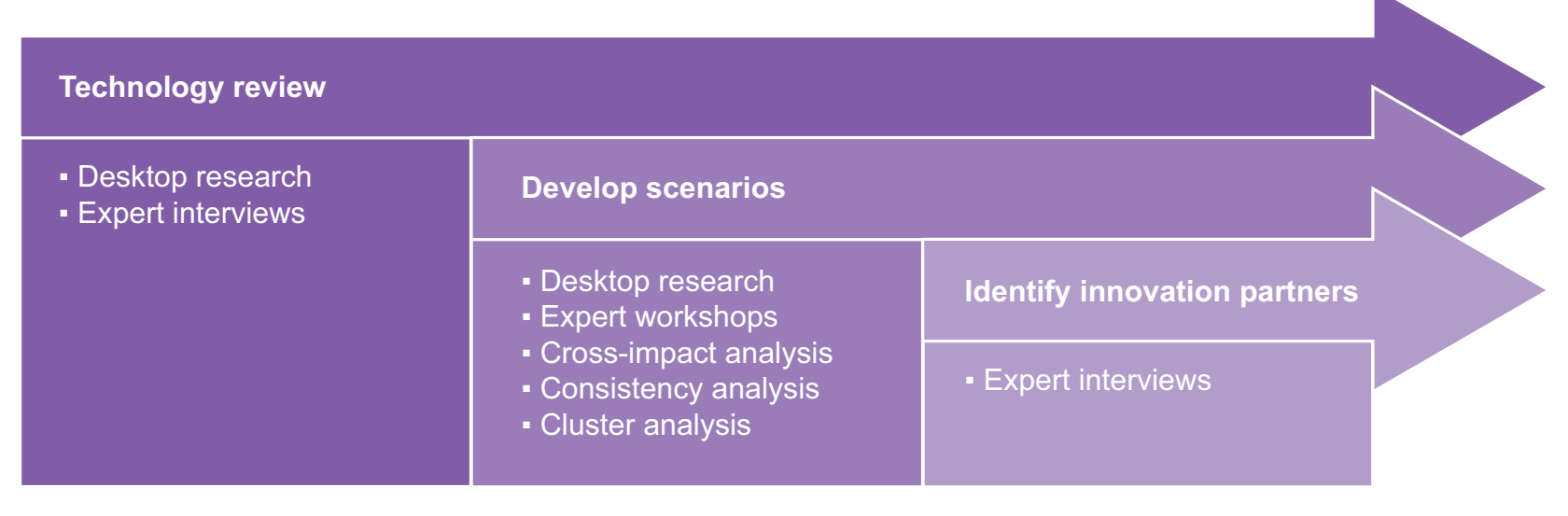

Figure 1.1. Study tasks and methodologies 

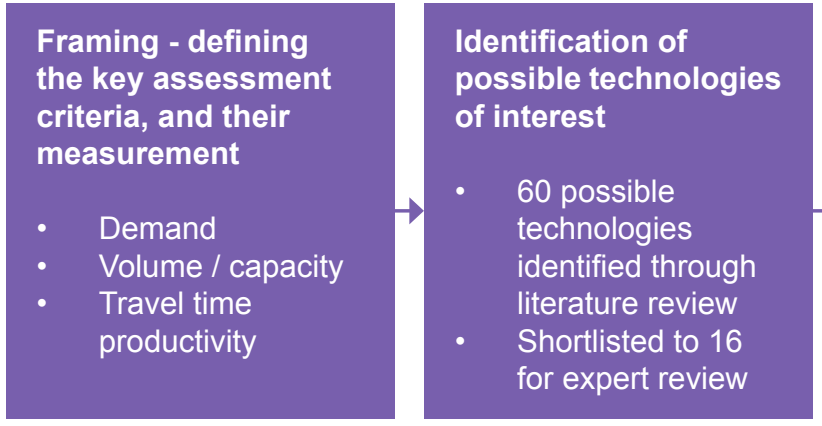

Characterisation of technologies against framing criteria

Interviews with 17 experts to rate technologies against key assessment criteria
Comparison of technologies across key criteria

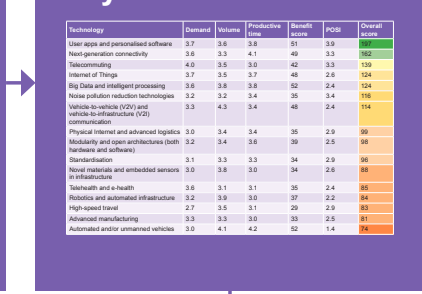

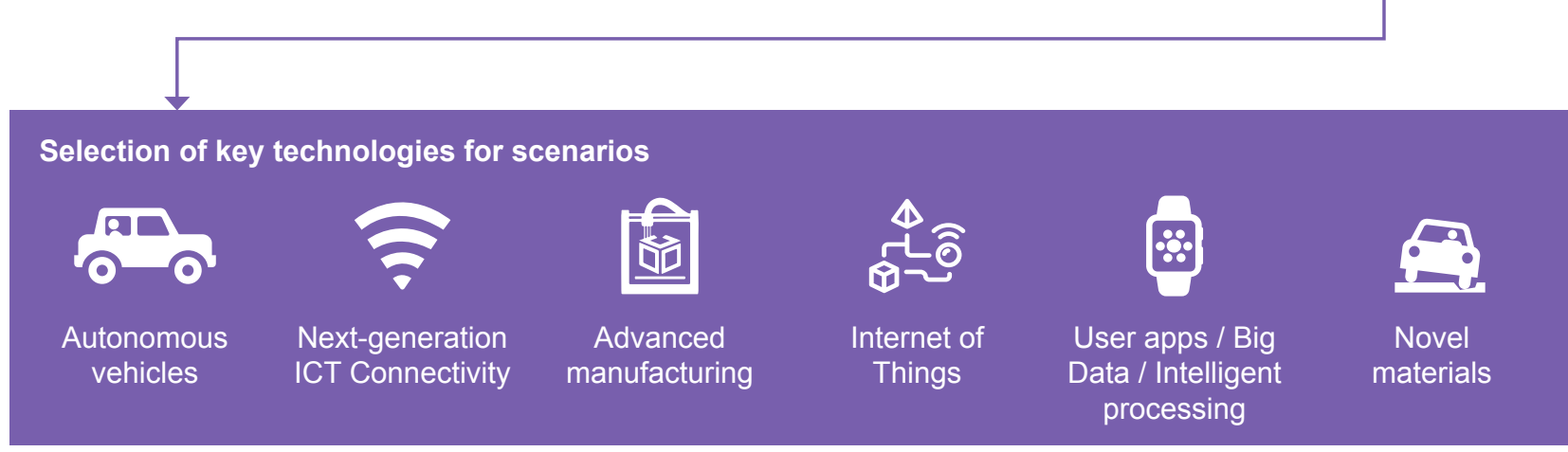

Figure 1.2. The STREAM methodology for technology assessment

The scenario development process used the scenario framework presented in Gausemeier et al. (1998), which combines expert opinion, gathered via in-person workshops, with crossimpact analysis, consistency analysis and cluster analysis using specialised computer support. Even though it relies more on substantive expertise than on formal research and modelling, the approach was highly empirical.

We operationalised this approach in five steps, as shown in Figure 1.4 and briefly discussed below. The methodology is presented in more detail in Appendix B.

\section{Select influencing areas}

We adopted a framework that recognises that individuals, households and businesses need and desire to participate in activities and that participating in these activities generates travel. We assumed that in future people will continue to participate in such activities, but that this participation, and the travel generated by it, may be influenced by social and economic factors and future technologies.
We focused on four activities that may influence travel:

- Undertaking work and business

- Seeking healthcare

- Shopping

- Making long-distance journeys for work or leisure.

These were selected on the basis of several criteria: the share of journeys made for these purposes, the possibility of major change in the activity, and the need to capture both within-city and between-city travel.

A fifth activity, freight movement, was included because it is important to the economy and it contributes to and is affected by transport capacity constraints. Furthermore, delivery of packages to individuals is an area of increasing growth, and many of these movements are between businesses, so they would not be captured in the other four activities. 


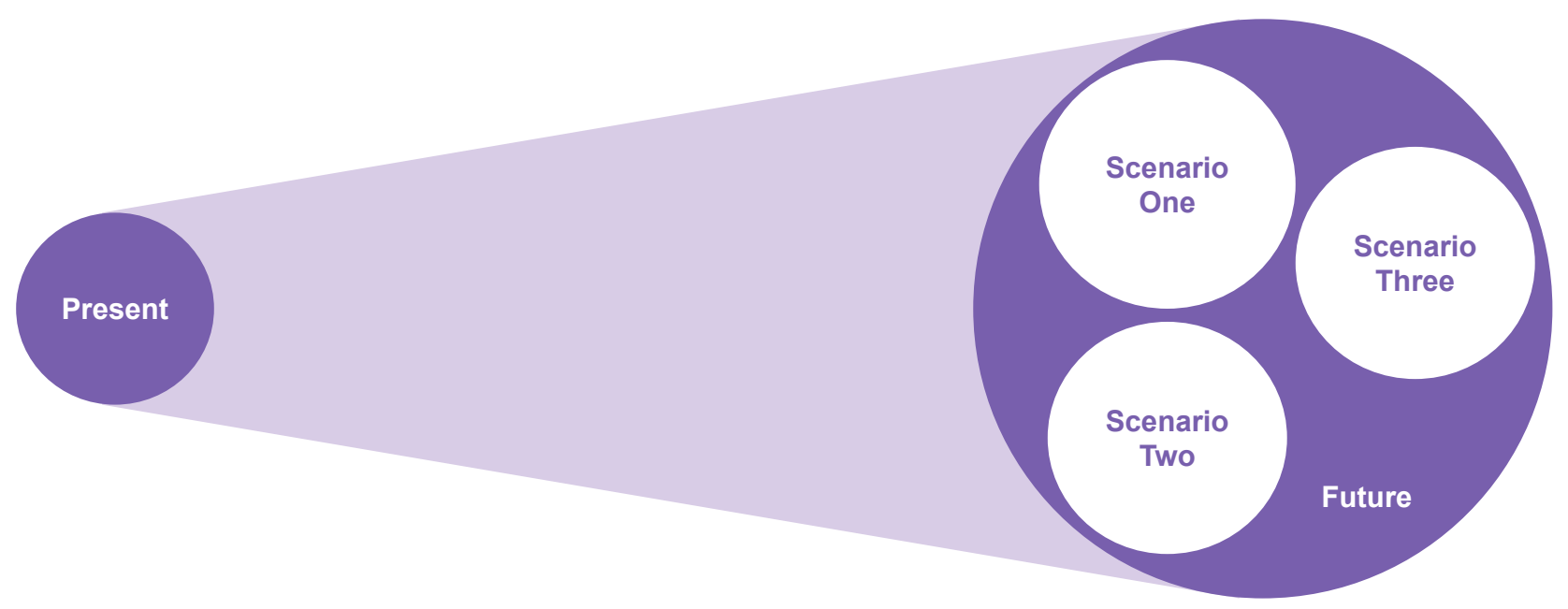

Figure 1.3. The range of future scenarios

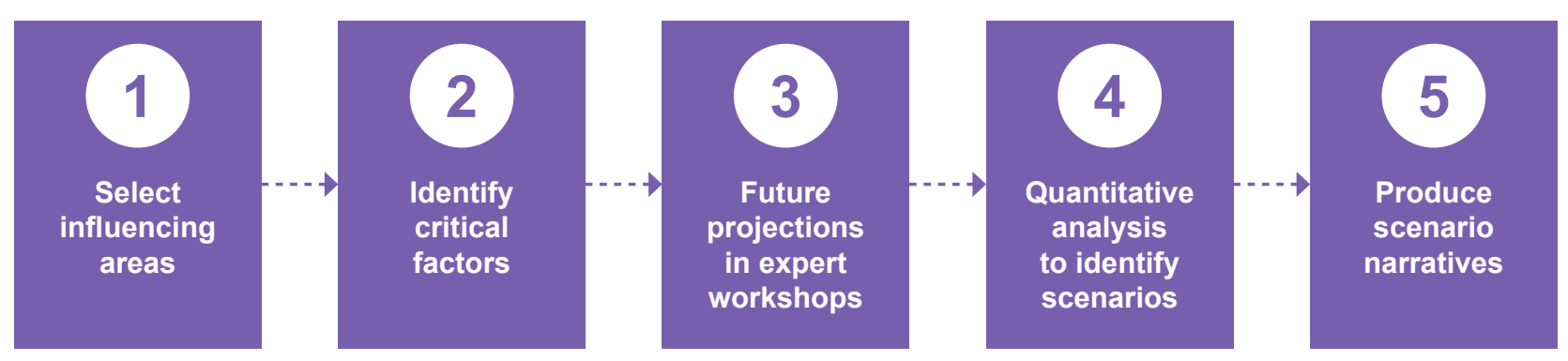

Figure 1.4. Scenario methodology

\section{Identify critical factors}

For each activity, we identified key social and economic factors that could substantially influence travel for the activity in future. For example, the prevalence of online shopping is likely to influence retail travel. We narrowed the factors using two criteria. First, we selected factors whose future state is uncertain, because different outcomes would lead to different scenarios. Second, we looked for 'active' factors, that is, those that have a substantial impact on other factors or on travel in general. Appendix $B$ provides a full list of the 29 factors considered. Six of these were common across all activities (for example, we expect that GDP per capita growth will affect multiple activities). For each activity, we identified four or five specific factors.

\section{Elicit projections on critical factors}

The research team held one workshop for each activity to collect expert opinion. At each workshop, we asked experts to make projections for both the common and the activity-specific factors for 2035, the impact of each projection on travel, and the impact of key technologies on both factors and travel. For example, we asked the freight experts to project the trends in warehousing, whether it would become more centralised or more decentralised (and whether that would be influenced by any of the technologies). Many of these projections were qualitative; we asked about increases vs. decreases, rather than estimated percentage change. The number of projections depended on the degree of consensus on likely futures among the experts. We also asked the experts 
to provide their reasoning (or assumptions) for each projection.

Over 75 experts participated across all of the workshops, including policymakers as well as people from academia and the private sector; most were experts in a particular activity, while others were experts on particular technologies.

\section{Integrate into scenarios}

To assemble the projections into distinct scenarios, we established consistency (or lack thereof) among projections across all factor pairs. Consistency means how well the projections 'fit' and how realistic it would be for both to happen simultaneously. For example, an increase in London-centric development is consistent with rising property prices, but inconsistent with declining prices. We then used an online tool called the RAHS ${ }^{1}$ platform to group projections across all activities. Of all the mathematically possible groupings of projections, RAHS eliminated those that were deemed inconsistent. Of those remaining, RAHS identified clusters of factors and projections that formed unique scenario frameworks. Because of the large number of factors, we made separate runs considering one technology at a time, and then grouped together outputs with similar characteristics.

\section{Produce scenario narratives}

There is no hard and fast limit on the number of scenarios that should be developed - selecting those that differ most meaningfully requires expert judgment. Of the many clusters produced, the research team selected three to develop further. These varied in two significant ways: the projected levels of gross domestic product (GDP) growth and total travel. The three clusters were called:

- Driving Ahead

- Live Local

- Digital Divide.

The Driving Ahead scenario is based around high growth in both measures, while Live Local and Digital Divide have lower (but differing) growth rates in GDP and lower travel. Drawing on the reasoning and assumptions that surfaced during the expert workshops, we developed written narratives. These were validated with the experts who attended the workshops, to ensure that they were plausible, understandable and internally consistent.

\subsubsection{Draw policy and innovation implications}

The three scenarios were then used to identify innovation investments and policies that are robust, in other words those that provide substantial benefits across the range of scenarios, those that ensure positive societal outcomes for the different scenarios, or those that support development of key technologies. To do this, we undertook interviews with 14 experts from government, academia and industry. The interviews followed a semi-structured approach, examining:

- Aspects of each scenario that were positive and negative for Britain

- Key technologies driving the positive impacts, and enablers and barriers to their development

- Policy and investment implications of the scenarios. 


\section{Chapter Two}

Key techologies
that could influence

transport efficiency

in 2035 
Prior to developing the scenarios, we identified technologies that are being developed today that could affect travel effectiveness and efficiency in 2035. We considered over 60 technologies, shortlisting these to the following six based on expert advice (see Appendix A for details).

The key technologies that were selected for consideration in the scenarios were:

\section{- Autonomous vehicles}

- Next-generation ICT connectivity / telecommuting / telehealth

- User apps, Big Data, intelligent processing

- Advanced manufacturing (including 3D printing)

- Internet of Things

- Novel materials and embedded sensors in infrastructure.

Below we provide brief descriptions of each of these, as provided to experts who participated in the scenario development process.

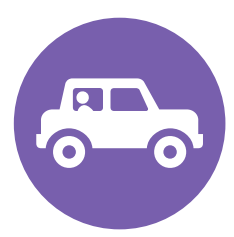

\subsection{Autonomous vehicles}

Autonomous, automated,

driverless and unmanned vehicles represent a range of overlapping descriptions for an emerging field of technologies that enable a vehicle to sense its environment and navigate without human input.

For road vehicles, there is significant variation in the complexity and degree of autonomy built into different systems currently under development. As such, the US National Highway Traffic Safety Administration (NHTSA) defines automation along a sliding five-point scale, reflecting growing levels of sophistication and independence in autonomous decisionmaking.

Current prototypes of self-driving cars use a variety of technologies to sense and map their surroundings, including radar, lidar, ${ }^{2}$ GPS and digital cameras, enabling onboard software to

\section{Table 2.1. NHTSA taxonomy of autonomy levels}

\begin{tabular}{l|l|l|l|l|l}
\hline Category & Definition & Examples \\
\hline $\begin{array}{l}\text { Level zero - } \\
\text { No automation }\end{array}$ & $\begin{array}{l}\text { The driver is 'in complete and sole control of the primary } \\
\text { vehicle controls (brake, steering, throttle and motive power) at } \\
\text { all times and is solely responsible for monitoring the roadway } \\
\text { and for safe operation of all vehicle controls'. }\end{array}$ & $\begin{array}{l}\text { Standard vehicle, and/ } \\
\text { or monitoring systems (for } \\
\text { driver information only), e.g. } \\
\text { forward collision warning }\end{array}$ \\
\hline $\begin{array}{l}\text { Level one -Func- } \\
\text { tion-specific }\end{array}$ & $\begin{array}{l}\text { The vehicle is able to 'assist or augment the driver in operat- } \\
\text { ing one of the primary controls - either steering or braking/ } \\
\text { throttle controls (but not both)'. }\end{array}$ & $\begin{array}{l}\text { Automatic braking, cruise } \\
\text { control, lane centring }\end{array}$ \\
\hline $\begin{array}{l}\text { Level two - Com- } \\
\text { bined function }\end{array}$ & $\begin{array}{l}\text { The vehicle is able to coordinate two or more 'primary func- } \\
\text { tions' simultaneously, but a driver remains in overall control. }\end{array}$ & $\begin{array}{l}\text { Adaptive cruise control work- } \\
\text { ing in concert with automatic } \\
\text { lane centring }\end{array}$ \\
\hline $\begin{array}{l}\text { Level three - } \\
\text { Limited self-driv- } \\
\text { ing }\end{array}$ & $\begin{array}{l}\text { The vehicle is able to control all 'safety-critical functions under } \\
\text { certain traffic or environmental conditions', but would need } \\
\text { to relinquish control to a driver on occasion to deal with more } \\
\text { complex driving scenarios. }\end{array}$ & $\begin{array}{l}\text { Current autonomous vehicle } \\
\text { prototypes }\end{array}$ \\
\hline $\begin{array}{l}\text { Level four - } \\
\text { Full self-driving }\end{array}$ & $\begin{array}{l}\text { 'Vehicle is designed to perform all safety-critical driving } \\
\text { functions and monitor roadway conditions for an entire trip'. } \\
\text { The vehicle may be occupied or unoccupied, and is solely } \\
\text { responsible for safe operation. }\end{array}$ & $\begin{array}{l}\text { Fully-independent, driverless } \\
\text { car }\end{array}$ \\
\hline
\end{tabular}

Source: NHTSA (2013), 4-5. 


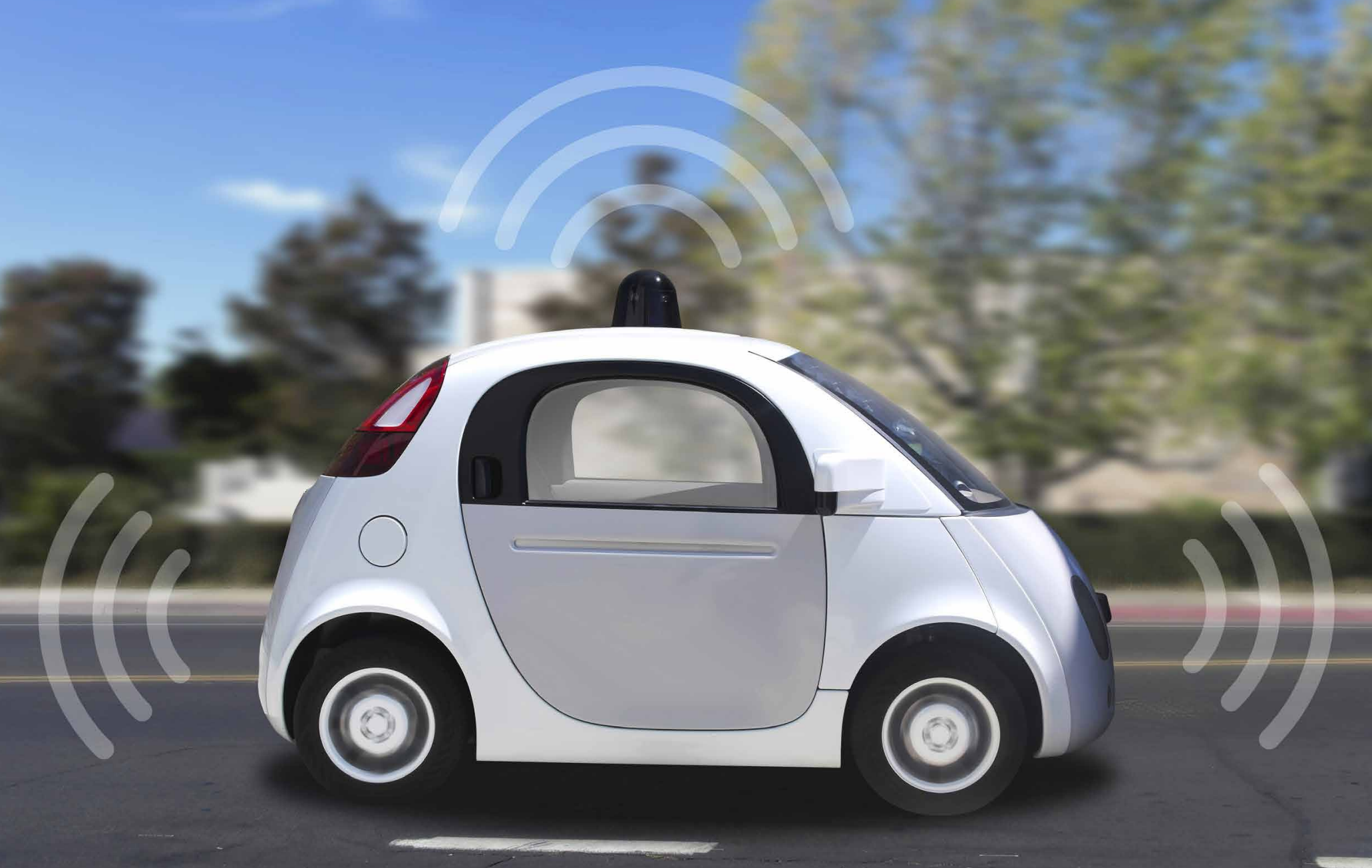

avoid collisions or other potential problems. These techniques may reduce the frequency of crashes due to human error, as well as enabling vehicles to 'platoon' closely together or travel at higher speeds, able to exploit computers' faster reaction times to shorten braking distances. There are also potential gains in terms of driver productivity - with the average driver in England spending 235 hours behind the wheel every year, new technology may allow road users to work or relax while in their autonomous car (Dearden 2015). Similarly, autonomous vehicles may improve the accessibility of road travel to the elderly, underage, disabled, intoxicated, unlicensed or otherwise impaired. An additional result of autonomous technologies may be a change in parking behaviours - as a vehicle could drop an occupant off at their destination and park at a distance - or even ownership models, for instance by marrying driverless cars with car-sharing apps. To explore these potential advantages, in 2015 the UK government announced the allocation of $£ 19$ million to support pilot schemes in Milton Keynes, Bristol, Coventry and Greenwich (Dearden 2015).

Predictions for the future market potential of the technology vary significantly. The overall market for Intelligent Mobility, which includes driverless cars, has been valued at $£ 900$ billion by 2025 (Transport Systems Catapult 2015b). KPMG also predict annual economic benefits from autonomous and connected vehicles of around $£ 51$ billion by 2030 (KPMG 2015), while separate 
studies by IHS and the Boston Consulting Group suggest fully autonomous (i.e. NHTSA 'level four') vehicles could make up around 10 per cent of global sales in 2035 (Worstall 2014). This would build on the proliferation of functionspecific automation (i.e. automated parking) in the late 2010s, with semi-autonomous, 'level three' vehicles on the market around 2025. At the same time, a number of barriers remain that may limit popular uptake of the technology, including concerns over safety, liability, security, privacy and cost, as well as regulatory issues and the slow pace with which existing stocks of road vehicles are replaced (The Economist 2013a).

Autonomous technologies are not confined to the road alone, however. There has also been significant investment in applying autonomy to other modes of travel. Unmanned aerial vehicles (UAVs) or 'drones', both big and small, are increasingly a feature of the aerospace sector; while similar developments are underway for both surface and underwater maritime transport. As with automated cars, these air and sea vehicles vary in sophistication from remotely or optionally piloted systems through to fully independent craft capable of choosing navigational paths and making decisions based on a series of objectives or an end location. These technologies have a range of potential applications to UK transport, for instance by reducing the reliance on the road or rail networks. A number of logistics and retail firms have expressed interest in using small UAVs to perform automated deliveries, with Amazon beginning trials in Cambridge, UK, in 2014 (Financial Times 2014).

In the resulting scenarios and analysis, when we refer to AVs we are referring to those with an autonomy level of four.

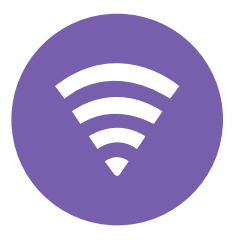

\subsection{Next-generation connectivity}

Next-generation connectivity denotes a range of

telecommunications technologies that aim to improve bandwidth, network availability and download/upload speeds for wireless communication. Examples include 5G, Li-Fi, fibre optic, low-cost satellites and even UAVbased Wi-Fi connectivity. 5G (5th generation) mobile networks represent the next major phase of mobile telecommunications standards, aiming to improve data rates, coverage and the efficiency with which large numbers of devices use the same radio frequency spectrum. $\mathrm{Li}-\mathrm{Fi}$ (a portmanteau of light and $\mathrm{Wi}-\mathrm{Fi}$ ) uses light rather than radio waves to create a wireless network, using rapidly pulsing light-emitting diodes (LEDs) to broadcast data to compatible devices. Fibre optic cables, meanwhile, allow for faster broadband connection speeds than metal wires. Advances in launch vehicles and small, low-cost satellites (e.g. CubeSat) also raise the possibility of greatly improved (and more affordable) satellite coverage, while a number of companies including Google and Facebook are exploring the potential use of high-altitude long-endurance (HALE) unmanned aircraft or 'drones' to provide Wi-Fi connectivity to large areas.

Using such technologies, the wireless industry is reported to be aiming to deliver the first $5 \mathrm{G}$ networks by 2020 , although a number of analysts suggest that these may not become widely available until 2025 (Shankland 2015). British Telecom has also announced plans to provide broadband speeds of 500MB per second across the UK by 2025 , with a pilot scheme scheduled to commence for 4,000 homes and businesses in summer 2015 (McCaskill 2015). Samsung, meanwhile, has already conducted trials for $1 \mathrm{~GB}$ per second, with researchers at the University of Surrey suggesting it may even be possible to support wireless connections at up to $800 \mathrm{~GB}$ per second - the equivalent of downloading 33 highdefinition films every second (BBC News 2014). 


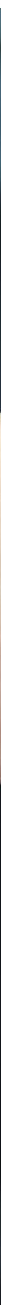

Such technologies could have a wide range of implications for transport, both direct and indirect (Dredge 2014). Reliable connectivity and minimal latency are important enablers for networking autonomous vehicles together, for instance - while $4 G$ takes around 15 to 25 milliseconds for one car to tell another that it has begun braking, that delay could drop to 1 millisecond with $5 \mathrm{G}$ data speeds (Shankland 2015). At the same time, next-generation connectivity could facilitate the rapid expansion of the so-called Internet of Things, with between 50 and 100 billion devices connected to the Internet by 2020 (BBC News 2014).

This could potentially transform the management of logistics as well as the ability of people and businesses to access information remotely, facilitating greater uptake of telehealth or telecommuting services, with knock-on effects for transport demand. In the health domain, for instance, the global market for remote telecare devices and related services is estimated to have risen by around 20 per cent annually since 2008 , with a range of new technologies allowing for the remote monitoring of patient vital signs (Deloitte Centre for Health Solutions 2012). Particularly significant is the growing convergence between wearable technology, cloud computing and user software - with smartphone operating systems playing host to over 40,000 medical, health and fitness apps, many of which are also supported by new wearable products such as the Apple Watch. A further development has been growing investment in telepresence technologies. In Japan, for instance, a number of trials have explored the possibility of providing health and social care to an ageing population remotely, 


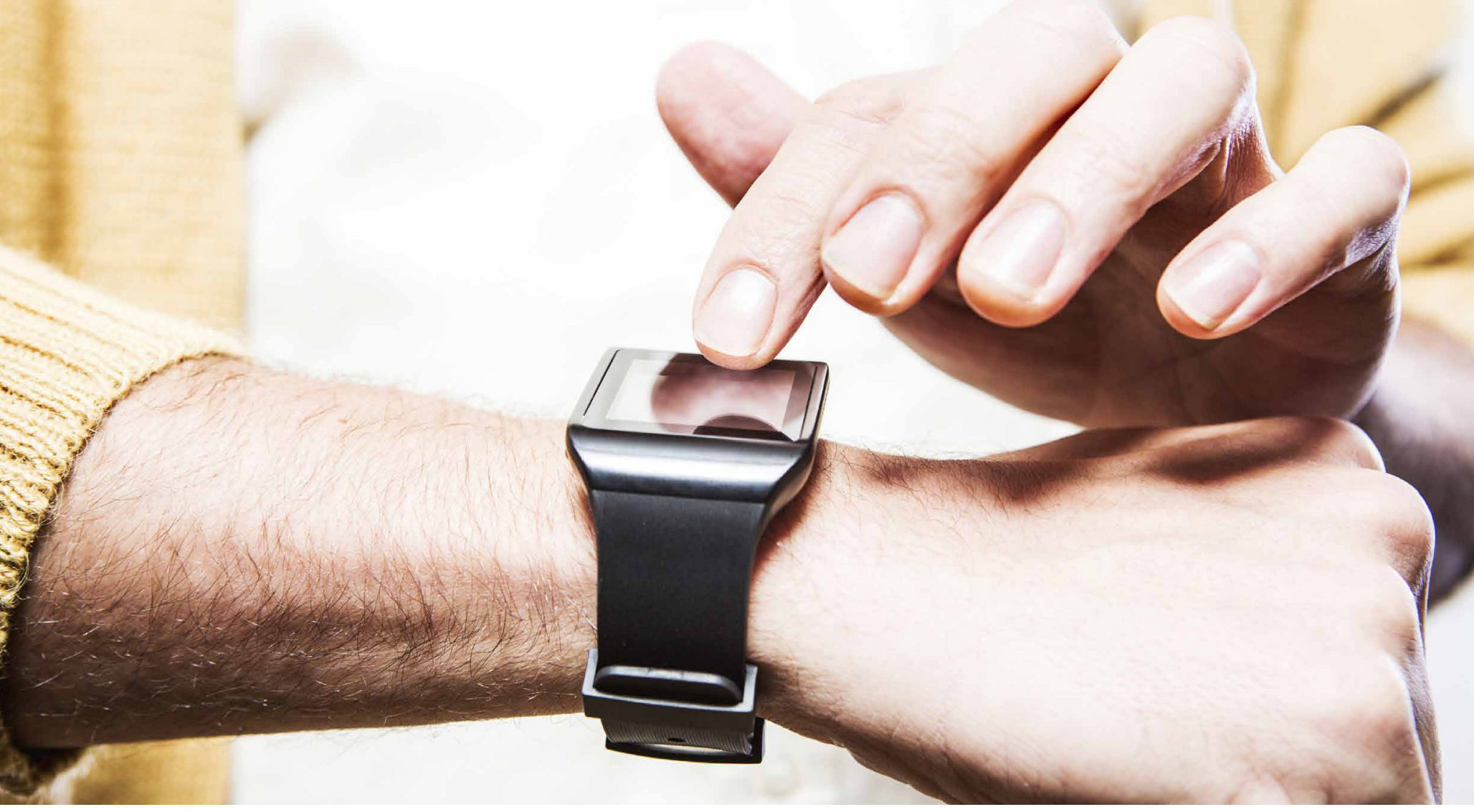

using a combination of health monitoring devices, robotic attendants or digital avatars, all supported by connections to the cloud (Grifantini 2015). The telecommuting market has experienced similar growth, especially in high-technology businesses, where the United States Census Bureau recorded a 70 per cent increase in home-based working between 2000 and 2010 - a trend likely to continue into the future (The Economist 2013b). Critics caution, however, that the ideas of telecommuting and telehealth have lengthy histories of unfulfilled predictions of revolutionary change, with many of the main barriers being social and cultural, rather than to do with the technologies themselves (The Economist 2014). If these obstacles can be overcome, however, next-generation connectivity could enable a range of new business and health solutions that would have significant implications for transport in 2035.

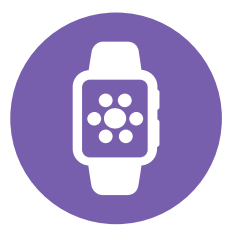

\subsection{User apps and Big Data}

Big Data is a broad term referring to the growing generation and collation of vast amounts of data, with the sheer volume of information presenting novel challenges (as well as opportunities) in terms of analysis, storage and visualisation. At the same time, advances in ICT may generate new 'smart' ways of processing and leveraging these data in future. Examples include the growing use of data mining, predictive algorithms, machine learning and even artificial intelligence (Al). These technologies may enable new, flexible and targeted approaches to complex systems such as transport.

Future advances in ICT technology and personal electronic devices may also affect the nature of the software and hardware with which travellers gain access to the transport network, travel information and other services. In the virtual sphere, the period to 2035 is expected to see the ongoing 
proliferation of mobile 'apps', personalisation and Big Data, providing individuals, companies and transport providers with new ways of accessing and visualising data to inform transport decisions, as well as easing processes such as ticketing, navigation and payment, boosting intermodal connections. Recent years have seen the emergence of popular taxi apps such as Uber (Cellan-Jones 2015), freight haul apps such as Cargomatic (Graham 2015), transit planners such as Citymapper and Moovit (Shead 2015), contactless payments (Jones \& Buckle 2015), live traffic alerts (Pieters 2015), car-sharing apps (Bloomberg 2015) and digital cycle hire services (Nicholls 2015).

A number of schemes are also underway to unite such functionalities in one cohesive system. In Finland, for example, the city of Helsinki has announced plans to roll out a comprehensive, point-to-point 'mobility on demand' system by 2025, which would allow users to purchase a range of different travel options in real time from their smartphones, eliminating the need for individual car ownership (Greenfield 2014). This builds on the Helsinki Regional Transport Authority's deployment in 2013 of its Kutsuplus minibus service, which lets riders specify their own pick-up and drop-off points via smartphone, before aggregating all users' requests and calculating an optimal route that most closely satisfies them all (Barry 2013).

A related development is the emergence of wearable technology, with the growing proliferation of smart watches or even clothing capable of conveying information to the user. Similarly, advances in biometrics, voice and facial recognition technologies may support ongoing personalisation. The confluence of Big Data, user apps and these other technologies may have wide-ranging applicability to transport: on the one hand enabling transport planners to monitor a huge range of variables in real time, optimising traffic flows and identifying potential issues before they occur, and on the other empowering users to make more informed travel decisions, investigating a wide range of different travel options at their convenience (Shankleman 2013).

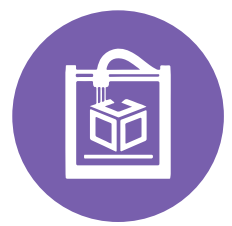

\subsection{Advanced manufacturing}

Advanced manufacturing comprises a range of novel technologies that aim to improve products and manufacturing processes. This includes the use of additive manufacturing (including $3 \mathrm{D}$ printing as well as other more advanced techniques), robotics, novel materials (e.g. bio, nano, composite, smart), and other advanced equipment (e.g. lasers, plasma, waterjet). More widely, it also includes the application of novel methods, digital tools, rapid prototyping and synthetic environments (e.g. virtual or augmented reality) to aid design and production processes. While the nature and impact of advanced manufacturing is likely to vary from one sector to another, the technology has the potential to create a wide range of new designs, reduce workforce size and materials waste, make products much more customisable for consumers, and change when and where manufacturing occurs. 3D printers, for instance, may allow a business to rapidly produce items on demand, customised for individual customers, or allow people to download blueprints online and print objects at home.

While additive manufacturing, in particular, has been the subject of extensive media focus, expert perspectives on the technology's future prospects vary significantly. The technology has already seen extensive use in certain niche areas, such as 'rapid prototyping' or the development of lightweight parts for aircraft (Hellgren et al. 2013), and recent years have seen a shift away from prototyping to using additive manufacturing for direct production. Final products now comprise over 20 per cent of output, with projections suggesting this figure may reach 50 per cent by 2020 (The Economist 2011). The technology has been the subject of significant business and public excitement, with a number of commentators suggesting it could lead to a 'Third Industrial Revolution' (Sissons \& Thompson 2012; Campbell et al. 2011), the reshoring of manufacturing to rich countries, and 
the diffusion of production away from centralised factories to local businesses, shops and homes (The Economist 2012). As a result, it has received significant interest and investment, with the additive manufacturing sector growing by double digits in recent years - by nearly 30 per cent in 2011 alone - with a possible total supply chain value of $£ 80$ billion annually by 2020 (Hague \& Reeves 2013).

However, critics caution that industry and media may overestimate the technology's readiness level, as well as the barriers to full implementation. A study by the Centre for Business Relationships, Accountability, Sustainability and Society found that public expectations for the technology tend to give an exaggerated perspective on additive manufacturing's future potential, based often on selective and anecdotal evidence (Smith 2012). This disconnect is also partially linked to the different definitions and terminologies encompassed in this field, which equate 3D printing and additive manufacturing when in fact these technologies are overlapping but distinct. While additive manufacturing is applied to high-value manufacturing using advanced techniques at an enterprise level, 3D printing produces low-value goods that are more limited in their size, complexity, resolution, materials and final part integrity, and is often conducted by amateur hobbyists. Nonetheless, both elements of the technology are expected to become more widespread within the next 10 years, as equipment and material costs continue to fall. By 2035, the proliferation of advanced manufacturing techniques and devices may have significant knock-on effects for freight movement, telecommuting and overall transport demand.

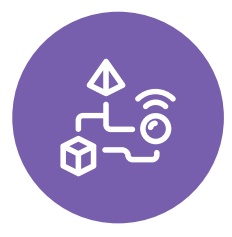

\subsection{Internet of Things}

The Internet of Things (loT) is a network of physical objects capable of detecting and communicating information between each other through the use of embedded chips, sensors and connectivity. It builds out from today's Internet by creating a pervasive and self-organising network of unique, identifiable and addressable physical objects, such as 'smart' meters, wearable technology and domestic appliances. The use of embedded sensors allows for a wide array of data to be gathered in real time - data that are then communicated from machine to machine without need for human-to-computer interaction. Cloud computing provides the necessary infrastructure to collate, monitor and analyse this data, allowing devices to make increasingly 'smart' decisions (Burrus 2014). Improvements in network connectivity and component miniaturisation are expected to facilitate the rapid expansion of this so-called Internet of Things, with between 50 and 100 billion devices connected to the Internet by 2020 (BBC News 2014).

A much-publicised example already in use today is Google's NEST thermostat, which automatically attempts to reduce home energy usage by learning its owner's behaviours. NEST detects when its owners are away from the house via their smartphone, and can be controlled remotely via Wi-Fi (Arthur 2014). The global retailer, Amazon, has also begun to offer subscribers to its Prime scheme a range of wireless-connected buttons, which they can place around their home and press when they are running low on certain household items, triggering an immediate online order to replenish them. A number of manufacturers are similarly trying to develop products, from fridges to washing machines, that can sense when domestic supplies are running low, monitor faults remotely and analyse usage behaviour to improve efficiency (The Economist 2015). This trend could have significant ramifications for logistics and retail in 2035, with knock-on effects for transport demand. 


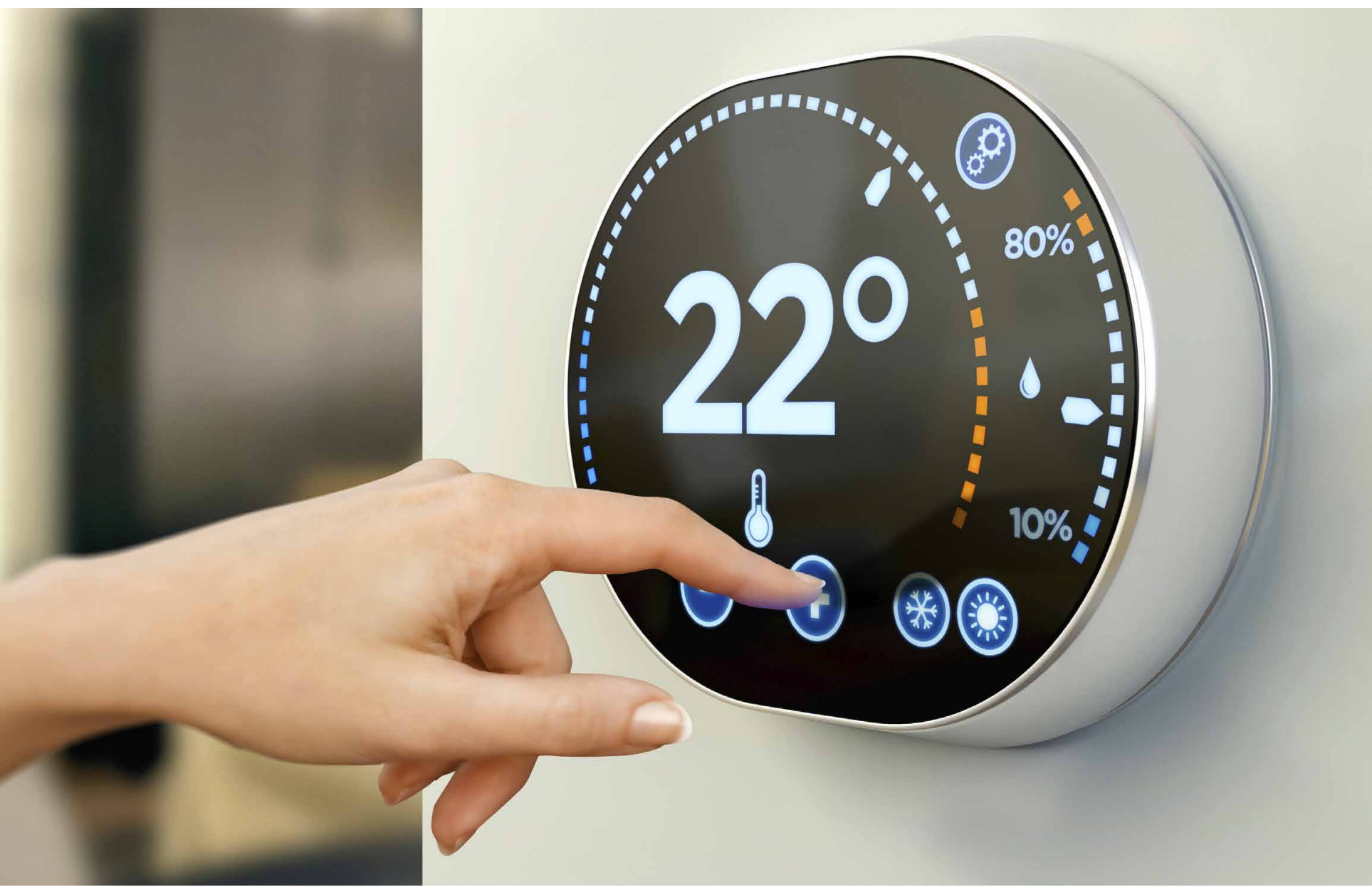

Another area of potential significance is the impact of the Internet of Things on telehealth (see Section 2.2). The global market for remote telecare devices and related services is estimated to have risen by around 20 per cent annually since 2008 , with a range of new technologies allowing for the remote monitoring of patient vital signs (Deloitte Centre for Health Solutions 2012).). Allowing care to be delivered remotely, enabled in part by the Internet of Things, could have significant implications for transport demand out to 2035, although a number of social, cultural and regulatory barriers remain (The Economist 2014).

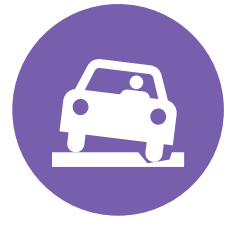

\subsection{Novel materials and embedded sensors in infrastructure}

A range of advances in materials science and production techniques may have potential ramifications for future transport infrastructure.

The creation of affordable, highly resilient materials, for instance, may serve to reduce damage and wear-and-tear of road surfaces, while others may help reduce or improve friction as needed. In addition, self-healing materials could automatically repair ruptures or abrasions, without the need for work by a human crew. In 2014, for instance, researchers at Bath, Cambridge and Cardiff universities unveiled a novel concrete blend, which uses micro-capsules of bacteria to plug cracks and 
crevices (Gardner 2014). Embedding sensors and actuators in roads, rails or runways might also provide continuous self-monitoring of their health, enabling transport planners to anticipate faults or issues, targeting inspection and repair efforts in a more intelligent way. This could significantly reduce incidents such as large-scale roadworks, railway faults or runway closures, all of which can cause significant delays. Vehicle manufacturers are also increasingly applying similar principles to engine and vehicle design, reducing the frequency of breakdowns and thus also the disruption to drivers or pilots and others around them.

Scientists have also raised the possibility of applying LEDs or temperature-sensitive paint to road surfaces to warn drivers about icy conditions, as well as embedding heating elements within to help melt snow. In 2014, the Netherlands installed the world's first solar cycle path, replacing the traditional road surface with solar panels to generate power and preventing icing, improving throughput and reducing accidents (Atkinson 2015). Similarly, using conductive or inductive materials in roadways could enable wireless charging of electric vehicles and devices, reducing the 'range anxiety' currently limiting those technologies and thus also the requirement to interrupt journeys with recharging stops.

Networking these different infrastructure-based technologies with embedded IP connectivity - using the model of the Internet of Things could also bring a range of new functionalities for personal user apps; for instance, a faulty rail signal could automatically alert not only the railway company but also rail travellers, so that they could plan alternative routes. At the same time, there are a number of obstacles to successful implementation, with the Royal Academy of Engineering citing concerns over lack of investment, data quality, privacy and the long lifetime of existing infrastructure (2012). 


\section{Chapter Three. Three future transport scenarios}
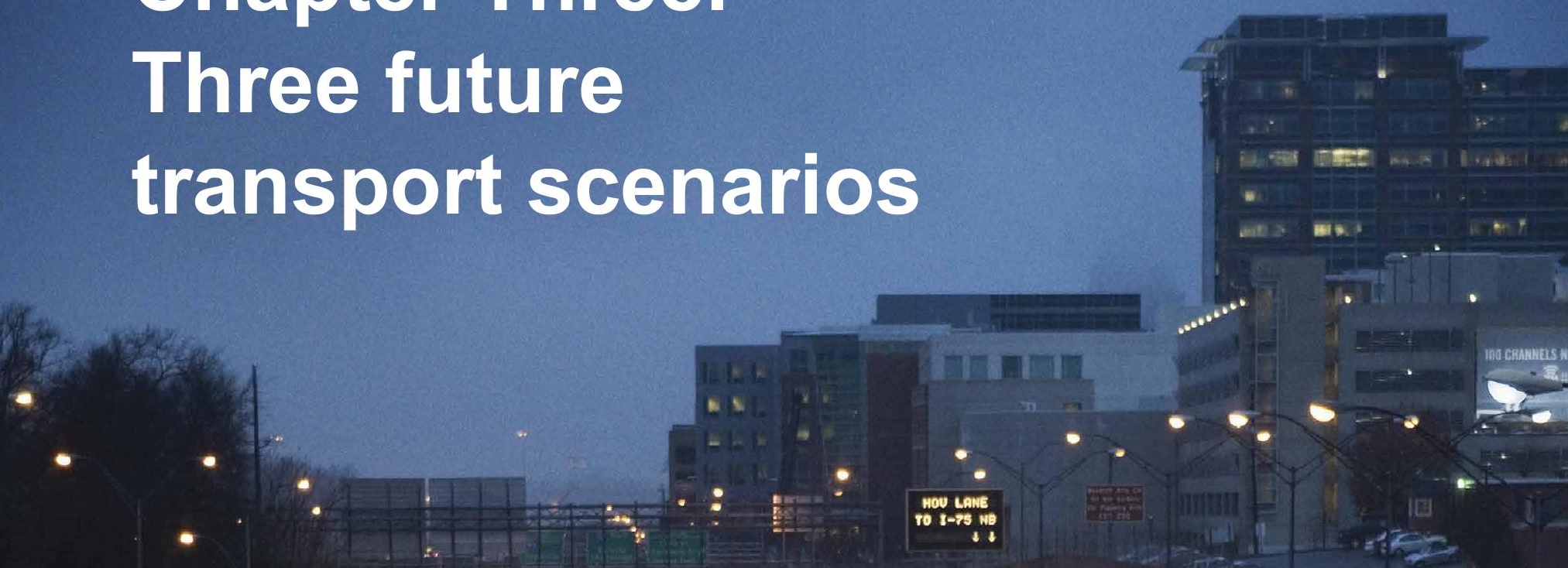

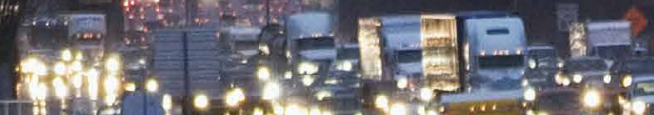

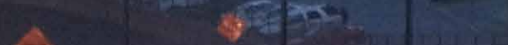

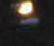

9.:

a......

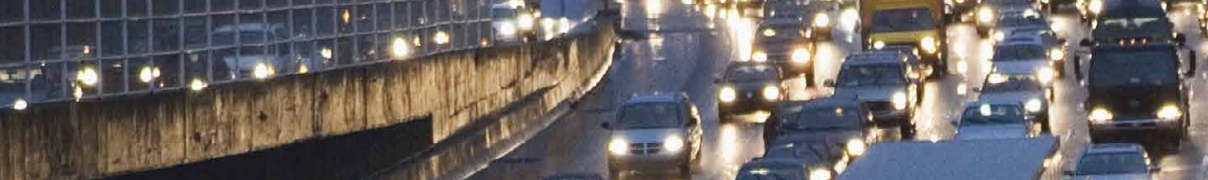

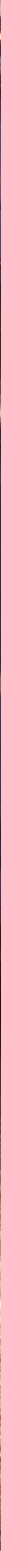


This chapter presents the three scenarios developed in this study:

- Driving Ahead: a high-growth future with fully autonomous vehicles and more travel

- Live Local: a modest growth future with high use of technologies that substitute for travel

- Digital Divide: a lower growth future with rising income inequality where technologies tend to be used mostly by the affluent.

These scenarios are built around two principles. First, we differentiate the scenarios by economic growth and changes in travel demand: in each, different technologies are more prominent. We do not anticipate a scenario in which every technology reaches its full potential; technologies, as with other trends, have winners and losers.

Second, we intend for the scenarios to be plausible, but challenging. For example, not everybody agrees on the likelihood of fully autonomous vehicles operating on city streets within 20 years. Among those who think it is unlikely, part of their assessment is based on the current level of research and testing, and an understanding of funding and policy issues that affect the development of this technology. We are challenging those assumptions (which could very well be true), instead postulating that with sufficient investment and the removal of barriers, a fully autonomous vehicle could indeed drive through London in 2035. Our goal is to portray the various technologies at their plausible limits within the stated timeframe, not to state what is most likely given various existing barriers.

We also make the assumption that there will not be substantial investment in transport infrastructure over the next 20 years. We do this in order to illustrate changes in travel speed or reductions in congestion from technology adoption or changes in travel demand. This helps focus the scenarios on the impacts of the technologies, and which ones might be the most beneficial, as well as where there is a need for innovation investment or policy intervention.

We have written the scenarios in broad terms, in the interest of keeping them general and concise. We recognise that overall trends may mask underlying disparities. Not every potential change affects every sector, or even every segment of the population. An overall assessment, for example, that travel costs are rising does not mean that every element of every cost on every travel mode is increasing. Rather, we are trying to identify the broadest of trends and how they differ from the present situation.

As is customary in scenario writing, we write from the perspective of 2035, looking back on how we arrived at this future point in time. Each scenario also includes a vignette suggesting how life might be lived in this particular future. 


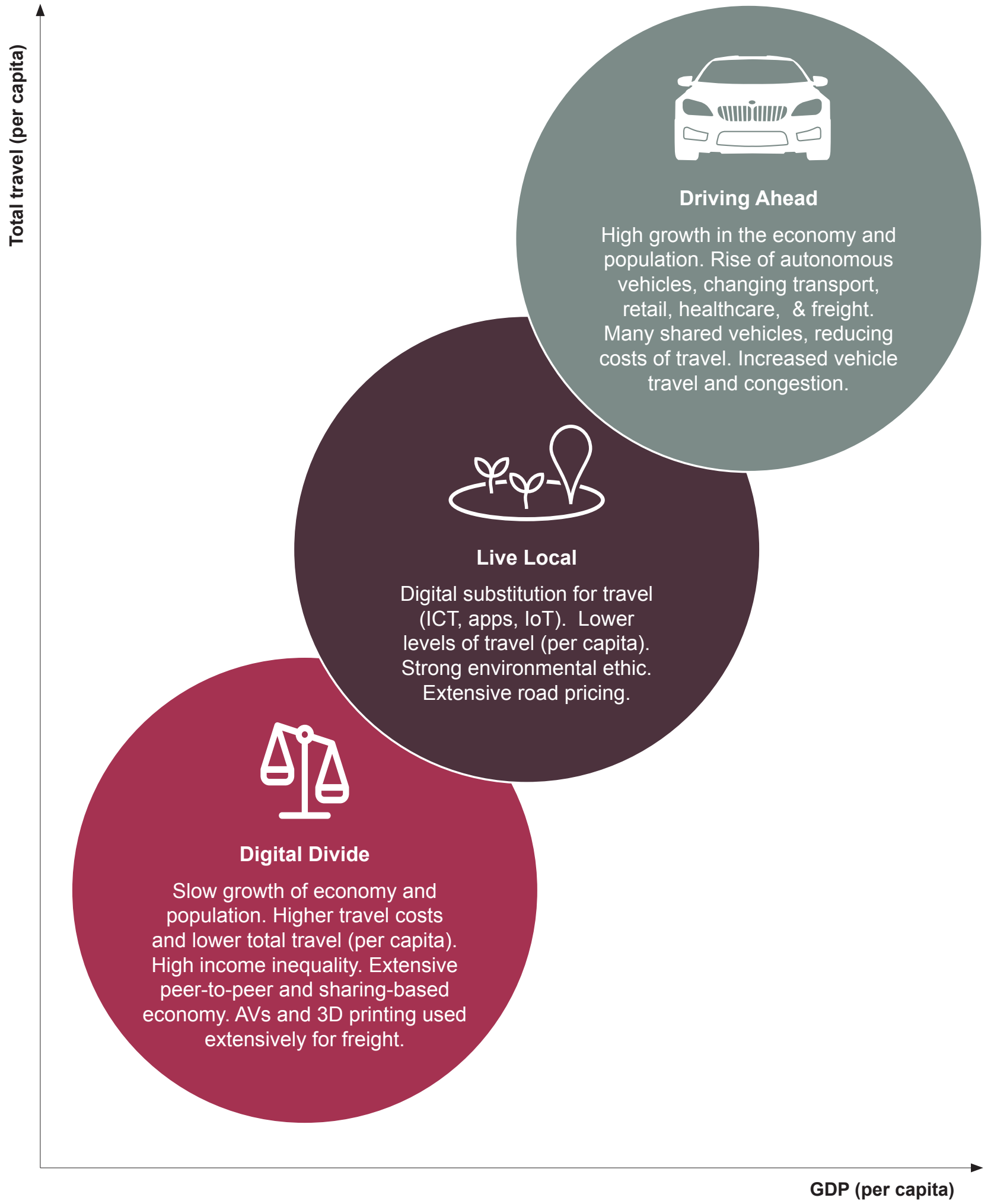

Figure 3.1. The Driving Ahead, Live Local and Digital Divide scenarios 


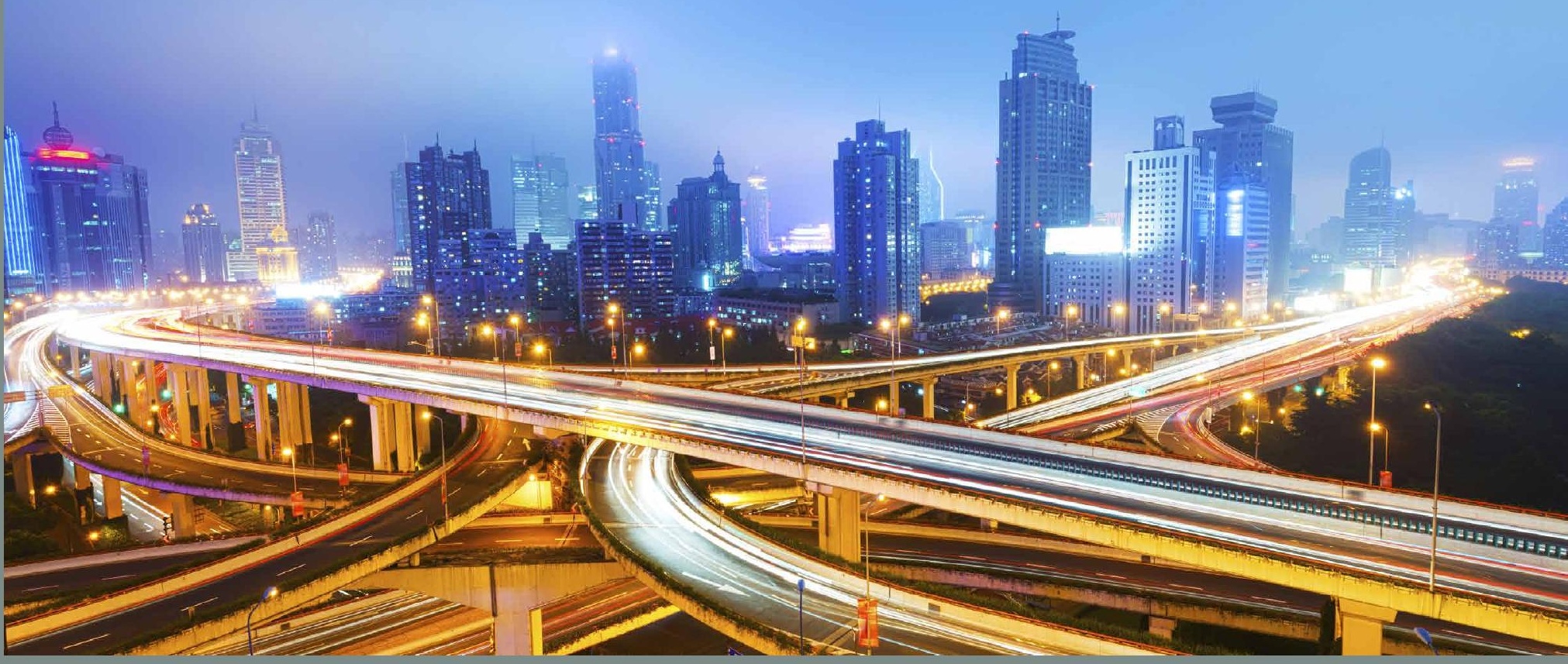

\subsection{Driving Ahead}

Summary: In this scenario, both gross domestic product (GDP) and per capita travel have continued to rise at rates higher than anticipated. ${ }^{3}$ Growth in both of these is being stimulated by the rise of autonomous vehicles, which are changing the face of not only transport, but also healthcare and retail. Many of these are shared vehicles, reducing costs for those who no longer have to own cars. The ease of use has led to growth in vehicle travel and congestion, as being stuck in traffic no longer means being unproductive. As the population has grown, the large proportion of older people who live on their own has greater flexibility to travel, especially for medical visits, and the freight and retail sectors make heavy use of autonomous vehicles for both long-haul freight as well as delivery to customers.

General demographic and economic trends: GDP per capita has been growing on average by more than the forecast 1.6 per cent per year. Growth has been driven by reshoring of manufacturing and increases in productivity and employment due to technology development. The healthy economy is also one reason for higher increases in population, because the UK has attracted a sizeable number of immigrants. As a result, the proportion of the population who are over 65 is smaller than predicted decades ago, because the growth in that demographic segment has been slower than that of migration, which generally brings in younger, economically active people.

Technology development: The defining technology of the past ten years has been the fully autonomous vehicle - one that drives in any location without any human assistance. It did 
not arise in a vacuum, of course; research has been ongoing for years. A key development was the creation of cheaper sensors, which brought prices down considerably. In addition, faster broadband speeds throughout the country have allowed for rapid updating of the detailed maps that are essential for fully autonomous vehicles (now commonly known as FAVs) to function properly, especially in urban environments. Vehicles passed relatively quickly through the various levels of automation, and FAVs have been commercially available since the mid-2020s.

Information and communications technology (ICT) has certainly developed to a considerable extent, but it has had a lesser impact on travel patterns. Higher broadband speeds are a reality in most areas, although some rural areas still lack good coverage. But instead of substituting for travel, the market for ICT has been for increasingly sophisticated connectivity in vehicles. Data privacy and security remain an issue for some people, as hackers keep up with security improvements, but the advantages of in-vehicle connectivity generally far outweigh privacy concerns.

Advanced manufacturing has not developed as rapidly as some other technologies, and is important mainly in a few niche markets. The fast-growing robotics sector, including automotive applications, with its major engineering challenges, has attracted more talent than other manufacturing segments. Whilst serial manufacturing methods account for the large volume of items in demand, 3D printing (additive manufacturing) has found uses in niche items. These niches are for products that otherwise are difficult to manufacture and for spare parts where the economies of scale offered by serial production do not apply. Consumer markets for customised products have not been particularly lucrative.

Work and business: In 2035 the physical workplace has not changed that much, but FAVs have allowed people to live further from work, meaning longer but more productive commute journeys. Some models even feature workspace amenities such as telepresence screens and connections. Improvements in the scheduling algorithms for vehicle sharing have meant that a larger fraction of commuters ride to work with one or two other passengers. Working hours for many have become longer, not shorter, as it is increasingly expected that employees are available to work even during their commute. However, people also have more flexibility in their hours, since they can more easily work on their journey. People also continue to conduct many business meetings in person.

With travel comparatively easy, some employees don't mind living further from their offices, and as a result commuting distances have increased. Housing prices have continued to climb, so people are moving further out of congested cities to find lower prices, with the trade-off of longer commutes. London continues to be the hub of business creation, so the demand for housing in the southeast remains strong, and prices throughout the region are high.

Health: FAVs have made it easier for people to access medical care, since people who cannot drive due to medical conditions can still attend appointments in person. Some FAVs now cater to this segment of the market. 'Medivans' have low-floor entry and medical alert call buttons in case of an onboard emergency. Some of these are owned by hospitals, which deploy them to bring patients in for treatment. Often a member of medical staff rides along as well to start gathering some of the basic information from the patient, which is then transmitted to the doctor who will see the patient. For patients who don't require that level of care, but who cannot drive, regular FAVs can still shuttle them to their appointments, so in-person visits have increased. FAVs have also had some negative health consequences, since the average journey now involves less walking and the need to drive is no longer a limiting factor for social drinking.

The over-65 population is a smaller share than predicted (roughly 22 per cent, as opposed to 
25 per cent). The proportion of people of this age who live at home has increased, since they can meet their medical needs with Medivans, as well as some home-based monitoring of chronic conditions and home visits.

Real-time telehealth delivery is only a partial substitute for in-person visits to a GP. Most people still prefer to monitor symptoms at home on a stand-alone device, and then bring it to their appointment for the doctor to analyse rather than transmitting the data electronically. These improvements have made the country healthier overall, although this is partly attributable to the younger (and healthier) workers brought in by immigration.

Retail: The retail sector is booming with an increased population and high economic growth. Both per capita and total consumption are up. Online sales have increased considerably, and FAVs have been instrumental in last-mile deliveries to customers' houses and workplaces. On a daily basis FAVs arrive at a block of flats or an office building and alert customers that their packages have arrived. Usually this happens at a set time of day, and people then have a fixed amount of time to pick up their packages or a contact person will keep them until the customer can fetch them. The same vehicles can also take returns of unwanted items. This 'daily drop-off' service is fairly new but catching on quickly. While delivery drones have been tested, manoeuvring through large cities has proved challenging. Some are in use in more rural areas, but urban deliveries are generally made with FAVs.

The ease of delivery for goods ordered online has contributed to a decline in high street retail. Footfall is still high in many areas; more restaurants and leisure activities have moved in, and parking is less of a problem since many shoppers are dropped off by FAVs. However, retail purchases on high streets have declined. Some stores offer delivery of goods purchased in person, since many people are already signed up for daily drop-offs, and some think this will be one of the elements that saves high street retail. Person-to-person retail has also continued to increase because FAVs make shipping such purchases very easy.

Freight: FAVs have had two transforming effects on the freight sector. First, the growth in online shopping and daily drop-off has opened up new opportunities to partner with retailers, and start-ups have edged into the package delivery market. Generally customers sign up for a monthly fee that covers all deliveries, regardless of amount. The value is less in the fleet and more in the algorithms that make this new delivery model viable and lucrative. Eventually one or two firms will be the winners, since customers value the ability to get one delivery with goods from a variety of retail outlets. Second, FAVs are frequently used for long-haul journeys. Most of the high-volume motorways across the country have a dedicated lane for exclusive FAV use. As carriers faced shortages of drivers, they began buying FAVs for their fleets and have been pleased since there have been fewer crashes, fewer employee problems and lower costs. Lorries can platoon for miles, with three or four vehicles following a lead lorry, reducing wind drag and therefore fuel costs. Without drivers who need to sleep, many goods can move at night when road capacity is more available.

Due to both lower fuel costs and higher property costs, the prevailing model for non-consumer goods is one of greater centralisation of warehouses outside major urban centres. These major hubs have also attracted some reshoring of manufacturing. This trend is also encouraged by increasing labour costs in other countries, the need in many industries for skilled factory workers and engineers and, to a lesser extent, security concerns in countries with political turmoil.

Long-distance travel: The leisure travel market is reasonably strong. While people's actual leisure time has if anything decreased, disposable income is high, providing many opportunities for much needed short breaks. Here too, FAVs have become specialised, with some models designed for long trips; in 
addition to being tall enough to stand in, they have mini-refrigerators, multiple screens and excellent entertainment options. The maps that FAVs rely on to drive safely also carry a wealth of information about destinations and what attractions might be found along the way - everything from historical facts to good restaurants and activities for children. While some Britons still prefer self-drive holidays, the popularity of FAVs for road trips is increasing as they provide the pleasures of driving through the countryside without the bother of actually driving.

In general, attitudes to the environment have become more important in people's travel decisions, but vehicles have also become less environmentally damaging. The proportion of petrol- and diesel-powered vehicles has been gradually declining in favour of hybrids and fully electric vehicles. The new features still use more energy than standard cars, but the emissions are lower because of the fuel sources.

Travel implications: Overall FAVs have lowered the cost of travel for many users, not because of their price, which is still higher than conventional vehicles, but because increasingly FAVs are not purchased by households but shared. In this 'mobility on demand' model, households belong to a service from which they can order vehicles to serve specific journey purposes, either on a recurring or one-time basis. Part of the attraction of the shared model is the increased specialisation of vehicles. FAVs now come equipped for commuting, medical travel or long-distance travel. These services have replaced taxis, and public transport providers have upgraded their buses and some trains to FAVs. Conventional public transport services are dwindling, but still exist along some major corridors, serving lower-income passengers who cannot afford to use FAVs.
A thriving network of specialised mobility companies competes to provide vehicles on demand. Each one provides a wide array of vehicle types, but they compete on cost, on whether the rider is solo or willing to share the ride with others, and on the quality of the onboard amenities they offer. Cars can be ordered on the spot with mobile apps, usually arriving within 10 minutes, or an employee could request that a commuter FAV pick her up every day at 7.30 a.m. Private vehicle ownership is still high, especially of conventional cars, but many urban households have tried the shared model and found that it suits their needs. In villages and rural areas, car ownership is still the standard.

However, the ease of use of FAVs generally means more vehicle travel per capita and, not surprisingly, more congestion. The effects differ depending on location. Increasing commute distances means higher levels of congestion, both on inter-urban motorways and in cities. The introduction of FAV-only lanes on some interurban motorways provides faster travel times for FAVs and lorries, although this exacerbates congestion in the general-purpose lanes. One partial solution in some cities is encouraging or requiring deliveries to take place at night. While there has been talk of introducing road pricing to help alleviate congestion, the political will to do so has been lacking.

While data security remains an issue for autonomous vehicles, most users have accepted the risk; the vehicles themselves are safer since human error is no longer the primary cause of collisions, and cyber-attacks have been few and far between, although they have occurred. Insurance costs are lower for consumers, although the shift in liability has contributed to higher costs because the car manufacturers have had to take on additional insurance. 


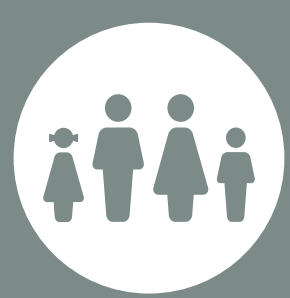

It's the usual mad rush in the Borowski household on Friday morning. Beneficiaries of the UK's more welcoming immigration policy, the parents originally came from Poland. With highly sought-after IT and engineering skills they made a good life for themselves before starting a family in Britain. Mum Hanna is getting breakfast ready while Dad Tadeusz is chivvying the children. All need to be on time as their FAVs will pick them up at 8 a.m. on the dot. The children are collected by a large autonomous vehicle - it already holds a couple of their school friends and will pick up a few more before dropping them all at the local secondary school. Hanna's FAV arrives to take her to a business meeting. She hops in and settles down to work at the desk inside. Her working day starts the moment she leaves the house, connecting her via superfast Wi-Fi to the rest of the world. Although her meeting is 100 miles away she doesn't mind the journey - she is riding in a moving office, with coffee facilities included.

Tadeusz meanwhile spends a little more time organising some domestic arrangements: when his FAV arrives to take him to his senior engineering role at the local FAV factory, he settles down to order the weekly shop from within the vehicle. His vehicle is not as sophisticated (or expensive) as Hanna's, because he doesn't need a full office. After ordering the shopping Tadeusz begins to plan the family's annual holiday. They usually travel somewhere hot and sunny for a couple of weeks when the children are off school. Hiring a car abroad is much easier with FAVs as there is no need to adapt to driving in different road conditions (or on the other side of the road), and they can organise it through the same company that provides their day-today mobility needs at home - plenty of customer loyalty bonuses are available. Traffic is terrible - so many FAVs on the road at peak times mean that despite setting off in good time, and having sophisticated apps guiding and monitoring traffic, Tadeusz will still be late for work. He calls into his first meeting of the day using the FAV's systems - virtual meetings are no substitute for the real thing, but in this case it will have to do.

While he is at work, Tadeusz's mother calls. Her home health monitor has flagged up a warning and she isn't sure what to do. Tadeusz talks her through how to book an appointment with the GP and ensures that all the information from the monitor is made available to them - the privacy and data security systems are complex and a bit confusing.

After school and work the family FAVs are all booked to take them out to a restaurant and cinema complex. The family meet up there, and enjoy an evening meal out to celebrate the end of a busy week. Then a single FAV takes them home. Tadeusz and Hanna enjoy a drink together - neither needs to worry about driving home - while the children are engrossed in social media, catching up with the school friends they said goodbye to a couple of hours earlier. 


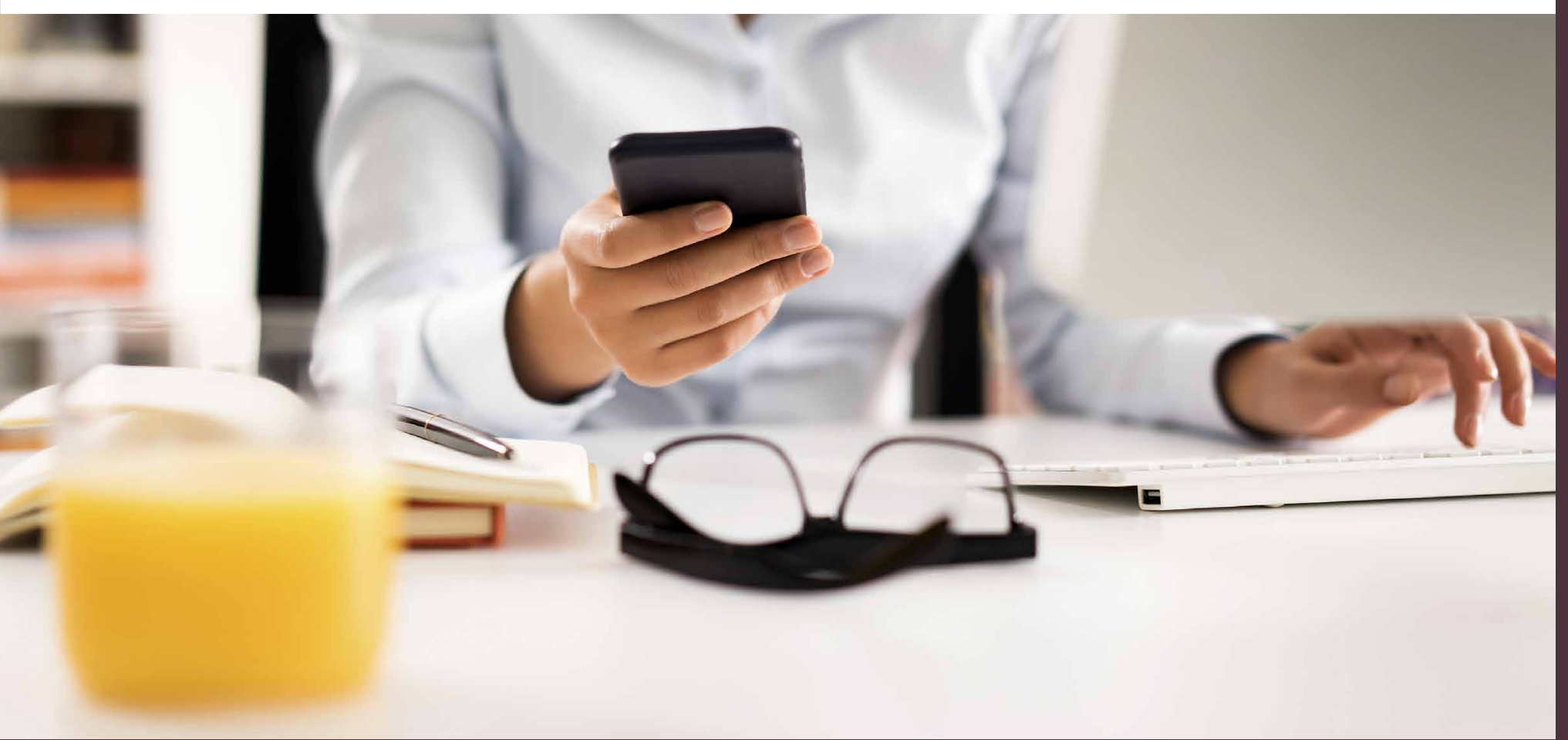

\subsection{Live Local}

Summary: This scenario is distinguished by more use of digital substitution for travel and lower per capita travel. The most advanced technologies developed by 2035 are more powerful ICT, user apps and the Internet of Things. They have led to some profound changes in travel demand, because their ease of use has led to far greater use of telepresence. At the same time there has been an evolution in environmental attitudes with a robust 'Live Local' movement that frowns on excess travel, as well as greater decentralisation of both population and employment away from London. Two other factors have contributed to the decline in per capita travel: first, autonomous vehicles have not become widespread, and second, road pricing has become sophisticated and effective.

General demographic and economic trends: In 2035, demographic trends have been on a fairly stable trajectory. The population has been growing at about 0.6 per cent annually, meaning that the UK population is now roughly 72.6 million. Birth rates and immigration have been largely steady. Some 25 per cent of the population is over 65, higher than in 2015 when it was 18 per cent. Economic growth has been similarly steady but not spectacular, at 1.6 per cent annual growth in gross domestic product (GDP) per capita.

\section{Technology development: The UK's} information technology sector has developed quite rapidly, spurred by investments in the 2020s to bring broadband speeds of 500MB per second across the UK by 2025 . Government investment in ICT infrastructure in urban and rural areas alike has made the cost of highspeed access affordable and encouraged an ecosystem of technology entrepreneurs who have developed a broad swathe of applications available to both consumers and businesses. The long-awaited Internet of Things finally became an everyday reality around 2030, meaning that many people live in 'smart houses' that do everything from adjusting the temperature when residents arrive home to ordering household supplies when they run low. 
While autonomous vehicle development continues, policymakers continue to argue about appropriate regulation and car manufacturers have not been able to iron out liability issues, meaning that while the technology for producing these vehicles has been available for years, they are not yet commercially available. Luxury vehicles with a high degree of automation, such as hands-off self-parking, automatic lane-keeping and traffic-jam assist, have been available for some time, but they still require drivers who can retake control of the vehicle if needed. As luxury vehicles, they cost considerably more than conventional cars and the adoption pattern has been akin to that of hybrid vehicles, which are purchased largely by more affluent households. Many people dislike the semi-autonomous features, because they feel like the car is driving in an overly cautious way. The vehicles tend to sport showy infotainment systems, in the hopes of attracting more buyers, but the costs are still prohibitive. Car manufacturers have concentrated their efforts on lowering emissions and bringing down the cost of electric vehicles by improving battery life.

Advanced manufacturing, including 3D printing, has become prominent in industry but not the home market; the machines are too complex and costly for all but the most dedicated hobbyists to use.

Work and business: One of the greatest changes in the past 20 years is that telework has finally made a considerable dent in the amount of time people spend at workplaces, with attendant reductions in commuter journeys. This has been driven by five major improvements in telepresence: far higher speeds (no more jerky live videos with a half-second delay), increased ease of use (controls can be operated by almost anyone), greatly improved reliability (computer crashes are something that people remember from the past, like black and white televisions), enhanced data security and a reasonably affordable price. Telepresence no longer requires a specially equipped room; any room with a screen (and new housing and offices come with built-in screens standard in most rooms these days) can be almost instantly converted to a meeting space.
In-person business meetings are a thing of the past, except for very large gatherings such as conferences. Even high schools and universities have more students taking online courses than sitting in traditional classrooms.

There have been attendant cultural changes as well. First, the current generation of employees grew up with smartphones and video calls, and many employees value working from home to minimise distractions from co-workers when they need to concentrate (especially as private offices became scarce with increasing property prices). Second, the younger generation in particular has shown a decreasing tolerance for 'unnecessary' travel, similar to the cultural change that took smoking from sophisticated to scorned within a generation. A small but growing minority subscribe to a 'Live Local' ideal - purchasing locally made goods, reducing their carbon footprint, and cultivating a rich online social life.

Along with these changes, the structure of many white-collar workplaces has evolved towards more zero-hour contracts. A high percentage of workers in many knowledge fields are selfemployed, so they have no permanent offices. Many belong to one or more neighbourhoodbased cooperatives, so they have a nearby workplace where they can avoid the tedium of working from home all the time. With increasing GDP helping to fuel an increase in house prices, and not much land to build on, many people live in fairly small flats/houses, which explains why work cooperatives have become so popular. Commute distances have decreased simply because many people no longer have conventional commutes. The availability of highquality, reliable, high-speed broadband in even rural areas has also allowed some people to leave crowded, expensive cities like London and move to smaller cities and even rural villages, and many employers have done the same.

Health: Overall the UK is a healthier place due to technologies that enable health monitoring and telepresence. People make wide use of wearable personal health monitoring devices that transmit data to medical practices as needed, and 
specialised algorithms spot problems and flag them to patients before they even notice anything is wrong. Remote monitoring has also greatly helped the management of patients with chronic illnesses, since nurses can check indicators on a weekly or even daily basis. Through the Internet of Things, repeat prescriptions can be filled automatically and delivered to the home, and home sensors can detect some instances when a resident needs medical attention (for example, if a person falls). Many medical consultations take place via telepresence in the patient's home, which enables patients to see specialists without an in-person appointment, an important consideration in an era of more centralised NHS staffing. Other routine healthcare needs, such as flu jabs, immunisations for children and blood testing, are often covered in local workplaces, schools and walk-in clinics. In-person doctor's visits are generally limited to diagnostic and invasive procedures.

While new technologies benefit people of all ages, the change is most apparent in the over-65s. An increasing number can live at home as a direct result of better telepresence, which allows medical professionals and other family members to check up frequently on people living alone. Technologies have become easier to use, and the people who are 80 in 2035 have more familiarity with computer technologies than the previous cohort of people that age, plus many are still in good health.

Retail: The retail sector has gone through some major changes in the past 20 years. For one thing, online sales have increased enormously. Better search engines make it easy to find all kinds of things online and make comparisons before purchasing, and new apps make it easier to 'see' the items as they will be used (e.g. how a shirt will fit, or whether a sofa matches the curtains). The options for receiving goods ordered online have improved as well. Better algorithms provide more specific delivery windows, and a variety of options exist to pick up goods that customers don't want delivered at home: at-work delivery, neighbourhood hubs and the stores themselves. In-person shopping is thriving in two areas, delicatessens and fresh markets, which play into the 'Live Local' ethos, and destination retail, which functions to some extent as entertainment (e.g. outdoor clothing shops with climbing walls or toy shops with play areas for children).

Increasing use of online shopping means that retail in high streets is decreasing, continuing a long trend. Lots of goods are delivered, and loT technologies have been able to automate some of this (automatically reordering staple or nonperishable items on a recurring basis). Some high streets have successfully adapted, replacing chemists and do-it-yourself stores with high-end destination retail, more food outlets, services ranging from government offices to hair salons, and special events.

Finally, some retailers have radically changed their business models to focus more on product life cycles and sustainability. Manufacturers of consumer goods are now legally required to accept goods back after they have outlived their usefulness, so the responsibility for disposal rests with them and not consumers. In many cases they want to reuse the raw materials anyway, due to shortages. This has had a knock-on effect of turning some goods into services. For example, consumer electronics are seldom purchased outright, but instead leased from a provider who is then responsible for upkeep and eventual replacement. Fewer purchases mean that total consumption is decreasing as well, and when people do make purchases, they expect them to be more expensive but have a longer useful life. Secondhand markets, both in-person and online, are thriving, especially since regulations have made people pay far more for rubbish disposal.

Freight: Changes in freight go hand in hand with changes in retail. Due to online shopping, package delivery to consumers has grown significantly. Improved logistics mean that goods from multiple suppliers can be bundled in one shipment, but this does not always happen smoothly because it requires shippers to work with multiple carriers who do not necessarily want to share business information. But overall, fewer goods are delivered between warehouses 
and retailers, and a higher percentage go directly to the end consumer, meaning that disintermediation has increased.

3D printing has not made much of a dent in the home market, but its effects on manufacturing mean that an increasing proportion of goods can be printed at warehouses, so these have become more decentralised. Some forms of conventional manufacturing have become more nimble, in that they can easily adjust to consumer demand, and they have also gained a foothold in unconventional markets, such as 3D printing of food and medicines. Increased travel costs because of road pricing and driver shortages have accelerated this trend. They have also contributed to some reshoring of manufacturing, although this development is related more to rising labour costs in other countries and the need for high-skilled labour and quality control in some industries, such as pharmaceuticals.

Long-distance travel: The overall trend has been towards taking fewer but longer holiday trips. Leisure time is also increasing, in part because of the structure of work, so there is a trend towards taking longer trips (several weeks or more) during which travellers soak up the local atmosphere and work on a part-time basis. The 'Live Local' types prefer to travel via lesspolluting modes (rail as opposed to air), and frown upon long-distance travel generally.

An explosion in leisure travel-related apps means that people are able to plan lengthy trips at relatively short notice. For example, it's very easy to compare costs across different modes and accommodation and to make last-minute bookings. Good translation apps make it simple to communicate across language barriers, and security-based apps can provide instant advice on coping with an emergency. Finally, both travel modes and destinations compete to some extent on their environmental footprint (or lack thereof).

Travel implications: Generally speaking, travel is more expensive than 20 years ago, which is why people are willing to forego some trips and interact online. The influential factors are the cost of fuel, extensive road pricing to address congestion, and higher prices for rail and air travel because of the need to maintain ageing infrastructure. Climate legislation has mandated more taxes and fees to discourage travel. Changing public acceptance of the need to reduce travel made it possible to institute widespread mileage-based road pricing, which has led to better management of road capacity. Some technological improvements, such as digital signalling for trains, have also pushed up the cost of tickets. Travel that happens is also made easier by the plethora of ride-sharing apps, and travel information apps make transfers between modes seamless.

However, travel is generally slower and more of a struggle than it was in the 2020s. Peakhour road pricing has reduced congestion in some key corridors, especially along motorways where cars compete with trucks for road space and in bus-only lanes in cities, but not necessarily everywhere. Some road capacity in cities has been reallocated to slow modes, such as bicycling and walking, so vehicle travel speeds have fallen. Just in the past year or so, two intercity motorways have seen one lane converted to semi-autonomous vehicleonly lanes in anticipation of the day when cars and lorries will not require drivers at all. Speed limits have been reduced as a safety measure. With the majority of driving taking place in conventional vehicles, time spent in cars is still unproductive. Not much new investment has been made in other forms of infrastructure, so local and inter-urban rail and air remain overcrowded in many cases and one delay can have a major cascading effect.

All of this has a dampening effect on travel, and people are less likely to make journeys for mundane reasons. Per capita travel has therefore decreased: people commute less and make fewer local journeys. Of course, with a higher population, the overall number of miles travelled is higher than it was 20 years ago, but the decline in per capita travel is quite pronounced. 


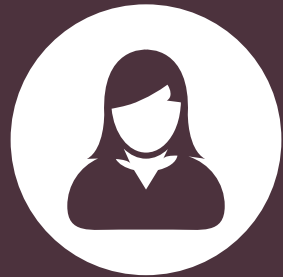

It's 7 a.m. and Mia, 29, is awoken gently as her smart studio flat gradually raises the illumination in the bedroom area, simulating dawn. She gets ready for the day, drinking the coffee that her 'butler' has already prepared just the way she likes it. It is Friday, so she sorts out some clothes that she no longer wants. The sensors in the clothing detect their new location in the recycling zone and alert an automatic collection robotic vehicle. This vehicle, which travels on local pavements, has access permissions and enters the flat, collects the clothes and takes them to a local centre. The clothes are automatically listed on a secondhand trading system, and if they sell they will be delivered to the new owner, with the money (minus a small fee) going into Mia's account. Unsold clothes are returned to the manufacturer for recycling, with a smaller return fee paid to Mia.

Over breakfast Mia browses the selling sites. If she likes the look of something, a wave of her hand through the 3D interface shows her how it will look - clothing is mapped onto her 3D avatar, which poses and twirls to show how it fits. Another wave completes the purchase, which is delivered directly from the manufacturer to home. After breakfast and shopping, Mia begins work. Another gesture and the breakfast bar of the studio realigns into a workspace. Mia checks into the various task-assignment sites where she is registered to signal her availability for work as a computer programmer - her last assignment was finished yesterday and she is looking for a new job. A task matching her skillset is available and she checks out the payment terms - they look OK so she accepts the job and starts work, using a blocking app to avoid distractions from social media and advertising. Mid-morning she checks into a 'coffee' site - various friends from around the world are checked into the same site. They can see each other's workspace environments at full size - the walls of Mia's flat are effectively screens that can project 3D images - so their 'virt' meet-up has a very real feel. Lunch is delivered from a local deli where Mia has a regular order - they pride themselves in using local organic produce and make their own bread on site. While she works, her 'guardian angel' (wearable health app) regularly reminds her to get up and move around, and mid-afternoon she goes out for a run.

For dinner, Mia meets up with some friends in 'real' (physical meeting) - they walk to the local 'village', a central zone filled with restaurants, wine bars and 'experiences' (such as live theatre, swimming pool, gym and sauna). They talk about their holiday plans. Most of them are planning local holidays - rural retreats to experience a 'back to basics' holiday where they have to cook their own meals and wash their own clothes are popular - but one of Mia's friends has been saving for a trip to the US. Some of the group disapprove, but most are excited for her - it will be the trip of a lifetime. As Mia walks back to her flat, her guardian angel signals approvingly that she has met her exercise target for the day and all her vital signs are normal. 

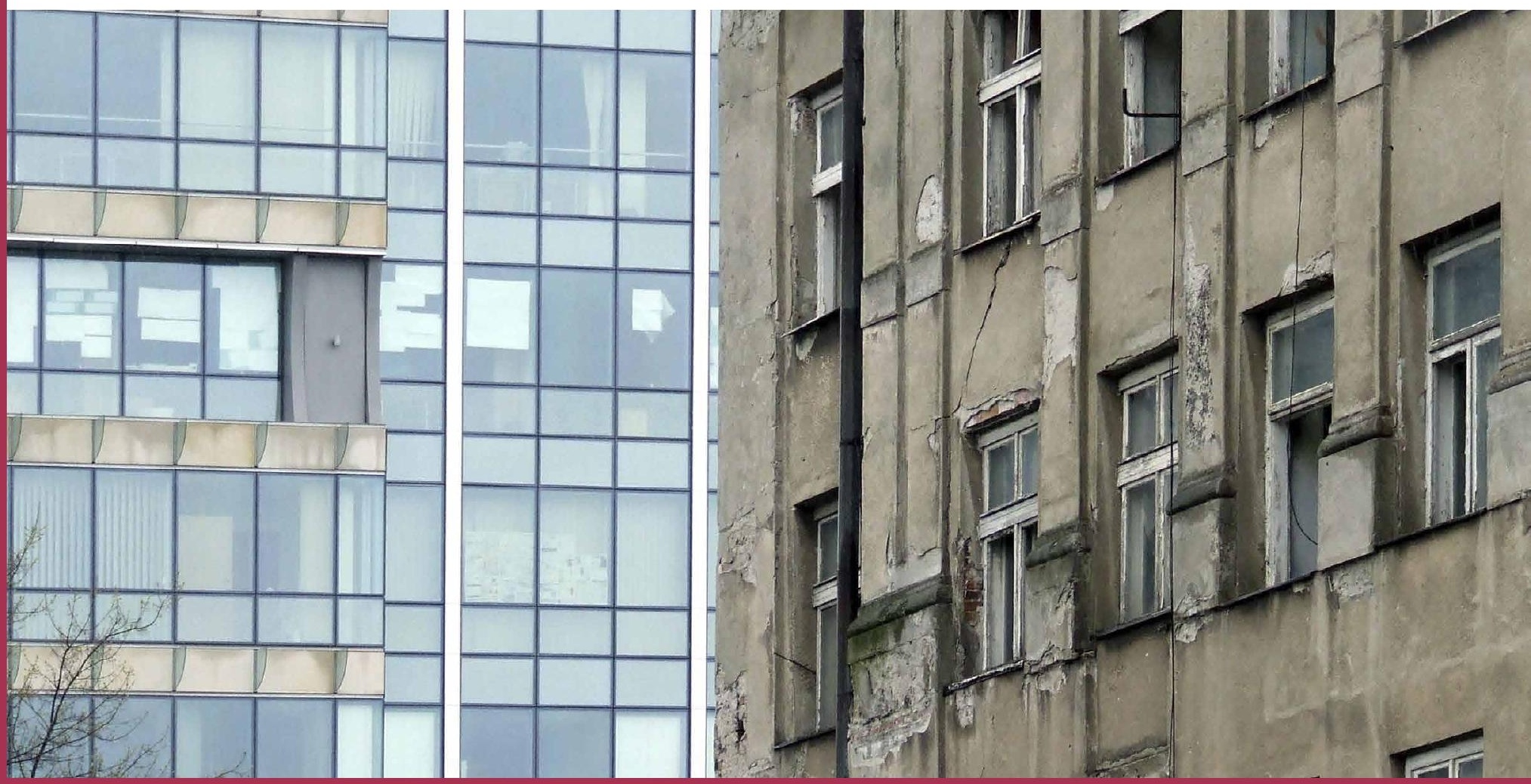

\subsection{Digital Divide}

Summary: In this scenario, the economy and overall population are growing at slower-thananticipated rates. Income inequality is high and, while advanced technologies have been commercialised, many remain financially out of reach for much of the population. Lower GDP growth combined with increased travel costs has led to lower levels of travel per capita. Advanced ICT has contributed to businesses moving away from London, which has remained very expensive. Autonomous vehicles and 3D printing are used fairly extensively in the freight sector, with warehouses around the country serving as 3D printing locations. An extensive person-to-person and sharingbased economy has developed, because many people cannot afford to buy everything new.

General demographic and economic trends: GDP per capita growth has slowed from the predicted trend of 1.6 per cent annually. Most European countries have experienced fairly slow growth in the past decades due to continued problems of increasing levels of debt and stalled consumer demand, and while the UK is generally faring somewhat better, it shares these general economic trends. Although overall growth is modest, increasingly income gains have been accruing to the wealthiest 20 per cent of the population. The remaining 80 per cent have seen stagnant or declining wages (in real terms).
UK population growth has been lower than the forecast 0.6 per cent annually, due to a combination of modest birth rates and relatively low immigration. Stringent immigration policies are in place, and the UK is not attracting large numbers of immigrants due to sluggish growth. At the same time, people are living longer so the proportion of over $65 \mathrm{~s}$ has increased to close to 30 per cent.

Technology development: The UK has seen fairly substantial advances in technology over the past two decades. One area of note is the 
deployment of a new generation of both fibre optic cable and Li-Fi-based wireless networks ( $\mathrm{Li}-\mathrm{Fi}$ being light-enabled $\mathrm{Wi}-\mathrm{Fi}$ ). These have increased the speed and ease of connectivity for individuals and businesses alike and spawned revolutions in mobile apps and the ability to connect devices to the Internet of Things everything from home appliances to medical monitoring equipment to sensors embedded in roads. However, gaps remain in terms of access. Big cities and gentrifying small towns generally have the best access, while other small towns that are struggling economically still live with early 21 st century technology that seems increasingly antiquated.

Fully autonomous vehicles have become a reality in the past five years, after much hype. The first models were extremely high-end luxury vehicles, essentially available only to the very rich. Prices have declined only slightly since then, since the lack of a potential mass market tends to keep prices high. So despite being available they constitute a tiny fraction of the car fleet.

Advanced manufacturing methods have boomed and 3D printing is regularly used for specialised applications where customised products are required. Most of these are not consumer products, but instead range from replacement parts for heavy machinery to medical devices such as custom joint replacement (for example, shoulders and knees). In the industrial sector, robots are increasingly embedded in production processes, and improvements in virtual reality have made it more efficient to visualise and find potential flaws in major construction projects, whether bridges or skyscrapers.

Work and business: Employees with steady jobs work remotely more often than not. Firms are able to invest in the latest ICT offerings to provide extremely fast connections, video links and data security to their employees, many of whom could not afford them otherwise. Most employees can easily work from home or other off-site locations. Telepresence has improved vastly over the past decade, so off-site team members or long-time clients often interact this way. Important meetings still generally take place in person.

Although property prices have moderated slightly, rents are still high and companies concerned with overheads (especially startups, of which there are many) save money by setting up their businesses outside of London. As a result, London is no longer the centre of job growth that is was 20 years ago, although many national and international companies still locate there for the prestige, if they can afford it. Employers have also cut down on office space per person. It's not unusual to have 'hot-desking' arrangements, in which employees have no permanently assigned space but sign up on a daily basis for a workspace.

For many, the structure of work itself has changed quite dramatically because of technologies that enable outsourcing. Far fewer people work in regular employment, and many scrape together a living in the so-called gig economy, combining numerous overlapping tasks (from driving a shared vehicle to doing online administrative support work), renting out their spare sofas and taking a string of short-term assignments on a contract basis. Technologies enable all of these, as it's very easy to sign up on numerous platforms and advertise one's skills, and government-certified third-party online financial firms oversee the payment process. Some people appreciate the flexibility and continual change, but many find it hard to get ahead financially. Houses are too expensive to purchase for many, and turning a series of low-paying jobs in the peer to peer or sharing economy into a proper business requires too much capital. While the official statistics show that commute distances have decreased, for those in the gig economy, given the irregular nature and location of the work undertaken, conventional commuting no longer exists.

Health: Overall, the UK is a less healthy place than 20 years ago. This is in part because the proportion of the population over 65 is larger 
than it was, and in part because the incidence of chronic medical problems is growing among all adults. The senior population may be living slightly longer, but for many the added years are not healthy ones. While there have been some impressive medical advances in genetic drugs, low-impact surgery and organ transplants, many are available only to those with private insurance and the majority of Britons have not benefited. A divide exists between the more affluent, who monitor their health with sophisticated apps, and the less affluent, who on the whole are less healthy.

Even for the over $65 \mathrm{~s}$ who are able to continue living at home - a larger share than in 2015 - visits to the doctor are frequent. The technologies that might enable more homebased care, such as monitoring devices and telepresence, are too expensive for many older people to afford. Because of government cutbacks, the NHS cannot afford to deploy these technologies as widely as they would like, so they remain centralised at a small number of facilities. For example, the kind of high-quality telepresence that makes a doctorpatient encounter successful requires fairly sophisticated technology at both ends, highspeed connections, a dedicated room at the doctor's surgery and support staff to make sure the technology is working correctly. It simply hasn't become a less-expensive substitute for routine visits.

While the NHS has tried to shift some routine medical appointments to non-traditional settings, the proportion of care delivered this way has not changed a great deal. Worksites were considered a good venue for such care, but as noted above fewer people report to conventional worksites and this population is difficult to reach. There has been some success with pharmacybased walk-in treatments, but with an increase in online shopping fewer people drop in to their local pharmacy.

Retail: The retail industry is not doing very well. Per capita consumption, as measured by spending on consumer goods, has stagnated, for several reasons: flat incomes keep many people from buying much more than necessities, the sharing economy means that households buy fewer big-ticket items (including cars) and retailers have decreased their prices due to low demand. The luxury market is one of the few bright spots, since those with money continue to spend it, but spending by the middle class is down. Online sales are up across the board, as mobile apps have enabled easier purchasing and clever companies have devised personally targeted ad campaigns - a stroll past a shop generates a pop-up coupon, or the pub down the road entices new patrons with happy hour specials of their favourite beer. Not surprisingly, high street sales are down overall.

Because of the slow economy, person-toperson commerce is also thriving in several forms. People with goods they no longer need can easily sell them, or even more commonly, rent them out for a steady (albeit in most cases modest) income. Ever since tracking tags became common in many goods, people have felt more confident that items they rent to strangers will be returned. Everything turns up on the main rental apps, from tools and designer dresses to high-end kitchen implements and furniture. Cars have been rented person-toperson for some time now. In addition to renting goods, the person-to-person economy contains a fair amount of services as well. Anyone can go online to offer haircuts, dog walks, personal training or career coaching. Weeding out the serious offers from the frivolous can be difficult, but it is quite possible to make a living (generally a modest one) from these one-off tasks.

Freight: In conjunction with the growth of online and person-to-person purchasing, package delivery is up substantially. The freight industry has developed new models for this, one being the rise of delivery services that work exclusively with individuals for a monthly fee. Another is the widespread use of 'taskers' (private individuals with their own vehicles) who make deliveries within 
specific neighbourhoods under short-term contracts with freight carriers, much like ridesharing services but with packages instead of passengers. While some observers thought autonomous vehicles might take over this market, and a few firms have tested that model, problems with package theft made them reconsider. For short-distance delivery, it is actually cheaper to use the taskers.

For long-haul delivery, the freight industry was quick to adopt autonomous vehicles to save on labour costs. Even with higher purchase costs, fleet owners can make their investment back through savings made by not having to hire drivers. Autonomous vehicles can also better use night-time road capacity, making these journeys much more safely.

With some manufacturing moving back to the UK, the freight industry has become somewhat more decentralised, with more warehouses throughout the country. Many are co-located with 3D printing production sites. Cities contain more warehouses because deliveries to end users have increased so much. The industry has moved towards disintermediation, meaning that each article moved passes through fewer hands. This is in part because more goods are manufactured locally, and in part because direct delivery to the customer is more common.

Long-distance travel: While on paper leisure time has increased, given the decline in fulltime employment, in reality fewer people are able to make long-distance trips. For those in the gig economy, time not working is usually time spent lining up the next task. While that style of working is flexible, time off means time not earning money. It's hard to step away to take a proper holiday because somebody else is always competing for the same customers. However, those in the more affluent groups are still travelling both within the UK and abroad, and they are not particularly cost-conscious. So the market has tilted towards luxury travel experiences that are priced accordingly.

Environmental attitudes play some role in people's travels, but with long-distance travel mainly the province of the well off, travellers assuage any environmental guilt by purchasing carbon offsets. Some hotels and resorts compete on the basis of environmental features, whether energy efficiency or water conservation.

Travel implications: Overall, travel per capita is down and total travel has remained relatively flat as population growth has not been high. Several factors contribute to this. Telework is fairly common among the employed, and among those not conventionally employed much work is performed at home. The use of shared ride services and private package delivery means that a few people put many more miles than average on their cars than others, but the high use of shared rides means that the proportion of people who don't own cars at all is higher than in 2015. Not everyone likes sharing vehicles, so many continue to use conventional public transport services for daily travel.

The per-mile cost of driving has increased with fuel prices going up and road pricing being implemented in some places. Some of the larger cities have cordon congestion charges, based on the London model, and a few key motorways have distance-based tolls as well. Despite being effective, such tolls are often criticised as allowing the rich to buy their way out of congestion because they can afford to pay tolls daily, while the less affluent pay them only in special circumstances. Congestion has worsened but not to a huge extent; the main driver is the lack of new road capacity built over the past 20 years, and some roads are in poor shape too. 


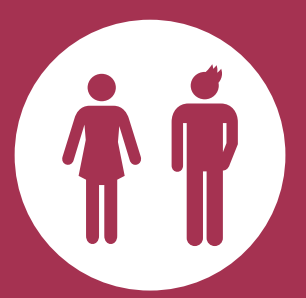

Having left school with few qualifications Max has struggled to make his way in the world. Now 25, he makes ends meet in a variety of low paid 'gig' economy roles. He rents a sofa in a mate's one-bedroom flat shared with three other young people. Property prices and wages being what they are in the city, people have to share. Max checks his mobile daily for jobs. He delivers packages around the local estates, where so many people live without proper addresses that drones would get lost or perhaps stolen. Local human knowledge beats machines here. He collects the parcels from the local 3D depot by moped and bikes round the estates delivering them. He is paid per delivery, so the quicker he can get round the better. Each parcel is tracked, so cheating the system is hard. Once he's delivered the morning parcels he goes to his next job, walking dogs in the local park. He loves animals and enjoys being outdoors, but collecting each animal from its home without a car involves quite a lot of extra walking. He gets some soup from a café in the park for lunch.

The afternoon brings more parcels to deliver. Then he heads back to the flat to play immersive online computer games for money - he is skilled enough to make a bit of money selling items collected during gameplay to less devoted but wealthier players. He isn't yet good enough to command a following on social media and make a living that way, but maybe someday.
By contrast, his sister Jules is an entrepreneurial and successful young woman. Her day begins very early as she has quite a drive into the office/ factory - she can't yet afford an autonomous car, although next year she hopes to get one so she can work (or catch some extra sleep) on the way in. It's her own business, started two years ago and growing very rapidly. Her firm designs specialist medical components on a bespoke basis, prints them on site and ships them to hospitals all over the country, often on challenging timescales. She has a small staff of technologists and engineers, as well as a marketing and sales team. Unusually, they all work on site most of the time. Located well outside London, property prices in the area are actually affordable, and the quality of life is good. However, the poor rural broadband coverage even now means that true remote working isn't possible. The office itself is very well connected. Meetings can be conducted virtually with clients using the office interface suite - a sophisticated immersive system that can substitute for quite a lot of faceto-face interactions. But connectivity from home, particularly for those in the more remote villages, is very poor. There was some talk of using drones to provide superfast broadband but there weren't enough local subscribers to pay for it. Jules might invest in this herself once her business becomes more successful.

As the day ends, Jules is the last to leave. She would like to take an evening off to go out with friends, but business comes first, at least for now. 
Chapter Four.

What do these scenarios

mean for policy and

innovation investment? 
The implications of the scenarios for policy and innovation investment were explored in interviews with stakeholders representing government, academia and industry. In total 14 interviews were undertaken, with, for the most part, one scenario selected by the stakeholder for discussion in each. Four respondents covered all scenarios in their interview, while the remainder mainly chose to talk about the scenario they found most plausible or most relevant to them. This meant that both the Driving Ahead and Live Local scenarios were discussed in eight interviews and the Digital Divide scenario in six.

Based on the experts' responses to the scenarios we have derived recommendations for policy and innovation investment. We have done this using three frames of analysis: (i) considering barriers and enablers for three key technologies: AVs, next-generation ICT and Big Data / open data; (ii) considering key policy implications that are drawn from the scenarios; and (iii) identifying innovation investments that are robust across scenarios. These are discussed in the sections that follow. We then consider the potential need for new business models.

Finally we present our recommendations and a strategic roadmap for policy and investment. These recommendations reflect high-level observations on policy and innovation investments, based on consideration of the potential future landscape for transport, across the range of technologies discussed. When thinking about the likely development pathway for any one technology, further in-depth studies will be necessary to consider the impact of policies or innovation investments on how that technology may develop.

\subsection{Barriers and enablers for key technologies}

From the interviews, three technologies were identified as having the most impact on activities and travel in the scenarios: AVs, next-generation
ICT and user apps / Big Data. Experts identified a number of barriers and enablers to the roll out of these technologies. A significant proportion of the discussion related to $A V s$, even though these were not the explicit focus of the interviews. This may be because the roll out of AVs will be much more disruptive and involve much more uncertainty than the other technologies. We have aggregated the barriers and enablers into six categories: (i) public acceptability and consumer demand; (ii) data security and privacy; (iii) interaction with legacy systems; (iv) legal and regulatory frameworks; (v) standardisation and interoperability; and (vi) the nature of the market. We discuss each, in turn, covering the implications for each technology and the role of government, if relevant.

\subsubsection{Public acceptability and consumer demand}

Public acceptability and consumer demand were issues identified for all three technologies, as discussed below.

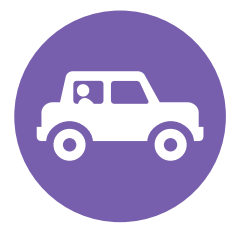

\section{Autonomous vehicles}

Public acceptability issues for AVs include concerns as to whether a machine can be trusted to deliver the expected increased levels of safety (without resulting in vehicles that are too risk averse to increase the effective capacity of the existing network). On the other hand, substantial increases in travel safety could also be a facilitator of demand. What is more, reductions in accidents could lead to reductions in travel delays. Recent survey results for the UK indicate that 39 per cent of transport users would consider using driverless cars (Transport Systems Catapult 2015a), while another survey from the US found that 36 per cent of respondents were 'somewhat' likely to use them (Zmud, Sener \& Wagner 2015). These proportions may change as people learn more and gain more experience with AVs.

Ultimately, consumer demand will depend on the ability of AVs to fulfil consumers' needs, 
in terms of ease of participation in activities, productive use of journey times and the cost of travel. The potential high cost of AVs, at least for early adopters, may be a barrier, particularly if the full benefits of the technology, for example in terms of safety, may not accrue to owners whilst there are both autonomous and nonautonomous vehicles on the roads (Anderson et al. 2014). Should car-sharing models flourish, the costs of car ownership could be reduced considerably. Lower car use costs may also result if $\mathrm{AV}$ technology provides improved fuel efficiency through more efficient driving and platooning, if sharing models incorporate more fuel-efficient or electric vehicles, and if personal insurance costs decline. Reductions in the cost of driving may lead to increases in travel and congestion, which would have a negative impact on society and consumer demand, unless managed through policy interventions such as road pricing (such policy interventions are discussed in Section 4.2).

Governments have a role to set safety standards for new technologies and to ensure that such standards are met. Moreover, Anderson et al. (2014) warn of the potential problem that many of the societal benefits of AVs, such as increases in safety and reductions in emissions, will not accrue wholly to the purchaser of the vehicle, but to society more generally, and therefore that subsidies or other incentives, such as AV-only lanes, may be necessary to encourage take-up, particularly in the early adoption phase.

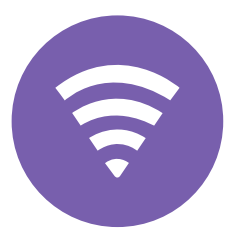

\section{Next-generation ICT}

For next-generation ICT technologies, public acceptability relates to consumer attitudes to teleworking, telehealth (and/or telecare), teleshopping and to virtual leisure activities. Most research has concentrated on workrelated aspects (Andreev et al. 2010). Even with ubiquitous high-quality connectivity, there needs to be a consumer appetite for operating in a more virtual world and the importance of face-to-face social interaction should not be underestimated (Pawlak et al. 2015). Moreover, the opportunity for teleworking will be limited to specific occupations; it may also be limited by the reluctance of employers to implement this model. ${ }^{4}$ Whilst teleworking could reduce employer workspace costs and employee commuting costs, home-based office costs would increase.

Information and communication technologies also have the opportunity to revolutionise how healthcare is accessed by the population, with knock-on effects for transport. Technology Enabled Care Services that encompass telehealth, telecare, telemedicine, telecoaching and self-care apps with remote video consultation are starting to be used in rural countries such as Australia. ${ }^{5}$ This technology is also developing in the UK, although current evidence for its effectiveness and cost effectiveness is mixed, and strong barriers to adoption remain (Greenhalgh et al. 2012; Henderson et al. 2013). Consumer preferences are likely to play an important role in their success.

Online shopping is one area that has already seen rapid growth. However, the impact of online shopping or e-commerce on travel is not clear. Mans et al. (2012) cite that most studies on the topic have found mixed results: in some cases, online purchases replaced a shopping trip and thus reduced shopping-related travel, but in others e-commerce resulted in new shopping trips, for example because people may have made a special trip to a shop for a specific item found online.

Consumer demand may be limited by lack of provision of connectivity, for example in rural areas. It will be essential that as the quality and speed of broadband and mobile phone services continue to improve that rural areas are 
not left behind. Government has a role here to support the provision of ICT services in hardto-reach areas and in legislating to ensure that the Universal Service Obligation - the legal entitlement to a basic service - keeps up with improving connectivity levels more generally.

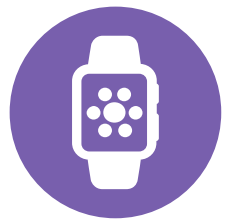

\section{Users apps / Big Data}

A lack of provision of connectivity to rural areas may also hamper individuals in these areas from benefiting from advances relating to users apps / Big Data.

Moreover, there may be disparities in access to services across the population. In 2014, six in ten UK adults used a smartphone. Although this was a 54 per cent increase from 2012, four in ten adults still did not have access to these services, with those aged 65-74 having particularly low levels of ownership levels (20 per cent in 2014) (Ofcom 2014).

In these areas there is a potential educational role for government to ensure that all those with access to services are able to benefit from them. There is also a generational aspect, as adapting to new technology becomes more difficult with age.

\subsubsection{Data security and privacy}

Data security and privacy could be significant barriers to the use of AVs, particularly in a connected environment. Recent examples of computer hacking of onboard systems indicate the potential scale of the problem (Greenberg 2015). Regulation around safety may be necessary both for AVs and for UAVs more generally. Data security and privacy issues are also paramount for teleworking, online shopping and telehealth and there is a need for reliable and robust systems. The success of apps and Big Data requires that consumers are willing to provide access to their personal data, leading to issues of privacy and security and perhaps questions on the value of these data.
These are also areas where government has a key role to play, specifically in supporting regulation of data security and privacy.

\subsubsection{Interaction with legacy systems}

The transition to driverless cars and their intermediate interaction with the existing system may be the least well understood - and perhaps the most uncertain - potential barrier to the adoption of full AV technology. Will these vehicles first operate in any sizeable scale on motorways or in cities? For freight or passenger travel? Will they be shared vehicles or personal vehicles? Will the path to the uptake of FAVs be evolutionary or revolutionary (Zmud, Tooley et al. 2015)? Such questions can only be answered through continued pilot and real-world testing, as well as research on consumer demand, vehicle development and regulatory facilitators and barriers. Government has a key role in all of these activities.

As mentioned above, consumer take-up for next-generation ICT applications, such as teleworking or telehealth, may be influenced by the reluctance of employers. According to Ham et al. (2012), inertia represents the greatest risk to the future of the NHS, with a need for health and social care leaders to embrace change and question established service models. Governments can support the adoption of such services through pilot testing, research, guidance on best practice and action in other areas to improve service reliability.

For user apps and Big Data, barriers may exist in terms of access to data (open data) and monetisation of data; again, these are traditional areas where governments could have a role in supporting development of frameworks to address these issues.

\subsubsection{Legal and regulatory frameworks}

Experts noted that a lack of legal and regulatory frameworks could hamper the development of AVs. In a US study, Anderson et al. (2014) note 
that the existing liability regime is unlikely to present concerns for owners or drivers of vehicles equipped with $\mathrm{AV}$ technologies; on the contrary, reductions in crashes and insurance costs are likely to encourage drivers and insurance companies to adopt these technologies. In contrast, manufacturers' product liability may increase, which could lead to delays in development. Some manufacturers have already stated that they will be fully liable, although there is currently no common industry position. ${ }^{6}$

Another issue raised in the interviews was that of maintenance of AV technology and software, which may require more frequent amendment than the vehicles themselves. Manufacturers or service providers might take responsibility for such maintenance, but further legislation may also be required. In terms of the legal and regulatory framework, the UK Department for Transport (DfT) has drawn up an action plan that includes a review of the existing set-up, as regards liability, vehicle use and safety that will also be informed by real world testing (DfT 2015a). It has also published a Code of Practice for the testing of automated vehicle technologies.

Furthermore, new regulatory frameworks for some services, for example taxis, may be required with the introduction of new technologies.

\subsubsection{Standardisation and interoperability}

The issue of standards was one that came up many times in discussion with experts regarding potential barriers or facilitators to AV development. Many felt that for producers, standardisation may be a facilitator for the successful deployment of AV technology, particularly as it enables interoperability relating to vehicle-to-vehicle (V2V) or vehicle-toinfrastructure (V2I) communications. But opinion was divided as to the best way to develop and set such standards, and when was the best time to do so. For example, in one case experts noted that the US Department of Transport (DoT) has said it will fast-track a proposed rule that would require all new cars to have specific V2V communication technology. It is aiming to send the proposed rule to the Office of Management and Budget for review by the end of 2015, a year ahead of schedule. Some felt that this was positive for innovation, providing a signal for producers on what the key communication technology would be; others felt that the legislation was too early and could be focused on the wrong technology. Unlike V2V, no V2I mandate is expected that would provide impetus and focus. Meanwhile, the European standards organisations, $\mathrm{CEN}^{7}$ and $\mathrm{ETSI}^{8}$, have elected to set basic standards for connected vehicles, known as Cooperative Intelligence Transport Systems (C-ITS) (European Commission, 2014). Although eCall ${ }^{9}$ is an example of the EU mandating the technology and communications protocol for car-makers, a non-regulatory approach currently appears to be the preferred solution in Europe for AV (eCall 2015).

Given the role of Big Data as an enabler for other technologies, such as the loT and $\mathrm{AV}$, and the use of apps across multiple platforms, standards and interoperability will also play a key role for this technology.

Governments have a role to monitor and, if needed, support development of standards, particularly those supporting interoperability of systems. However, such decisions should not be taken too early. When considering the development of standards, policymakers need

6 Volvo, Google and Mercedes-Benz have all stated that they will take full responsibility (http://www.autoblog.com/2015/10/09/volvo-accept-autonomous-car-liability/)

7 European Committee for Standardization (CEN).

8 The European Telecommunications Standards Institute (ETSI).

9 eCall is an initiative to bring rapid assistance to motorists involved in a collision anywhere in Europe. In the case of a crash, eCall automatically calls the nearest emergency centre, informing them of the location of the crash site. 
to take account of the maturity of the technology, the multiplicity of stakeholders, the complexity of the overall system and the multiplicity of competing approaches (O'Sullivan \& BrevignonDodin 2012). O'Sullivan and Brevignon-Dodin (2012) also point to the value of detailed roadmapping-type exercises to support emerging technology development, bringing in a range of public and private sector stakeholders to coalesce around the needs, priorities and approaches for standards development.

\subsubsection{Nature of the market}

The nature of the market can also be a facilitator or barrier to technology development. While the automotive industry has traditionally been dominated by a small number of car manufacturers, the market for $\mathrm{AV}$ may facilitate access for new entrants from the technology side, or potentially the creation of new firms combining skills from both sectors.

In terms of next-generation connectivity, largescale coverage may provide opportunities for new players, as a range of possible technologies to do this become available. A barrier for new entrants may be the cost of entry to the marketplace; there is also the question of whether such providers would be required to provide universal coverage, which could increase the cost of service provision substantially.

Both next-generation ICT and Big Data enable activities across a range of markets. ICT acts as a facilitator to tele-activities such as e-commerce, which is already changing the nature of the retail market. One consequence of this is an increased number of trips for the delivery of merchandise purchased online. With growth in online retail expected to continue, the need for data processing algorithms to allow efficient, cost-effective delivery could lead to technology innovations in this area.

For healthcare in the UK, Ham et al. (2012) indicate the need for an approach that facilitates new providers to enter the market, as well as enabling existing providers to try different approaches.

In terms of Big Data and apps, the current lack of integration of the transport sector was seen as a possible facilitator for new entrants to provide user information to improve journey planning. Examples of this can already be found in both freight and passenger transport sectors. Future developments in areas such as road pricing, climate change and environmental protection could provide additional opportunities.

Although not discussed in the interviews, the increasing interest in the loT from industrial sectors could lead to Big Data innovations (Lee 2015; Xu 2014).

\subsection{The implications of the scenarios for policymaking}

The scenarios for 2035 present three distinct futures that depend not only on technological development but also on changes in social, economic, environmental and policy factors. Unlike some scenario studies, our goal was not to deliver opposing positions (i.e. positive/ optimistic vs negative/pessimistic). Instead the scenarios represent value-neutral combinations of future projections regarding the chosen factors and technologies. As such, depending on one's overall perspective, each scenario contains both positive and negative implications for individuals and societies, businesses and other organisations, and the UK economy and government.

The scenario summaries below were crafted to highlight implications derived from the interviews with experts, particularly regarding policy-related aspects of the three scenarios. In this way they differ from the scenario summaries previously presented in this report.

\section{Driving Ahead}

A critical mass of fully autonomous vehicles is on the roads that function without a human 
operator anywhere, anytime. Safety benefits are being realised and parking challenges are being solved. Industry and regulators remain vigilant about data privacy and cybersecurity. Vehicles operate mostly in a shared mobility-ondemand model, reducing overall dependence on owning a private car or operating an entire inter- or intra-urban fleet. Traditional public and freight transport are struggling to find customers. Industrial sectors such as health, retail and work are transformed - with winners and losers. Economic growth is strong; consumer consumption is strong especially for online sales and person-to-person retail. Not surprisingly, people and goods are traveling more, and congestion is high. Urban travel is neither faster nor reliable. Rural customers are waiting for business models that address their autonomous mobility needs.

\section{Live Local}

ICT, Big Data analytics and user apps enable ordinary people to enjoy the promise of the Internet of Things. A relatively strong environmental ethos flows down from government regulation and up from citizen attitudes. Reuse of products and materials is prevalent. Instead of buying new items, people are leasing or sharing them. Technology is enhancing end-toend journeys, when people travel at all. Road pricing has become quite sophisticated and effective. Government and localities have fewer requirements to facilitate the movement of people and goods. People are reducing their transport footprint and living digital, consumption-light lives. This creates a new economic reality that favours creative entrepreneurs and penalises those less skilled in technology.

\section{Digital Divide}

The UK has seen substantial advances in digital technology development. Such technology has positive outcomes for those with access to it. Income and opportunity inequalities are high. Steady employment is only for the wealthy; others rely on the 'gig' economy. With few training opportunities, the less-skilled have a difficult time keeping up with the technology requirements of jobs. High stress has health implications for young and old, with a disparity in healthcare provision. Person-to-person commerce is thriving, but spending is down. Per capita consumption has stagnated. Government struggles to close the divide with policy and investment strategies.

Technology without doubt has implications for individuals, society, businesses and government. As the scenarios have demonstrated, new technologies may bring about changes in congestion and the amount of travel, patterns of consumptions, quality of life and health, the nature of work, how communities develop, how peoples' mobility needs are met, how goods are delivered, and how businesses operate and organise in the future. Table 4.2 presents the main categories of overall implications and the varying ways in which these may play out across the three scenarios, with some being detrimental to individuals, society and businesses, and others being beneficial.

Changes across the scenarios pose enormous challenges for policymakers. A passive or reactive governmental approach will not be sufficient to mitigate negative implications and facilitate positive ones. The bulleted items below indicate issue areas that are within the purview of government policy:

- Governments have a role in training and up-skilling workers. Across all scenarios, innovation is important and entrepreneurs do well. Bottom-up solutions are driven by demand. Innovators that bring new passenger mobility services and freight/ package delivery services to market may need supporting policies to do so. However, there are also likely to be job losses: AVs could replace the need for drivers of taxis, buses and lorries, fewer accidents will mean fewer people will need to work on repairing vehicles, advanced manufacturing methods 
Table 4.2. Implications of scenarios for society, businesses and government

\begin{tabular}{|c|c|c|c|}
\hline \multirow{2}{*}{$\begin{array}{l}\text { Overall } \\
\text { implications }\end{array}$} & \multicolumn{3}{|c|}{ Scenario-specific effects } \\
\hline & Driving Ahead & Live Local & Digital Divide \\
\hline $\begin{array}{l}\text { Economic } \\
\text { growth }\end{array}$ & $\begin{array}{l}\text { Economic benefits for technolo- } \\
\text { gy and app firms and 'personal } \\
\text { mobility' industry } \\
\text { Social benefits of increased } \\
\text { mobility } \\
\text { Increased road safety and re- } \\
\text { duced costs of accidents positive } \\
\text { for economy }\end{array}$ & $\begin{array}{l}\text { Economic benefits for local } \\
\text { communities (cottage industries) } \\
\text { and digital industrial sector, in } \\
\text { general }\end{array}$ & Economic growth stagnated \\
\hline $\begin{array}{l}\text { Travel } \\
\text { volume and } \\
\text { type }\end{array}$ & $\begin{array}{l}\text { Increased congestion as people } \\
\text { and goods are travelling more } \\
\text { (per capita) } \\
\text { Critical mass of FAVs on roads } \\
\text { operating mainly as shared mo- } \\
\text { bility-on-demand } \\
\text { Less demand for traditional pub- } \\
\text { lic (mass) transit } \\
\text { Urban travel neither faster nor } \\
\text { more reliable }\end{array}$ & $\begin{array}{l}\text { Less movement of people and } \\
\text { goods (per capita) due to ICT, } \\
\text { 3D printing for manufacturing } \\
\text { and environmental ethic } \\
\text { Good apps encourage rideshar- } \\
\text { ing/loadsharing, multi-modality } \\
\text { and seamless journeys } \\
\text { Long-distance travel: shorter } \\
\text { trips }\end{array}$ & $\begin{array}{l}\text { Less movement of people and } \\
\text { goods (per capita) } \\
\text { Congestion has worsened due } \\
\text { to lack of new road capacity } \\
\text { and lack of road maintenance } \\
\text { FAVs are luxury vehicles } \\
\text { Use of conventional public } \\
\text { transport and shared ride } \\
\text { services }\end{array}$ \\
\hline $\begin{array}{l}\text { Local/region- } \\
\text { al develop- } \\
\text { ment }\end{array}$ & $\begin{array}{l}\text { People live further from work } \\
\text { FAVs are shared leading to more } \\
\text { inter-household connections }\end{array}$ & $\begin{array}{l}\text { Community development and } \\
\text { enhanced local culture }\end{array}$ & $\begin{array}{l}\text { Not all people or communities } \\
\text { have access to new technol- } \\
\text { ogies }\end{array}$ \\
\hline $\begin{array}{l}\text { Nature of } \\
\text { work and } \\
\text { employment }\end{array}$ & $\begin{array}{l}\text { FAVs allow work on the move } \\
\text { and productive use of travel time } \\
\text { Negative impact on some job } \\
\text { types, e.g. taxi drivers, lorry } \\
\text { drivers }\end{array}$ & $\begin{array}{l}\text { ICT enabler of remote working } \\
\text { for certain job types / population } \\
\text { groups }\end{array}$ & $\begin{array}{l}\text { Substantial proportion of soci- } \\
\text { ety not in steady employment, } \\
\text { instead rely on 'gig' economy } \\
\text { Negative impact of automation } \\
\text { on employment }\end{array}$ \\
\hline $\begin{array}{l}\text { Patterns of } \\
\text { consumption }\end{array}$ & $\begin{array}{l}\text { Per capita consumption increas- } \\
\text { ing, especially for online sales } \\
\text { and person-to-person retail } \\
\text { Decline in high street retail }\end{array}$ & $\begin{array}{l}\text { Increased per capita consump- } \\
\text { tion trends are slowing } \\
\text { Reuse of products and materials } \\
\text { Leasing or sharing products } \\
\text { instead of buying new } \\
\text { Decline of high street retail }\end{array}$ & $\begin{array}{l}\text { Per capita consumption } \\
\text { stagnated } \\
\text { Only luxury market thrives } \\
\text { New person-to-person and } \\
\text { shared economy retail models } \\
\text { (e.g. Ebay } 2.0 \text { ) } \\
\text { Decline of high street retail }\end{array}$ \\
\hline $\begin{array}{l}\text { Movement of } \\
\text { goods }\end{array}$ & $\begin{array}{l}\text { FAVs important for freight: } \\
\text { reduced labour costs and driver } \\
\text { availability issues }\end{array}$ & $\begin{array}{l}\text { Less requirement to move } \\
\text { goods; fewer numbers of deliver- } \\
\text { ables per household } \\
\text { ICT/user apps/Big Data sup- } \\
\text { port consolidation of deliveries } \\
\text { across shippers }\end{array}$ & 'Taskers' for freight deliveries \\
\hline $\begin{array}{l}\text { Quality of life } \\
\text { and health }\end{array}$ & $\begin{array}{l}\text { Traffic safety benefits of FAVs; } \\
\text { although some negative conse- } \\
\text { quences due to reduced level of } \\
\text { walking and cycling } \\
\text { Accessibility benefits for all types } \\
\text { of people }\end{array}$ & $\begin{array}{l}\text { Enable work-life balance re- } \\
\text { duced time spent travelling to } \\
\text { work for some } \\
\text { Education and health services de- } \\
\text { livered in new innovative formats } \\
\text { New technologies enable elderly } \\
\text { to live longer in their homes }\end{array}$ & $\begin{array}{l}\text { Unequal access to ICT mag- } \\
\text { nifies differences within society } \\
\text { 'Gig' economy brings stress, } \\
\text { health issues } \\
\text { Disparity in healthcare provi- } \\
\text { sion }\end{array}$ \\
\hline $\begin{array}{l}\text { Regulatory } \\
\text { and legal } \\
\text { challenges }\end{array}$ & $\begin{array}{l}\text { Standards for interoperability for } \\
\text { AV, V2V, V2I } \\
\text { Managing data privacy/cyberse- } \\
\text { curity without hindering innovation } \\
\text { Government subsidies as invest- } \\
\text { ment incentives for entrepre- } \\
\text { neurs } \\
\text { Storage/bandwidth power at } \\
\text { affordable prices }\end{array}$ & $\begin{array}{l}\text { Policy to support equitable } \\
\text { investment in ICT development } \\
\text { and digital infrastructure } \\
\text { Policy to encourage cross-com- } \\
\text { munity collaboration } \\
\text { Policy to manage road transport } \\
\text { / reduce carbon footprint (i.e. } \\
\text { road pricing) } \\
\text { Role of government to support } \\
\text { entrepreneurs }\end{array}$ & $\begin{array}{l}\text { Addressing income and oppor- } \\
\text { tunity gaps } \\
\text { Public investment in training } \\
\text { and re-skilling } \\
\text { Policy to support social and } \\
\text { economic benefits of sharing } \\
\text { economy }\end{array}$ \\
\hline
\end{tabular}


will replace traditional manufacturing jobs. In the period of new technology adoption, training and up-skilling of workers may need to be a government priority.

- Government policy will have to take account of the likely uneven distribution of technology benefits. While technology in each of the scenarios has the potential to create significant value, in some cases this value may not be evenly distributed and may even contribute to widening income and opportunity inequalities. Advancing technology could create disproportionate opportunities for some highly skilled workers and owners of capital while replacing the labour of less skilled workers with machines. Employment-related income and opportunity inequalities spill over into the health, housing and retail sectors as well. In addition, some communities may be better placed than others to take advantage of ICT opportunities and others may be disadvantaged. The development of 'strong' communities may have less positive outcomes. Communities may respond in unproductive ways and become more physically isolated or culturally extreme. Policy may be needed to encourage cross-community engagement and collaboration to help create a fair distribution of resources and benefits. This places an even greater importance on training and education, and increases the urgency for government to find ways to address rising inequalities.

- Emerging transportation services will change mobility patterns and may create new sources and types of congestion to which governmental policy will have to respond. Traditional policy or planning actions may not address the manifestations of congestion due to new passenger mobility and freight delivery patterns. Road pricing appears in several of the scenarios as a means of mitigating the negative implications of these changing mobility patterns.

Government should monitor the changing patterns of road congestion and should introduce effective demand management policies, such as road pricing, as necessary to mitigate negative consequences.

- Government policy should be alert to the potential for combinations of technologies to multiply impacts. Certain technologies (e.g. ICT and autonomous vehicles) could be used in combination, reinforcing each other and potentially driving far greater impact - both negative and positive. Other technologies require an enabling technology (e.g. user apps and the loT) to be able to fulfil their promise. Technology assessments cannot be undertaken in isolation but need to consider the entire technology ecosystem. For example, it may be necessary for government to rethink how to measure the economic impact of technology - to look beyond GDP and employment and to find metrics that truly capture the positive and negative values (added or subtracted values) when combinations of technologies take hold.

\subsection{Identifying robust innovation investments}

What is clear from the development of these scenarios is that the future is uncertain. It cannot be known how the world will look in 2035 - what will be the key technologies that influence how we work, shop, access healthcare, take holidays or ship goods and the travel generated from these. In this study we have developed three plausible visions, all of which differ substantially in terms of the technologies that will influence people's activities and travel.

When thinking about investments in future technologies, governments cannot be expected to 'pick the winner', but rather they should aim to identify innovation investments that are robust across the range of future possibilities. In this spirit, three strategic areas were identified by experts as being important 
across the range of scenarios. Each of these is discussed below, along with the potential role of policy and government.

\subsubsection{Investment in next-generation ICT}

Next-generation ICT was considered crucial for all scenarios, both because of the direct benefits of connecting individuals and businesses, facilitating activities such as teleworking, telehealth, e-commerce and the management of logistics, and also indirectly by enabling other technologies. For example, faster connections can support the safety benefits of $A V s$ (see Section 2.2 for details).

The private sector is rolling out plans to deliver next-generation telecommunications infrastructure and services. The wireless industry is reported to be aiming to deliver the first $5 \mathrm{G}$ networks by 2020 , although a number of analysts suggest that these may not become widely available until 2025 (Shankland 2015). British Telecom has also announced plans to provide broadband speeds of $500 \mathrm{MB}$ per second across the UK by 2025 (McCaskill 2015). Samsung, meanwhile, has conducted trials for 1GB per second, with researchers at the University of Surrey suggesting it may even be possible to support wireless connections at up to $800 \mathrm{~GB}$ per second - the equivalent of downloading 33 highdefinition films every second (BBC News 2014).

So what is the role of government in the rollout of next-generation ICT? While recent government policy has resulted in more connectivity, particularly in rural areas (DCMS 2015; DEFRA 2014), there remain questions as to the necessary quality of the provision and the degree of geographical coverage that can be and will be achieved. This may depend on who is providing the telecommunications infrastructure in 2035 , the business models for providing this infrastructure and the technology enabling it; for example fibre optic, wide-area network communication or satellite-based systems or a fusion of technologies are potential alternatives. In addition to the physical provision of ICT, the issue of equality of access for all population groups needs to be addressed. ${ }^{10}$ Thus there is a role for government to ensure high-quality ICT services are available to its population, across all geographies, and to provide education and support such that these services are accessible to all. Governments will also need to understand what 'high-quality' services actually means: specifically what quality of services is actually necessary to support next-generation services?

\subsubsection{Investment in Big Data / user apps}

Another crucial area for investment identified by experts was that of Big Data and user apps. Beyond the need for massive data processing necessitated by AV technology, Big Data is seen as a facilitator for innovation in the development of new transport services more generally, particularly to improve the efficiency of existing infrastructure and services and to increase customer satisfaction. Together these can offer huge potential for the expansion of new mobility services, whether as part of an autonomous or non-autonomous vehicle sharing schemes, or through more efficient transporting of freight, or by allowing travellers to seamlessly travel across modes.

In order to realise the full potential of these technologies, frameworks and legislation may be necessary to address issues of data governance, transparency, value distribution, security and privacy - and governments need to have a role in developing these. In the context of $\mathrm{AVs}$, these issues may be particularly complex because stakeholders will include government agencies, private sector firms (big and small),

10 For example, evidence from the literature suggests that while only 3 per cent of 9-19 year olds have never had access to the Internet (Livingstone et al. 2005), a much greater proportion of adults are non-users (Selwyn 2006). 
and consumers. The complexity surrounding how data collection, storage and analysis are managed creates challenges for policymakers who need to craft a regulatory balance between the beneficial uses of data and consumer protection. Unlocking the full potential in a responsible way requires addressing current uncertainties and points of tension. Governments also have a role in brokering issues of data ownership and sharing, factors that are going to continue to grow in importance in these innovation areas. They also need to continue to support open data initiatives, particularly in areas that lead to social, environmental and economic benefits for society.

\subsubsection{Investment in pilot/real-world testing}

There was near consensus that innovative solutions to transport problems need to be pilot tested in real-world settings: the aim being to examine the efficacy of the technology, consumer responses or concerns, and environmental consequences. Moreover, piloting of new technologies, or indeed experimentation, involving testing, learning by doing and iterative improvements (Thomke 2003) may benefit British businesses, enabling them to be at the forefront of implementation of new technologies, contributing to development of intellectual property, spin-offs, as well as skills and jobs (Chesbrough 2007).

Again, there is a question over government's role in pilot testing, and whether and when it should be financially supporting or even driving pilot and real-world testing of new technologies. When considering positive externalities, it may be that such investments are further justified when the technology has the potential to offer substantial benefits to society. An example may be AVs, which could have a positive impact on safety, congestion, energy use and, ultimately, land use (Anderson et al. 2014). Driverless cars are to be tested over a 36-month period in four locations in England with projects covering public reaction, legal and insurance issues as well as the testing of vehicle and related infrastructure technology. ${ }^{11}$

Governments can also influence pilot testing through regulation. For example, unmanned aerial vehicles (UAVs), commonly referred to as drones, are another innovative transport solution for which testing and increased usage in the real world may lead to substantial changes in travel. In the US, where drone use is currently illegal, both Amazon and Walmart have applied to US regulators for permission to test drones for home delivery and pick-up (Layne 2015). In the UK, however, licensing of UAVs currently falls within the remit of the Civil Aviation Authority, and thus both Google and Amazon plan delivery drone services in the UK in the relatively near term. Different positions have also been adopted in relation to connected vehicles in the EU and US (see Section 2.1).

\subsection{Need for new business models}

A separate but important aspect of technology development that was raised in the interviews was the need for new business models across all the technology sectors to cope with the rapidly changing business environment. $A$ related question concerns the ability to attract appropriate finance.

The move from ownership to leasing of goods was discussed at the expert workshops for the scenario development and is an important theme in the scenarios. In particular, in the Live Local scenario consumer electronic goods are leased from suppliers, continuing a trend already seen with mobile phones.

11 The following four cities will run formal trials that will last between 18 and 36 months from January 2015: (i) Greenwich, South East London, (ii) Milton Keynes and Coventry (working together as one project), and (iii) Bristol. For further information see: https://www.gov.uk/government/news/driverless-cars-4-cities-get-green-light-for-everyday-trials. 
The provision of goods as services is not limited to physical consumer goods but also applies to transport in the form of mobility services. In 2014, more than three-quarters of all new car purchases were made on finance provided through dealerships (BBC News 2015). A number of possible car ownership models have been proposed in the scenarios. A shared ownership, 'mobility on demand' model, which allows for vehicle specialisation, is explored for FAVs in the Driving Ahead scenario. However, shared mobility services are not dependent on the adoption of FAVs, as noted in the Digital Divide scenario, where cars are rented from person to person. There are also existing examples of car-sharing services (e.g. Zoom, Zipcar and Car2Go). In this study the focus has been on technology and the role of different fuel types has only been nominally considered and it is entirely possible particular ownership models may develop, dependent on fuel source. Regardless of the ownership model, there are opportunities for new entrants in the industry. This is exemplified by companies such as Uber, which has changed the way in which we purchase transport services, and also by the interest in autonomous/connected vehicle development from both traditional car manufacturers and companies such as Google.

The retail sector has already been subject to significant change due to ICT-enabled online shopping (Wrigley \& Lambiri 2015). This has led to high street retailers entering the online space along with new online competitors. The future relationship between physical and online retail spaces is one that could lead to new business models. In the scenarios, future models for this sector include 'destination retail', in which shops additionally provide entertainment. However, person-to-person business models could also thrive.

Changes in the retail sector, culminating in the delivery of goods directly to consumers, have also meant that the package delivery sector is ripe for new business models. A number of possibilities are explored in the scenarios. Individuals could sign up to a subscription service, paying a monthly fee for deliveries. How these deliveries are made will depend on technology. Widespread use of FAVs could lead to new entrants in the market partnering retailers and possibly consolidation as consumers prefer to receive deliveries from one supplier. Otherwise 'taskers' (individuals using their own vehicles) contracted by freight carriers may prevail.

In our scenarios, loT services and additive manufacturing products were seen as being less important, perhaps limited by constraining our outlook to 2035. However, over the longer term, business models for these services and products will need to be developed.

\subsection{Strategic roadmap of policy and innovation investment}

Below we present key recommendations for policy and investment based on experts' views on robust investments; our analysis of the policy implications that are drawn from the scenarios; and consideration of the barriers and enablers for development of AVs, next-generation ICT and Big Data / open data. These high-level recommendations are derived from consideration of the potential future landscape for travel, across a range of technologies.

As the future transport scenarios play out, it will be up to business leaders, entrepreneurs, researchers and government policymakers to maximise their opportunities while dealing with the challenges. Government policymakers need to ensure that the proper regulatory frameworks are in place, for example regarding data privacy, data sharing, interoperability and overall transportation network management, before the benefits of technologies such as AVs or nextgeneration ICT can be fully realised. In other cases, government may need to be flexible, enabling the market to move technologies from piloted concepts into the economy. Premature regulation can have an inhibiting effect, especially when technologies are evolving rapidly and there are many uncertainties. 


\section{Box 4.1. Strategic roadmap of policy and investment}

In order to encourage efficient and effective transport in future, government agencies should:

As a priority, invest in and monitor technological interventions that are robust across a range of future scenarios:

- Be aware of what quality of ICT services are needed to support future technologies and services, such as next-generation telecommuting and telehealth, user apps, Big Data, V2V and V2I communication, and ensure that these services are available, across all geographies.

- Support the development of frameworks and systems necessary for addressing issues of data governance, transparency, value, privacy and security, ensuring balance in regulation between the beneficial uses of data and consumer protection. Contribute to brokering on issues related to data ownership and data sharing. Support Open Data initiatives that lead to social, environmental and economic benefits for society.

- Support pilot testing of new technologies and services, particularly those that will bring substantial societal benefits.

Develop policies to ensure that new technologies lead to the best outcomes for society:

- Monitor road congestion and introduce road-pricing policies to manage travel demand, if required.

- Support training and up-skilling of workers to ensure they have the skills needed for future jobs.

- Ensure equity of access to technologies that have the possibility of bringing substantial societal benefits, across geographies and society.

Address key barriers to innovation for AVs, next-generation ICT and Big Data / user apps / intelligent processing:

- Monitor and, if necessary, address future liability and safety regulatory issues for AVs.

- Monitor and, if necessary, support the development of standards supporting interoperability

of systems, ensuring that such standards are developed in consultation with all relevant stakeholders.

- Provide education to ensure that all those with access to new services are able to benefit from them, particularly monitoring the use and take up of new technology by the elderly.

\subsubsection{Next steps}

This study has identified three technologies that are likely to have a substantial impact on future travel: AVs, next-generation ICT and user apps / Big Data. Further work is now required to envisage roadmaps of implementation for each, thinking through how policy may impact on their development and use in society. For without thoughtful facilitation, these technology areas are unlikely to develop in ways that will provide the maximum societal benefit.

Finally, we note that emerging technologies often receive a great deal of notice. The hype machine can be equally misleading in what it chooses to ignore. There is no clear relationship between the amount of talk a technology generates and its potential to create value. The lesson for government is to make sure that decisionmakers and policymakers have the knowledge to assess technology advancement and their associated potential impacts, to ensure new technologies deliver the best outcomes for society. This requires monitoring and appraising future technologies and their social impact, considering the entire technology eco-system, to ensure that public investments are made in those technologies that will have a substantial positive impact on society. Government must also develop tools for the appraisal of transport investments more generally, incorporating the influence of new technologies in the analysis of whether such investments are economically justified and, if possible, making sure that they benefit from future technologies. 



\section{References}

Amer, Muhammad, Tugrul U. Daim \& Antonie Jetter. 2013. 'A review of scenario planning.' Futures 46(0): 23-40. As of 4 December 2015: http://www.sciencedirect.com/science/article/pii/ S0016328712001978

Anderson, James M., Nidhi Kalra, Karlyn D. Stanley, Paul Sorensen, Constantine Samaras \& Oluwatobi A. Oluwatola. 2014. Autonomous Vehicle Technology: A Guide for Policymakers. Santa Monica, Calif.: RAND Corporation. RR-443-1. As of 4 December 2015: http://www.rand.org/pubs/research_reports/RR443-1. html

Andreev, Pavel, Salomon Ilan \& Nava Pliskin. 2010. 'Review: State of teleactivities.' Transportation Research Part C 18: 3-20.

Arthur, Charles. 2014. 'How Google is moving into the home with Nest Labs acquisition.' Guardian, 14 January. As of 4 December 2015:

http://www.theguardian.com/technology/2014/jan/14/ how-google-home-nest-labs-acquisition

Atkinson, Bobby. 2015. 'This Dutch bike path could be the precursor to solar energy-capturing roads everywhere.' Equipment World, 22 May. As of 4 December 2015:

http://www.equipmentworld.com/this-dutch-bike-pathcould-be-the-precursor-to-solar-energy-capturingroads-everywhere/

Axhausen, Kay \& Tommy Gärling. 1992. 'Activitybased approaches to travel analysis: conceptual frameworks, models and research problems.' Transport Reviews 12(4): 323-41.

Babulak, Eduard. 2009. 'Teleworking and next generation cyberspace.' International Conference on Computational Intelligence.
Barry, Keith. 2013. 'New Helsinki bus line lets you choose your own route.' Wired, 11 October. As of 4 December 2015:

http://www.wired.com/2013/10/on-demand-publictransit/

BBC News. 2014. 'How will the $5 G$ network change the world?' 1 December. As of 4 December 2015: http://www.bbc.co.uk/news/technology-30224853

BBC News. 2015. 'UK new car sales surge to 10-year high in 2014.' 7 January. As of 4 December 2015: http://www.bbc.com/news/business-30706580

Ben-Akiva, Moshe, John Bowman \& Dinesh Gopinath. 1996. 'Travel demand model system for the information era.' Transportation 23: 241-66.

Bloomberg. 2015. 'Shanghai's plan to allow carsharing apps seen benefiting Uber.' 19 May. As of 4 December 2015:

http://www.bloomberg.com/news/articles/2015-05-19/ shanghai-to-legitimize-car-sharing-ride-apps-in-firstfor-china

Börjeson, Lena, Mattias Höjer, Karl-Henrik Dreborg, Tomas Ekvall \& Göran Finnveden. 2006. 'Scenario Types and Techniques: Towards a User's Guide.' Futures 38(7): 723-39.

Brockmann, Kathrin. 2012. 'Futures Analysis Cooperation Tool in the German Armed Forces.' Foreknowledge 4: 6-7. As of 4 December 2015: http://issuu.com/foreknowledge/docs/ foreknowledge $4 / 7 ? \mathrm{e}=0$

Bryant, Benjamin P., \& Robert J. Lempert. 2010. 'Thinking Inside the Box: A Participatory, ComputerAssisted Approach to Scenario Discovery.' Technological Forecasting and Social Change 77(1): 34-49. 
Burrus, Daniel. 2014. 'The Internet of Things is far bigger than anyone realises.' Wired, November. As of 4 December 2015:

http://www.wired.com/2014/11/the-internet-of-thingsbigger/

Campbell, Thomas, Christopher Williams, Olga Ivanova \& Banning Garrett. 2011. Could 3D Printing Change the World? Technologies, Potential, and Implications of Additive Manufacturing. Strategic Foresight Report, Atlantic Council, October.

Cellan-Jones, Rory. 2015. 'Will London's mayor put the brakes on Uber?' BBC News, 22 May. As of 4 December 2015:

http://www.bbc.co.uk/news/technology-32842332

Cervero, Robert, \& Mark Hansen. 2002. 'Induced travel demand and induced road investment: a simultaneous equation analysis.' Journal of Transport Economics and Policy 36(3): 469-90.

Chesbrough, Henry W. 2007. 'Why companies should have open business models.' MIT Sloane Management Review 48: 22-28.

CSIRO. 2015. Teleworking using spatial augmented reality, iAwards 2015. As of 4 December 2015: http://www.csiro.au/en/Research/Technology/iAwards/ Teleworking

Deloitte Centre for Health Solutions. 2012. Primary care: working differently. Telecare and telehealth - a game changer for health and social care.

Dearden, Lizzie. 2015. 'Driverless cars trialled on UK roads for first time in four towns and cities.' Independent, 11 February. As of 4 December 2015: http://www.independent.co.uk/news/uk/home-news/ driverless-cars-officially-trialled-on-uk-roads-for-firsttime-in-four-towns-and-cities-10037737.html

Department for Culture, Media and Sport (DCMS). 2015. 2010 to 2015 government policy: broadband investment. As of 4 December 2015: https://www.gov.uk/government/publications/2010-to2015-government-policy-broadband-investment/2010to-2015-government-policy-broadband-investment
Department for Environment, Food and Rural Affairs (DEFRA). 2014. Policy brief - how increased connectivity is boosting economic prospects of rural areas.

Department for Transport (DfT). 2015a. The Pathway to Driverless Cars: Summary report and action plan.

Department for Transport (DfT). 2015b. National Travel Survey: England 2014. 2 September. As of 4 December 2015:

https://www.gov.uk/government/uploads/system/ uploads/attachment_data/file/457752/nts2014-01.pdf

Dredge, Stuart. 2014. '20 ways gigabit-speed internet access might change our lives by 2025.' Guardian, 9 October. As of 4 December 2015:

http://www.theguardian.com/technology/2014/oct/09/ gigabit-speed-internet-2025-pew-internet-predictions

Durst, Carolin, Thomas Kolonko \& Michael Durst. 2012. 'Kooperationsdilemma in der Zukunftsforschung Ein IT-basierter Lösungsansatz der Bundeswehr' [Cooperation dilemma in future analysis: A web-based approach by the German Armed Forces]. Proceedings Multikonferenz Wirtschaftsinformatik, February 29.

eCall (homepage). 2015. As of 4 December 2015: http://ec.europa.eu/digital-agenda/ecall-time-savedlives-saved\#Article

European Commission. 2014. New connected car standards put Europe into top gear, 2014. Press Release, Brussels, 12 February. As of 4 December 2015:

http://europa.eu/rapid/press-release_IP-14-141_ en.htm

Financial Times. 2014. 'Amazon chooses Cambridge to test delivery drones.' 12 November. As of 4 December 2015:

http://www.ft.com/cms/s/0/df88991a-6a7a-11e4-bfb400144feabdc0.html\#axzz3arjFM4QN

Fishman, Tiffany D. 2012. Digital - Age Transportation: The Future of Urban Mobility. Deloitte University Press. As of 4 December 2015:

http://dupress.com/wp-content/uploads/2012/12/

Digital-Age-TRANSPORTATION.pdf 
Gardner, Bill. 2014. 'The end of potholes? UK scientists invent "self-healing concrete".' Telegraph, 2 December. As of 4 December 2015: http://www.telegraph.co.uk/news/uknews/road-andrail-transport/11268310/The-end-of-potholes-UKscientists-invent-self-healing-concrete.html

Gausemeier, Juergen, Alexander Fink \& Oliver Schlake. 1998. 'Scenario Management: An Approach to Develop Future Potentials.' Technological Forecasting and Social Change 59: 111-30.

Gerst, Michael D., Peng Wang \& Mark E. Borsuk. 2013. 'Discovering Plausible Energy and Economic Futures Under Global Change Using Multidimensional Scenario Discovery.' Environmental Modelling and Software 44: 76-86.

Glenn, Jerome C. 2007. 'Futures Research Methodology, BLED Forum 2007.' Washington, D.C.: The Millennium Project.

Glenn, Jerome C., \& Theodore J. Gordon. 2009. 'Futures Research Methodology, Version 3.0.' Washington, D.C.: Millennium Project. As of 4 December 2015: http://www.millennium-project.org/millennium/FRM-V3. html

Goodwin, Phil. 1996. 'Empirical evidence on induced traffic: A review and synthesis.' Transportation 23: 35-54.

Gordon, Theodore J., \& H. Hayward. 1968. 'Initial Experiments with the Cross Impact Matrix Method of Forecasting.' Futures 1(2): 100-16.

Graham, Jefferson. 2015. "UUber of trucks” hauls big business in Los Angeles.' USA Today, 21 May. As of 4 December 2015: http://www.usatoday.com/story/tech/2015/05/21/uberof-trucks-making-impact-in-los-angeles/27610727/

Greenberg, Andy. 2015. 'Hackers remotely kill a jeep on the highway.' Wired, 21 July. As of 4 December 2015: http://www.wired.com/2015/07/hackers-remotely-killjeep-highway/
Greenfield, Adam. 2014. 'Helsinki's ambitious plan to make car ownership pointless in 10 years.' Guardian, 10 July. As of 4 December 2015:

http://www.theguardian.com/cities/2014/jul/10/helsinkishared-public-transport-plan-car-ownership-pointless

Greenhalgh, Trisha, Rob Procter, Joe Wherton, Paul Sugarhood \& Sara Shaw. 2012. 'The organising vision for telehealth and telecare: discourse analysis.' BMJ Open 2(4).

Grifantini, Kristina. 2015. 'The robot will see you now: telepresence robots are providing check-ups, assistance and support for both doctors and patients.' Pulse, 19 February. As of 4 December 2015: http://pulse.embs.org/january-2015/the-robot-will-seeyou-now-telepresence/

Hague, Richard, \& Phil Reeves. 2013. 'Additive manufacturing and 3D printing.' Ingenia 55.

Ham, Chris, Anna Dixon and Beatrice Brooke. 2012. Transforming the delivery of health and social care. The case for fundamental change. London: The Kings Fund.

Hellgren, Tess, Maryse Penny \& Matt Bassford. 2013. Future Technology Landscapes: Insights, analysis and implications for defence - Case study documentation. Santa Monica, Calif.: RAND Corporation. RR-478/1MOD.

Henderson, Catherine, Martin Knapp, José-Luis Fernandez, Jennifer Beecham, Shashivadan Hirani, Martin Cartwright, Lorna Rixon, Michelle Beynon, Anne Rogers, Peter Bower, Helen Doll, Ray Fitzpatrick, Adam Steventon, Martin Bardsley, Jane Hendy \& Stanton P. Newman. 2013. 'Cost effectiveness of telehealth for patients with long term conditions (Whole Systems Demonstrator telehealth questionnaire study): Nested economic evaluation in a pragmatic, cluster randomised controlled trial'. British Medical Journal 346, f1035. 
Jones, Dennis, \& Adrian Buckle. 2015. 'As non-cash payments overtake hard currency, are we a few years off being a cashless society?' CityAM, 22 May. As of 4 December 2015:

http://www.cityam.com/216246/non-cash-paymentsovertake-hard-currency-are-we-few-years-beingcashless-society

Kahn, Herman, \& Thomas Pepper. 1979. The Japanese Challenge: The Success and Failure of Economic Success. New York, NY: Crowell.

Kahn, Herman, \& Anthony J. Wiener. 1967. 'The Next Thirty-Three Years: A Framework for Speculation.' Daedalus 96(3): 705-32.

Kane, Julius. 1972. 'A Primer for a New Cross-Impact Language: KSIM.' Technological Forecasting and Social Change 4(2): 129-42.

KPMG. 2015. Connected and Autonomous Vehicles - The UK Economic Opportunity. As of 4 December 2015:

http://www.kpmg.com/UK/en/IssuesAndInsights/ ArticlesPublications/Documents/PDF/Market\%20 Sector/Automotive/connected-and-autonomousvehicles.pdf

Layne, Nathan. 2015. 'Exclusive: Wal-Mart seeks to test drones for home delivery, pickup'. Reuters, 27 October. As of 4 December 2015: http://www.reuters.com/article/2015/10/27/ us-wal-mart-stores-drones-exclusiveidUSKCN0SK2IQ20151027

Lee In \& Kyoochun Lee. 2015. 'The Internet of Things (loT): Applications, investments, and challenges for enterprises.' Business Horizons 58: 431-440.

Lempert, Robert J., Steven W. Popper, \& Steven C. Bankes. 2003. Shaping the Next One Hundred Years: New Methods for Quantitative, Long-Term Policy Analysis. Santa Monica, Calif.: RAND Corporation. MR-1626-RPC.

Lienert, Paul. 2015. '12 million driverless cars to be on the road by 2035 - study'. Reuters, 8 January. As of 4 December 2015: http://uk.reuters.com/article/2015/01/08/autos-bcgautonomous-idUSL1N0UN2GQ20150108
Livingstone, Sonia, Magdalena Bober \& Ellen Helsper. 2005. Inequalities and the digital divide: findings from the UK Children Go Online project. London: LSE Research.

Mans, Janine, Erica Interrante, Lewison Lem, Judy Mueller \& Michael Lawrence. 2012. 'Next Generation of Travel Behavior: Potential Impacts Related to Household Use of Information and Communication Technology.' Transportation Research Record: Journal of the Transportation Research Board 2323: 90-98.

McCaskill, Steve. 2015. 'BT plots 500Mbps "ultrafast" broadband with G.Fast trials.' TechWeek Europe, 30 January. As of 4 December 2015: http://www.techweekeurope.co.uk/networks/ broadband/bt-gfast-fibre-ultrafast-superfastbroadband-160568

Mills, Julia, Stuart Shilson, Quentin Woodley \& Alice Woodward. 2011. Keep Britain Moving: The United Kingdom's Transport Infrastructure Needs. McKinsey \& Company.

Moktarian, Patricia, \& Ilan Salomon. 2001. 'How Derived is the Demand for Travel? Some Conceptual and Measurement Considerations.' Transportation Research Part A 35: 695-719.

National Highway Traffic Safety Administration (NHTSA). 2013. 'US Department of Transportation releases policy on automated vehicle development.' As of 4 December 2015: http://www.nhtsa.gov/About+NHTSA/Press+Releases/ U.S.+Department+of+Transportation+Releases+Polic y+on+Automated+Vehicle+Development

Nicholls, Jimmy. 2015. 'Santander launches app for Boris bike booking.' Computer Business Review, 12 May. As of 4 December 2015: http://www.cbronline.com/news/mobility/ apps/santander-launches-app-for-boris-bikebooking-4573886

Noland, Robert B., \& Lewison L. Lem. 2002. 'A review of the evidence for induced travel and changes in transportation and environmental policy in the United States and the United Kingdom.' Transportation Research Part D 7(1): 1-26. 
Ofcom. 2014. Adults'Media Use and Attitudes Report 2014. As of 4 December 2015:

http://stakeholders.ofcom.org.uk/market-dataresearch/other/research-publications/adults/adultsmedia-lit-14/

O'Sullivan, Eoin, \& Laure Brévignon-Dodin. 2012. 'Role of Standardisation in Support of Emerging Technologies.' Study for the Department of Business, Innovation and Skills (BIS) and the British Standards Institute, Institute for Manufacturing, University of Cambridge. As of 4 December 2015:

http://www.ifm.eng.cam.ac.uk/uploads/Resources/ Reports/OSullivan_Dodin_Role_of_Standardisation_ June_2012_2_.pdf

Pawlak, Jacek, Scott Le Vine, John Polak, Aruna Sivakumar \& Johanna Kopp. 2015. ICT and Physical Mobility: State of Knowledge and Future Outlook. As of 4 December 2015:

http://www.ifmo.de/tl_files/publications_content/2015/ ifmo_2015_ICT\%20and\%20Physical\%20Mobility_ en.pdf

Pieters, Janene. 2015. 'Road users to receive accident warnings through traffic apps.' NL Times, 21 May. As of 4 December 2015:

http://www.nltimes.nl/2015/05/21/road-users-toreceive-accident-warnings-through-traffic-apps/

Pillkahn, Ulf. 2008. Using Trends and Scenarios as Tools for Strategy Development. Erlangen: Publicis Corporate Publishing.

Popper, Steven, Nidhi Kalra, Richard Silberglitt, Edmundo Molina-Perez, Youngbok Ryu \& Michael Scarpati. 2013. 'Expediting Future Technologies for Enhancing Transportation System Performance.' National Cooperative Highway Research Program Report 750, Washington D.C.: Transportation Research Board.

Recker, Wilfred W., Michael G. McNally \& Gregory S. Root. 1986. 'A Model of Complex Travel Behaviour: Part I Theoretical Development.' Transportation Research Part A 20A(4): 307-18.

Royal Academy of Engineering. 2012. Smart infrastructure: the future.
Rohr, Charlene, James Fox, Andrew Daly, Bhanu Patruni, Sunil Patil and Flavia Tsang. 2013a.

'Modelling long-distance travel in the UK'. Transport Research Record, 2344, pp 145-152.

Rohr, Charlene, Andrew Daly, James Fox, Bhanu Patruni, Tom van Vuren \& Geoffrey Hyman. 2013b. 'Manchester Motorway Box: Post survey research of induced traffic effects'. disP - The Planning Review, ETH Zürich.

Rozenberg, Julie, Céline Guivarch, Robert Lempert \& Stéphane Hallegatte. 2012. 'Building SSPs for Climate Policy Analysis: A Scenario Elicitation Methodology to Map the Space of Possible Future Challenges to Mitigation and Adaptation.' Fondazione Eni Enrico Mattei Working Paper 52. As of 4 December 2015: http://www.feem.it/getpage. aspx?id $=4951 \&$ sez $=$ Publications $\&$ padre $=73$

Schweizer, Vanessa Jine, \& Elmar Kriegler. 2012. 'Improving Environmental Change Research with Systematic Techniques for Qualitative Scenarios.' Environmental Research Letters 7(4).

Selwyn, Neil. 2006. 'Digital division or digital decision? A study of non-users and low-users of computers.' Poetics 34: 273-92.

Shankland, Stephen. 2015. 'How 5G will push a supercharged network to your phone, home, car.' CNET, 2 March. As of 4 December 2015: http://www.cnet.com/uk/news/how-5g-will-push-asupercharged-network-to-your-phone-home-and-car/

Shankleman, Jessica. 2013, 'Public transport gets smart.' Guardian, 9 January. As of 4 December 2015: http://www.theguardian.com/public-leadersnetwork/2013/jan/09/centro-public-transport-travelsystems

Shead, Sam. 2015. 'Navigation app Moovit up to 800,000 UK users as it looks to close in on Citymapper and Google Maps.' Techworld, 20 April. As of 4 December 2015: http://www.techworld.com/news/apps/navigation-appmoovit-up-800000-uk-users-as-it-looks-close-in-oncitymapper-3608548/ 
Sissons, Andrew, \& Spencer Thompson. 2012. Three Dimensional Policy: Why Britain needs a policy framework for $3 D$ printing. Big Innovation Centre.

Smith, Alistair. 2012. Opportunities for, and potential contribution of, social science research relating to the nature and development of Additive Manufacturing. The Centre for Business Relationships, Accountability, Sustainability and Society, Cardiff.

The Economist. 2011. 'The printed world.' 10 February.

The Economist. 2012. 'A third industrial revolution.' 21 April.

The Economist. 2013a. 'Driverless cars: look, no hands.' 20 April.

The Economist. 2013b. 'The future of telecommuting: corralling the Yahoos.' 2 March.

The Economist. 2014. 'Telemedicine: stuck in the waiting room.' 11 October.

The Economist. 2015. 'The Internet of Things: of sensors and sensibility.'

Thomke, Stefan H. 2003. Experimentation matters: unlocking the potential of new technologies for innovation. Harvard Business Press.

Transport Systems Catapult. 2015a. Traveller Needs and UK Capability Study.

Transport Systems Catapult. 2015b. Modelling for Intelligent Mobility. As of 4 December 2015: https://ts.catapult.org.uk/documents/10631/169582/ Modelling+Intelligent+Mobility,+Feb+2015/73b7c9f9d05a-4fca-ad9f-0e226e48d6b7
Worstall, Tim. 2014. ' $9 \%$ of cars to be driverless cars by 2035.' Forbes, 1 January. As of 4 December 2015: http://www.forbes.com/sites/timworstall/2014/01/01/9of-cars-to-be-driverless-cars-by-2035/

Wrigley, Neil, \& Dionysia Lambiri. 2015. British High Streets: from Crisis to Recovery? A Comprehensive Review of the Evidence. University of Southampton.

World Bank. 2015. How ICTs Can Help Transport Systems Evolve. 14 May. As of 4 December 2015: http://www.worldbank.org/en/news/feature/2015/05/14/ information-and-communication-technologiesfacilitate-the-evolution-of-transport-systems

Xu Li Da, Wu He \& Shancang Li. 2014. 'Internet of Things in Industries: A Survey.' IEEE Transactions on Industrial Informatics 10:2233-2242.

Zmud, Johanna, Ipek N. Sener \& Jason Wagner. 2015. Consumer Acceptance and Travel Behaviour Impacts of Automated Vehicles. Texas A\&M Transport Institute.

Zmud, Johanna, Melissa Tooley, Trey Baker \& Jason Wagner. 2015. Paths of Automated and Connected Vehicle Deployment: Strategic Roadmap for State and Local Transportation Agencies. Texas A\&M Transport Institute. 


\section{Appendix A: Methodology for shortlisting key technologies}

We used the STREAM methodology Systematic Technology Reconnaissance, Evaluation and Adoption Methodology developed by Popper et al. (2013) to identify a shortlist of technologies for inclusion in the scenarios. This appendix explains the selection process, which included developing assessment criteria, identifying the potential technologies of interest and selecting the key technologies.

\section{Developing the assessment criteria to identify key technologies}

A key element of the STREAM methodology is the development of assessment criteria for evaluation of potential future technologies. Our study focus is on technologies that influence the efficiency and effectiveness of transport networks.

To support the identification of relevant assessment criteria, we reviewed the objectives and goals of UK organisations with responsibility for provision and oversight of transport, as well as Innovate UK and the Transport Systems Catapult. The governance of transport in the UK involves a large and complex arrangement of public bodies. For example, the Department for Transport is supported by a network of executive agencies, public corporations and non-ministerial departments, ranging from the Airports Commission to British Transport Police. A number of specific issues are also managed at an international level, with the British and Irish governments partnering on maritime navigation aids being one example. The identification of assessment criteria process covered the UK, devolved and regional institutions, as well as those with specific sectoral remits for road, rail, maritime, aviation and technology. A full list of UK transport stakeholders studied is provided in Figure A.1.

Using desk research of public documents, the study team identified and collated the publicly available stated missions, goals and objectives of the 18 organisations listed in Figure A.1. Recurrent

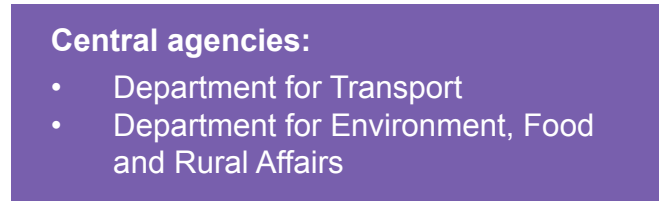

Devolved agencies:

Transport Scotland

Welsh Assembly Transport Strategy

Translink Northern Ireland

\section{Sectoral agencies:}

Civil Aviation Authority

Dover Harbour Board

Highways England (formerly Highways Agency)

Maritime and Coastguard Agency

NERL (formerly National Air Traffic Services)

Network Rail

Office of Rail and Road (formerly Office of Rail Regulation)

Transport Focus (formerly Passenger Focus)

Trinity House

\section{Regional agencies: \\ Transport for London \\ Transport for Greater Manchester}

Figure A.1. Overview of UK transport stakeholders examined Source: RAND Europe. 
Table A.1. Key assessment criteria for technologies

\begin{tabular}{|l|l|l|}
\hline Demand & Volume & Productive time \\
\hline Demand for travel & Effective capacity of infrastructure & Travellers' productivity \\
\hline Proportion of peak-time travel & Frequency of major delays & \\
\hline Availability of information to users & Average waiting times & \\
\hline
\end{tabular}

themes across the many stakeholders included emphasis on the economy, the environment and safety. The vision for the Department for Transport is typical: 'Our vision is for a transport system that is an engine for economic growth, but one that is also greener and safer and improves quality of life in our communities'. ${ }^{12}$

The study team initially identified 10 metrics covering three assessment criteria of efficiency, effectiveness and economic benefits. These metrics formed the basis of the questionnaire used to assess the technologies. However, when we analysed the data, we found that these metrics double-counted efficiency, since a technology that increased efficiency necessarily increased effectiveness if all other factors were held equal. Similarly, we found that three of our original metrics were implied by a combination of other metrics, which led to them having undue weight. We therefore revised our criteria and metrics through an internal workshop - to ensure that they represented independent dimensions.

Ultimately, we generated the following framework to assess emerging transport technologies (see Table A.1). Three high-level criteria were defined:

- Demand - which refers to the ability of the technology to influence the demand for travel.

- Volume - which refers to the ability of the technology to influence the number of vehicles that are able to use existing infrastructure.
- Productive time - which concerns the ability of travellers to engage productively whether professionally or personally - during their journey.

To illustrate how these criteria work in practice, a technology scored positively if it was able to reduce the overall demand of travel or enhance the effective volume of existing infrastructure, which would allow more vehicles to transport either people or goods. For example, next-generation ICT connectivity scored highly in terms of its ability to influence demand, through telecommuting, e-health and ecommerce, whereas vehicle-to-vehicle (V2V) and vehicle-to-infrastructure (V2I) communications scored highly in terms of influencing volume. For each criterion, specific metrics to qualify different aspects of the objective were identified. A scale of 1 to 5 was applied, with 5 indicating a positive impact (for example a significant increase of effective capacity of infrastructure, or a significant decrease in the frequency of major delays).

A further key assessment criterion is the possibility of successful implementation (POSI). This was characterised in line with previous iterations of the STREAM methodology in order to assess barriers to technology exploitation (see Table A.2). It was measured on a scale of 1 to 4 , where 1 indicated more than one significant concern and 4 indicated no significant concerns.

An overall score was derived for each technology, calculated as the product of all these measures: demand, volume, productive time and POSI. ${ }^{13}$

12 http://www.slideshare.net/sarahamcdermott/department-for-transport

13 The use of the product as an overall score follows the STREAM methodology. There are more sophisticated methods of defining a utility function, which could place greater weight on specific criteria, for example the POSI score, or on the scale of increase within a metric, e.g. whether an increase from 2 to 3 should have the same weight as 4 to 5 . However, without this information this information we assume that all factors are equally important in the product calculation, although we also examine how scores vary across the different criteria. 
Table A.2. Barriers affecting probability of successful implementation (POSI)

\begin{tabular}{|l|l|}
\hline Category of impediments & Specific Barriers to Implementation \\
\hline Technology & $\begin{array}{l}\text { Unfamiliarity with core or applied technology } \\
\text { Uncertainty concerning actual performance } \\
\text { Additional implementation requirements (training, etc.) }\end{array}$ \\
\hline Agency process or institutions & Need for new, or conflict with, existing regulations or standards \\
\hline External to agency & $\begin{array}{l}\text { Inertia of existing processes and methods } \\
\text { Insufficient political or public acceptance } \\
\text { Lacking presence of necessary vendor or support base }\end{array}$ \\
\hline
\end{tabular}

Source: Popper et al. (2013).

\section{Identifying and assessing potential technologies of interest}

Having generated a series of criteria through which to assess individual technologies, the next step was to identify candidate technologies for assessment. To do this, the study team reviewed a wide variety of literature, covering academic journals, grey literature and relevant news media. The aim was to generate a broad and varied longlist of potentially relevant technologies. The technologies covered in the longlist are grouped into three categories in Figure A. 2 below.

An internal workshop was then held to merge and reduce the list where possible, in order to develop a concrete set of discrete technologies that would become the primary focus of expert consultation during subsequent
Vehicle technologies:

- Autonomous vehicles

- Electric / hybrid vehicles

- Integrated vehicle health management

- On-board sensors and actuators

- Vehicle-to-vehicle and vehicle-to-infrastructure communication

- Personal rapid transit

- Dirigibles

- Ground effect / hover train / Mag-lev

- Hyperloop / vacuum or lowatmosphere trains

- Swarm technologies

- Hydrodynamic optimisation

- Noise pollution reduction
Infrastructure technologies:

- Inductive charging

- Road heating elements

- Self-healing road surfaces

- Embedded sensors

- Automated / robotic bridge inspection

Programmable lanes

- Intelligent street lighting

- Driver information systems

- Personal digital way-finders

- User apps and software

- Digital payment systems

- Improved fleet performance management

- Multi-modal journey and optimisation systems

- Recognition and control algorithms

- Novel parking technologies

- Automated cranes / docking / customs

- Offshore deep-water docking stations
Non-transport-specific technologies:

- Telehealth

- Telecommuting

- Advanced manufacturing

- Novel materials

- Nanotechnology

- Novel power sources

- Robotics

- Synthetic environments

- Augmented reality

- Human-machine interface

- Facial / voice recognition

- Biometrics

- Next-generation connectivity

- Big Data

- Artificial intelligence

- Quantum

- Internet of Things

- Smart cities

- Physical Internet

- Modularity

- Open architectures

- Bio-hacking

- Advanced agriculture

- Advanced weather

forecasting

- Standardisation

Figure A.2. Longlist of potential technologies 
Table A.3. Shortlist of candidate technologies for assessment

\begin{tabular}{|c|c|}
\hline Category & Technology \\
\hline Vehicle & $\begin{array}{l}\text { Autonomous and/or unmanned vehicles } \\
\text { Vehicle-to-vehicle (V2V) and vehicle-to-infrastructure (V2I) communication } \\
\text { High-speed travel } \\
\text { Noise pollution reduction technologies }\end{array}$ \\
\hline Infrastructure / system-level & $\begin{array}{l}\text { Novel materials and embedded sensors in infrastructure } \\
\text { User apps and personalised software } \\
\text { Robotics and automated infrastructure }\end{array}$ \\
\hline Non-transport-specific & $\begin{array}{l}\text { Telehealth and e-health } \\
\text { Telecommuting } \\
\text { Advanced manufacturing } \\
\text { Internet of Things } \\
\text { Physical Internet and advanced logistics } \\
\text { Modularity and open architectures } \\
\text { Next-generation connectivity } \\
\text { Big Data and intelligent processing } \\
\text { Standardisation }\end{array}$ \\
\hline
\end{tabular}

Source: RAND Europe analysis.

steps of the technology review process, specifically focusing on those influencing demand, volume and productivity, and those that do not require substantial infrastructure investment. The resultant shortlist included 16 emerging technologies, with a crosssection of technologies relating to vehicles (i.e. autonomous vehicles), infrastructure (i.e. automated dock equipment) and non-transportspecific developments (i.e. Big Data). This shortlist is detailed in Table A.3.

\section{Characterisation of technologies against framing criteria}

To carry out the technology assessment, the project team conducted 17 telephone interviews with a mix of practitioners, experts and researchers. Interviewees assessed only technologies with which they were familiar, so the number of responses per technology ranged from 8 to 15 . Interviewees scored each technology on the seven metrics in Table A.1 and on the POSI. We averaged all scores on each metric for a specific technology. Scores were also calculated for the assessment criteria (demand, volume, productive time) by taking the average of the metrics within each criterion.

\section{Comparison of technologies across key criteria}

Table A. 4 shows the average assessment criteria scores for all 16 technologies, as well as the score on the POSI. We used these averages to create two other composite scores: benefit and overall. The benefit score combines the three criteria (demand, volume and productive time) and suggests the potential future benefit of the technology. The overall score combines the three criteria with the POSI. So a technology could have a high potential benefit score but a low overall score if it faces significant barriers. For example, automated vehicles have a high benefit score but the lowest overall score.

We find that personal user applications and software was the highest scoring technology group overall; next-generation connectivity, the Internet of Things (loT), vehicle-to-vehicle (V2V) and vehicle-to-infrastructure (V2I) communications, Big Data and intelligent processing, and automated and/or unmanned vehicles all delivered high benefit scores, excluding implementation considerations. 
Table A.4. Assessment scores for shortlisted technologies

\begin{tabular}{|c|c|c|c|c|c|c|}
\hline Technology & Demand & Volume & $\begin{array}{l}\text { Productive } \\
\text { time }\end{array}$ & $\begin{array}{l}\text { Benefit } \\
\text { score }\end{array}$ & POSI & $\begin{array}{l}\text { Overall } \\
\text { score }\end{array}$ \\
\hline User apps and personalised software & 3.7 & 3.6 & 3.8 & 51 & 3.9 & 197 \\
\hline Next-generation connectivity & 3.6 & 3.3 & 4.1 & 49 & 3.3 & 162 \\
\hline Telecommuting & 4.0 & 3.5 & 3.0 & 42 & 3.3 & 139 \\
\hline Internet of Things & 3.7 & 3.5 & 3.7 & 48 & 2.6 & 124 \\
\hline Big Data and intelligent processing & 3.6 & 3.8 & 3.8 & 52 & 2.4 & 124 \\
\hline Noise pollution reduction technologies & 3.2 & 3.2 & 3.4 & 35 & 3.4 & 116 \\
\hline $\begin{array}{l}\text { Vehicle-to-vehicle (V2V) and vehi- } \\
\text { cle-to-infrastructure (V2I) communica- } \\
\text { tion }\end{array}$ & 3.3 & 4.3 & 3.4 & 48 & 2.4 & 114 \\
\hline Physical Internet and advanced logistics & 3.0 & 3.4 & 3.4 & 35 & 2.9 & 99 \\
\hline $\begin{array}{l}\text { Modularity and open architectures (both } \\
\text { hardware and software) }\end{array}$ & 3.2 & 3.4 & 3.6 & 39 & 2.5 & 98 \\
\hline Standardisation & 3.1 & 3.3 & 3.3 & 34 & 2.9 & 96 \\
\hline $\begin{array}{l}\text { Novel materials and embedded sensors } \\
\text { in infrastructure }\end{array}$ & 3.0 & 3.8 & 3.0 & 34 & 2.6 & 88 \\
\hline Telehealth and e-health & 3.6 & 3.1 & 3.1 & 35 & 2.4 & 85 \\
\hline Robotics and automated infrastructure & 3.2 & 3.9 & 3.0 & 37 & 2.2 & 84 \\
\hline High-speed travel & 2.7 & 3.5 & 3.1 & 29 & 2.9 & 83 \\
\hline Advanced manufacturing & 3.3 & 3.3 & 3.0 & 33 & 2.5 & 81 \\
\hline Automated and/or unmanned vehicles & 3.0 & 4.1 & 4.2 & 52 & 1.4 & 74 \\
\hline
\end{tabular}

Demand, volume and productive times all scored on a scale of 1 to 5 ; POSI is scored from 1 to 4 .

Benefit score $=$ Demand score $x$ Volume score $x$ Productive time

Overall score $=$ Demand score $\times$ Volume score $\times$ Productive time $\times$ POSI

\section{Selecting key technologies}

The final step in the technology review was the selection of technologies to include in the scenario workshops. The project team took part in a working meeting with the client and other stakeholders to capture their perspectives. The working meeting led to the following observations:

- Big Data and next-generation connectivity were considered as key technologies, which are likely to happen without substantial investment from Innovate UK.

- Although autonomous vehicles scored low in terms of implementation risk (POSI), they scored high in terms of benefits, and are thus identified as important.

\section{- Novel materials and embedded sensors} were also suggested to be a potential enabling technology, facilitating greater efficiency of the overall transport network through expanded data collection, remote monitoring and fleet health management.

- Advanced manufacturing was seen as having a wide range of potential applications to transport, including a possible reduction in overall demand for travel through use of more localised and 'on demand' manufacture of goods.

- Other technologies which were judged to be important included V2V/V2I, the loT, personal user applications (Apps), telecommuting (for work and business travel), E-health, and noise reduction.

- While modularity and standardisation may be important for technology development, they are more important as conditions or enablers for innovation rather than as specific technologies in their own right. 
Table A.5. Outcome of selection process

\begin{tabular}{|c|c|c|}
\hline Category & Technology & Rationale for selection/exclusion \\
\hline Vehicle & $\begin{array}{l}\text { Autonomous and/or unmanned vehicles } \\
\text { V2V and V2I communication } \\
\text { High-speed intercity travel } \\
\text { Noise pollution reduction technologies }\end{array}$ & $\begin{array}{l}\text { Included because high in terms of benefits } \\
\text { Excluded in lieu of autonomous vehicles } \\
\text { Excluded because required infrastructure develop- } \\
\text { ment } \\
\text { Excluded because of low cross-impact score }\end{array}$ \\
\hline $\begin{array}{l}\text { Infrastructure } \\
\text { /system-level }\end{array}$ & $\begin{array}{l}\text { Novel materials, embedded sensors } \\
\text { User apps and personalised software } \\
\text { Robotics and automated cranes, docking, } \\
\text { customs, etc. }\end{array}$ & $\begin{array}{l}\text { Included because of possibilities for reducing con- } \\
\text { gestion } \\
\text { Included but grouped with Big Data } \\
\text { Excluded because required infrastructure develop- } \\
\text { ment }\end{array}$ \\
\hline $\begin{array}{l}\text { Non-trans- } \\
\text { port-specific }\end{array}$ & $\begin{array}{l}\text { Telehealth and e-health } \\
\text { Telecommuting } \\
\text { Advanced manufacturing } \\
\text { Internet of Things } \\
\text { Physical Internet and advanced logistics } \\
\text { Modularity and open architectures } \\
\text { Next-generation connectivity } \\
\text { Big Data and intelligent processing } \\
\text { Standardisation }\end{array}$ & $\begin{array}{l}\text { Included but grouped with ICT } \\
\text { Included but grouped with ICT } \\
\text { Included wide range of potential applications to } \\
\text { transport } \\
\text { Included because of high impact score } \\
\text { Included but grouped with Big Data } \\
\text { Excluded because enabler, not technology itself } \\
\text { Included because high in terms of benefits } \\
\text { Included because high in terms of benefits } \\
\text { Excluded because enabler, not technology itself }\end{array}$ \\
\hline
\end{tabular}

- It was judged that the physical Internet should be eliminated from the list since it required the building of new infrastructure, which was outside the scope of the project.

- Other technologies suggested for elimination were robots at ports and highspeed intercity travel, since both most likely involved the development of new infrastructure.

Final selections (see Table A.5) came down to the practical point that it was necessary to limit the number of technologies considered in each workshop, to between three and four (ideally three). To do this, first we grouped similar technologies together. For example, next-generation ICT, telecommuting and telehealth were grouped together, on the basis that telecommuting and telehealth were facilitated by next-generation ICT development. We also grouped together Big Data, user apps and intelligent processing, on the basis that it would be difficult to distinguish the different impacts of these on different factors and travel. We then conducted a cross-impact analysis of the remaining technologies on the scenario factors and overall travel. ${ }^{14}$ From this exercise, the following technologies had the highest impact scores:

- Autonomous vehicles

- Next-generation ICT connectivity / telecommuting / telehealth

- Physical Internet and advanced logistics

- $\quad$ Advanced manufacturing (3D printing)

- User apps, Big Data, intelligent processing

- Internet of Things.

We found that many of the scores in the 'physical Internet and advanced logistics' category were driven by advanced logistics, and that this was probably better aggregated with Big Data and intelligent processing. Moreover, the technology 
Table A.6. Recommended technologies to be considered in scenarios

\begin{tabular}{|c|c|c|c|c|c|}
\hline Area & $\begin{array}{l}\text { Work/ } \\
\text { business }\end{array}$ & Retail & Health & $\begin{array}{l}\text { Long- } \\
\text { distance } \\
\text { travel }\end{array}$ & Freight \\
\hline Autonomous vehicles & $\checkmark \checkmark$ & & $\checkmark$ & $\checkmark \checkmark$ & $\checkmark \checkmark$ \\
\hline Next-generation connectivity & $\checkmark \checkmark$ & $\checkmark \checkmark$ & $\checkmark \checkmark$ & $\checkmark$ & \\
\hline $\begin{array}{l}\text { Advanced manufacturing } \\
\text { (3D printing) }\end{array}$ & & $\checkmark$ & & & $\checkmark \checkmark$ \\
\hline Internet of Things & & $\checkmark \checkmark$ & $\checkmark$ & & \\
\hline $\begin{array}{l}\text { User apps, Big Data, intelligent pro- } \\
\text { cessing and advanced logistics }\end{array}$ & $\checkmark$ & $\checkmark \checkmark$ & $\checkmark$ & $\checkmark$ & $\checkmark \checkmark$ \\
\hline $\begin{array}{l}\text { Novel materials and embedded } \\
\text { sensors in infrastructure }\end{array}$ & $\checkmark \checkmark$ & & & $\checkmark \checkmark$ & $\checkmark \checkmark$ \\
\hline
\end{tabular}

Notes: Two ticks indicate high influence; one tick lower influence.

review work had recommended eliminating the physical Internet on the basis that it required new infrastructure, which was considered outside the scope of the project.

We included $\mathrm{V} 2 \mathrm{~V}$ and $\mathrm{V} 2 \mathrm{I}$ in our analysis, but we found it difficult to separate out their impacts on travel activities from those of autonomous vehicles (and the impacts seemed to be lower, thus we chose to focus on autonomous vehicles).

Based on the impact analysis, we made the following suggestions for which technology to discuss in each workshop. The number of ticks provides some indication of importance (see Table A.6). 



\section{Appendix B: Scenario methodology}

This appendix describes in more detail the methodology used to develop the scenarios presented in this report. Exploring transport technology futures is a complex task that involves a considerable level of uncertainty. Scenarios are a time-tested tool to address this uncertainty (Pillkahn 2008). A scenario is a 'story with plausible cause and effect links that connects a future condition with the present, while illustrating key decisions, events, and consequences throughout the narrative' (Glenn 2007).

Scenarios were first used to evaluate multiple potential futures by RAND researchers in the 1960s (Kahn \& Wiener 1967), and techniques to develop scenarios have been considerably modified and expanded since then. Early techniques focused on qualitative descriptions of different futures (scenario writing) and mostly used intuitive approaches (Kahn \& Pepper 1979). Over the years, different process steps were strengthened and formalised to address the complexity of strategic issues. For example, consistency analyses began to be used to measure scenario quality and relevance. Results were documented in narratives with statements relating to key indicators. Today, scenarios are developed with more quantitative approaches that rely on multiple model runs and computer tools, which enhance the ability to address system complexity and make the resulting scenarios less arbitrary (see, for example, Gordon \& Hayward 1968; Kane 1972; Gausemeier et al. 1998; Lempert et al. 2003; Bryant \& Lempert 2010; Rozenberg et al. 2012; Schweizer \& Kriegler 2012; Gerst et al. 2013).

Today, as discussed in Amer et al. (2013), many methodologies are available to develop scenarios. Our approach applies both quantitative and qualitative components, combining expert opinion, gathered via inperson workshops, with cross-impact analysis, consistency analysis and cluster analysis using specialised computer support. We follow a fivestep process (see Figure A.3): (i) select activities (domains that affect mobility directly); (2) identify critical factors; (3) elicit projections on factors, via expert workshops; (4) integrate into scenario frameworks, using consistency analysis of projections and cluster analysis software; and (5) produce scenario narratives. Each of these steps is discussed in further detail below.

\section{Step 1: Select activities}

The aim of this part of the study is to develop scenarios about how transport may change in future. We adopt a holistic framework that recognises that individuals, households and even businesses need and desire to participate in activities - and participation in these activities generates travel (Recker et al. 1986; Axhausen \& Gärling 1992; Ben-Akiva et al. 1996, Moktahrian \& Salomon 2001). We assume that in future people will continue to need and desire to participate in such activities, but this participation, and the travel generated by it, may be influenced by social and economic factors and future technologies. Moreover, some technologies may replace the need to travel - for example next-generation ICT may reduce the need to travel to work or for business. Online shopping may also replace the need to travel for shopping, although to date it is not clear whether such services are substitutes or complements for travel. Mans et al. (2012) cite that most studies on this topic have found mixed results: in some cases, online purchases replaced a shopping trip and therefore reduced shopping-related travel, but in others e-commerce resulted in new shopping trips, for example because people may 


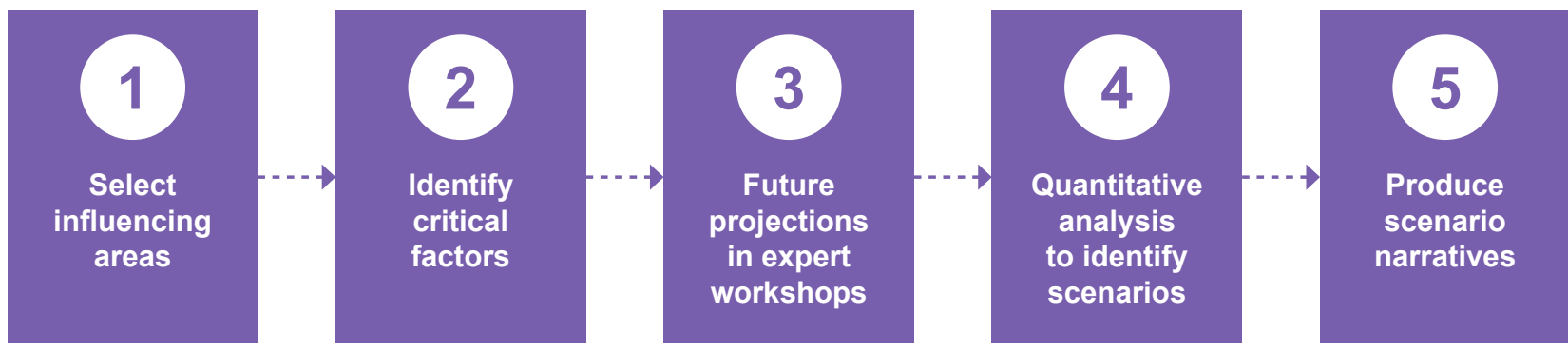

Figure A.3. Scenario methodology

have made a special trip to a shop for a specific item found online. Further, they note that the delivery of online merchandise may increase the number of trips for mail and package delivery.

In this report we focus on five activities that generate travel - work and business, retail, healthcare, long-distance travel and freight based on several criteria: the share of journeys made for these purposes, the possibility of major change in the activity, and the need to capture both within-city and between-city travel (which includes travel by UK residents outside the country and visits to the UK by residents of other countries). Freight movement is included because it is important to the economy, it contributes to and is affected by transport capacity constraints, delivery of packages to individuals is an area of increasing growth, and many of these movements are between businesses, so they would not be captured in the other four activities.

Work and business: In the UK, as in most countries, commute journeys (i.e. to work and other travel undertaken for business purposes) comprise the highest number of daily journeys - 19 per cent of all trips made by English residents in 2014 were for commuting or business purposes, accounting for 30 per cent of all distance travelled (DfT 2015b). This sector would cover potential changes in working arrangements, for example through teleworking, and business, for example through virtual meetings.
Retail: Shopping by individuals for groceries accounts for just under 1 in 5 trips (19 per cent) and 11 per cent of all distance travelled (DfT 2015b). Future shopping activities may be influenced by improvements in online shopping and delivery, new modes of delivery and the use of new technologies such as 3D printing.

Healthcare: While medical journeys are a small percentage of all journeys (about 2 per cent), ${ }^{15}$ given an ageing population and advances in healthcare delivery this may be an increasingly important area of focus.

Long-distance travel: Long-distance journeys are those greater than 50 miles one-way for commuting, business or leisure, including both trips within the UK and international travel. Domestic trips over 50 miles (including the domestic part of international trips, if that part is itself over 50 miles) represent 2 per cent of trips but 30 per cent of the total distance travelled in Great Britain (Rohr et al. 2013). Such journeys may be influenced by changes in leisure time and by autonomous vehicles.

Freight: The movement of goods both between businesses, as well as between businesses and individuals, is important because goods are moved by a variety of modes, just as individuals are, and because goods movement often uses the same capacity as people (e.g. lorries travel on motorways in the same way as personal vehicles). In many cases people and goods are competing for the same capacity. 
DfT (2015b) observe that trips for shopping and commuting (and visiting friends) have fallen consistently since 1995/97, and that this trend could have been impacted by delivery of goods at home and homeworking, both of which have increased since 2002.

\section{Step 2: Identify critical factors}

For each activity, through desk research and literature review we identified key social and economic factors that could substantially influence related travel. We focused on those factors that are critical and uncertain. These are summarised in Table A.7. A number of factors were found to be common across activities, meaning that we expect them to affect travel demand in all of them. These are identified as common factors.

In a separate task (see Appendix A), we identified six technologies that might also have a substantial influence on activities or related travel. These are summarised in Table A.6 (Appendix A).

Table A.7. Activities and critical factors

\begin{tabular}{|c|c|}
\hline Activities & Factor \\
\hline \multirow[t]{5}{*}{ Work/business } & Amount of telework \\
\hline & Commute distance \\
\hline & London-centric development \\
\hline & Proportion of in-person business meetings \\
\hline & Real estate prices \\
\hline \multirow[t]{4}{*}{ Retail } & Total consumption \\
\hline & Proportion of on-line sales \\
\hline & Person-to-person sales \\
\hline & Proportion of retail in high streets \\
\hline \multirow[t]{5}{*}{ Health } & Proportion of elderly people living at home \\
\hline & Health of the nation \\
\hline & Average frequency of medical visits \\
\hline & Centralisation of the health system \\
\hline & Proportion of healthcare delivered in non-traditional settings \\
\hline \multirow[t]{4}{*}{ Long-distance travel } & Leisure time \\
\hline & Attitudes to travel \\
\hline & Attitudes to security \\
\hline & Second home ownership \\
\hline \multirow[t]{5}{*}{ Freight } & Growth in package delivery \\
\hline & Disintermediation \\
\hline & Dominant warehousing and distribution strategy \\
\hline & Reshoring of manufacturing \\
\hline & Port capacity \\
\hline \multirow[t]{6}{*}{ Common factors } & GDP growth \\
\hline & Population growth \\
\hline & Proportion of the elderly \\
\hline & Strength of sterling \\
\hline & Cost of travel \\
\hline & Travel time / convenience \\
\hline
\end{tabular}




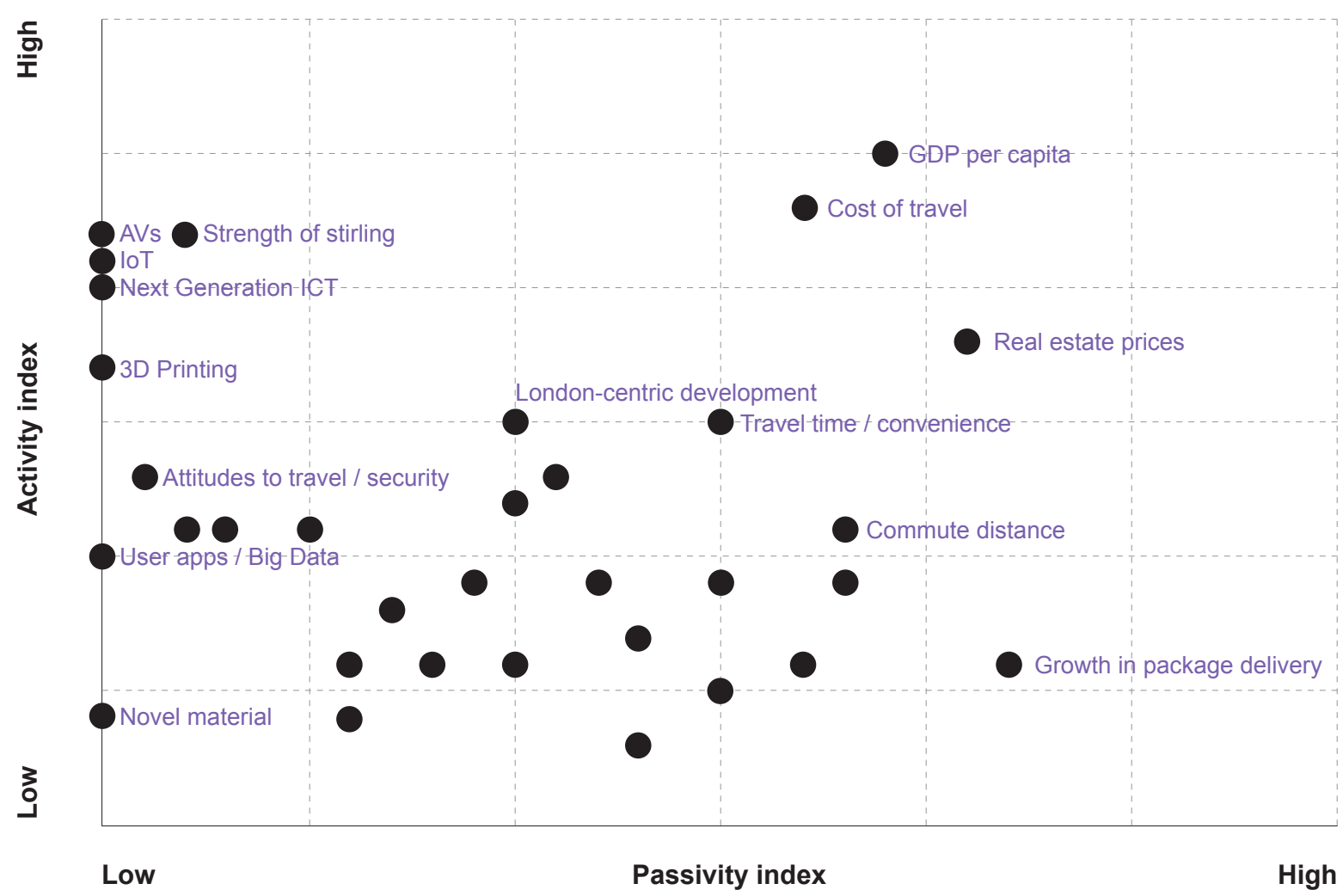

Figure A.4. Factor impact measured through cross impact analysis

As part of the work to finalise the factors and technologies for the scenarios, we undertook a cross-impact analysis to quantify the strength of influence of different factors. This supported the identification of the key drivers in the system as a whole (see Gausemeier et al. (1998) for a further description of this type of analysis). We recorded the impacts that the different descriptors have on each other in a cross-impact matrix using a scale from 0 (no impact) to 3 (strong impact). For example, we hypothesised that per capita GDP growth has a strong influence on total consumption, so that relationship would be rated 3 , while part-time work is unlikely to have an effect on the proportion of elderly living at home, so that was rated 0 .

The outcome of this analysis is the system diagram illustrated in Figure A.4. The Activity Index of a factor is the number of other factors that it influences. For example, GDP per capita growth and cost of travel influence a large number of other factors, so they are highly active. The Passivity Index is the opposite - the number of other factors that influence a factor. For example, many other factors affect package delivery, such as GDP per capita, cost of travel, etc., so this is considered a highly passive factor. A factor with both a high Activity Index and a high Passivity Index is strongly interconnected in the system, being both a driver and being driven at the same time.

In our analysis we assumed that new technologies could influence factors - for example, the introduction of autonomous vehicles would influence cost of travel and commute distance, among others. We also assumed that the technology factors would not be influenced by other factors, which is why their Passivity Index is zero. 


\section{Step 3: Elicit projections on critical factors}

The research team held one workshop for each activity to gather expert opinion on projections for the common factors, for activity-specific factors, the impact of both of these on total travel, as well as the impact of technologies on factors and travel. The workshops were all held in London in June 2015. Over 75 experts participated across all of the workshops, including policymakers as well as people from academia and the private sector; most were experts in a particular sector, while others were experts on particular technologies.
Prior to each workshop, each expert received a background paper consisting of three parts: trends and projections for the relevant common factors, definitions and trends for factors specific to the activity, and descriptions of the key technologies for the activity. The research team also circulated official projections for the common factors, where these existed, as a basis for discussion in the workshop. The projection could be qualitative or quantitative, as illustrated in the tables below.

Table A.8 presents the projections for the common factors and Table A.9 presents projections for the factors in the activity areas.

Table A.8. Projections for common factors

\begin{tabular}{|c|c|}
\hline Factor & Projection \\
\hline \multirow[t]{3}{*}{ GDP per capita growth } & Dampened, relative to baseline \\
\hline & $1.6 \%$ p.a. baseline growth, according to DfT central forecast ${ }^{1}$ \\
\hline & Increased, relative to baseline \\
\hline \multirow[t]{3}{*}{ Population growth } & Dampened, relative to baseline \\
\hline & $0.6 \%$ p.a. baseline growth, according to ONS forecast ${ }^{2}$ \\
\hline & Increased, relative to baseline \\
\hline \multirow[t]{3}{*}{ Proportion of the elderly } & Lower than baseline \\
\hline & 1 in 4 baseline proportion, according to ONS forecast ${ }^{3}$ \\
\hline & Higher than baseline \\
\hline \multirow[t]{3}{*}{ Strength of sterling } & Lower than baseline \\
\hline & Baseline, approximately $€ 1.30$ and $€ 1.60$ \\
\hline & Higher than baseline \\
\hline \multirow[t]{3}{*}{ Cost of travel } & Cheaper than baseline \\
\hline & Baseline $^{4}$ \\
\hline & More expensive than baseline \\
\hline \multirow[t]{3}{*}{ Travel time / convenience } & Slower than baseline \\
\hline & Baseline $^{5}$ \\
\hline & Faster than baseline \\
\hline
\end{tabular}

${ }^{1}$ As provided by DfT (2015b).

${ }^{2}$ According to ONS statistics, the UK population is projected to increase from around 65 million in 2015 to 72.6 million in 2035 (a growth rate of around $0.6 \%$ per annum). This is due to natural increase (more births than deaths) and because it is assumed there will be more immigrants than emigrants (a net inward flow of migrants).

${ }^{3}$ Based on ONS 2012 principal projections, the proportion of people aged 65 and over is set to increase from around 1 in 5 (18\%) in 2015 to around 1 in 4 (24\%) in 2035. The overall growth rate of 65 and over people from 2015 to 2035 is $49 \%$ (2\% annual average). A growth rate of $49 \%$ would mean an increase of 5.7 million people aged 65 and over from 2015 to 2035, i.e., 11.6 million in 2015 to 17.3 million in 2035.

${ }^{4}$ Based on DfT's Fuel Price Forecasting Model assumes that the price of petrol and diesel will increase in future, but that fuel efficiency improvements will lead to reductions in the cost of road travel over time for cars and LGVs, and increases for HGVs.

${ }^{5}$ The most recent road traffic forecasts made by DfT (see point 1 above) predict that road traffic will grow between $19 \%$ and $55 \%$ between 2010 and 2040 , resulting in road speed changes from $3.1 \%$ faster to $11.8 \%$ slower, on average, depending on the scenario. 
Table A.9. Projections for activity-specific factors

\begin{tabular}{|c|c|c|}
\hline \multicolumn{2}{|c|}{ Factor } & Projection \\
\hline \multirow{10}{*}{ 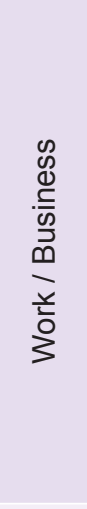 } & \multirow[t]{2}{*}{ Amount of telework } & Decreasing \\
\hline & & Increasing \\
\hline & \multirow[t]{2}{*}{ Commute distance } & Decreasing \\
\hline & & Increasing \\
\hline & \multirow[t]{2}{*}{ London-centric development } & Lower proportion \\
\hline & & Higher proportion \\
\hline & \multirow[t]{2}{*}{ Proportion of in-person business meetings } & Decreasing \\
\hline & & No change \\
\hline & \multirow[t]{2}{*}{ Real estate prices } & Decreasing \\
\hline & & Increasing \\
\hline \multirow{8}{*}{$\begin{array}{l}\overline{\bar{\pi}} \\
\stackrel{0}{\square} \\
\widetilde{\square}\end{array}$} & \multirow[t]{2}{*}{ Total consumption } & Decreasing \\
\hline & & Increasing \\
\hline & \multirow[t]{2}{*}{ Proportion of on-line sales } & Decreasing \\
\hline & & Increasing \\
\hline & \multirow[t]{2}{*}{ Person-to-person sales } & Decreasing \\
\hline & & Increasing \\
\hline & \multirow[t]{2}{*}{ Proportion of retail in high streets } & Decreasing \\
\hline & & Increasing \\
\hline \multirow{9}{*}{$\begin{array}{l}\frac{F}{\mathbb{D}} \\
\frac{\Phi}{1}\end{array}$} & \multirow[t]{2}{*}{ Proportion of elderly living at home } & No change \\
\hline & & Increasing \\
\hline & \multirow[t]{2}{*}{ Health of the nation } & Decreasing \\
\hline & & Increasing \\
\hline & \multirow[t]{2}{*}{ Average frequency of medical visits } & Decreasing \\
\hline & & Increasing \\
\hline & \multirow[t]{3}{*}{ Proportion of healthcare delivered in 'non-traditional' settings } & Decreasing \\
\hline & & No change \\
\hline & & Increasing \\
\hline \multirow{5}{*}{ 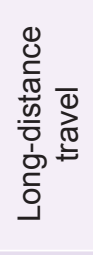 } & \multirow[t]{3}{*}{ Leisure time } & Decreasing \\
\hline & & No change \\
\hline & & Increasing \\
\hline & \multirow[t]{2}{*}{ Attitudes towards environment } & Less important \\
\hline & & More important \\
\hline \multirow{9}{*}{$\begin{array}{l}\frac{\vec{\nu}}{.0} \\
\frac{0}{0} \\
\frac{1}{4}\end{array}$} & \multirow[t]{2}{*}{ Growth in package delivery } & Slight growth \\
\hline & & Significant growth \\
\hline & \multirow[t]{2}{*}{ Disintermediation ${ }^{1}$} & No change \\
\hline & & Increasing \\
\hline & \multirow[t]{3}{*}{ Dominant warehousing and distribution strategy } & More centralisation \\
\hline & & No change \\
\hline & & More decentralisation \\
\hline & \multirow[t]{2}{*}{ Reshoring of manufacturing } & No change \\
\hline & & Increasing \\
\hline
\end{tabular}

${ }^{1}$ Disintermediation is the practice of bypassing one or more levels in the supply chain to distribute goods directly to customers. 
We asked experts whether they agreed with these projections, and to provide reasons that a certain projection might be plausible and under what conditions. We also asked them to discuss any qualitative effect on travel behaviour and mode choice, as well as the impact of the specific technologies on these factors. In a few cases, factors were dropped from the analysis when the experts in a particular workshop determined they would not have a significant impact; these are not included in Table A.9.

\section{Step 4: Integrate into scenario frameworks}

To assemble the projections into distinct scenarios, we established consistency (or lack thereof) among projections across all factors. Consistency here means how well the projections between two factors 'fit together' and how realistic it would be for both of them to happen simultaneously. The analysis is undertaken by examining the matrix of projections for all factors (see extract in Figure A.5). We judge how consistent or compatible a pair of projections is, assigning a 5 where projections are totally consistent and a 1 if they are totally inconsistent. For example, high GDP growth is deemed highly consistent with increasing real estate prices. On the other

\section{Evaluation scale}

$1=$ totally inconsistent

2 = partly inconsistent

$3=$ neutral

$4=$ partly consistent

$5=$ strongly consistent

\begin{tabular}{|l|l|}
\hline Commute distance & decreasing \\
\hline & no change \\
\hline & increasing \\
\hline $\begin{array}{l}\text { London-centric } \\
\text { development }\end{array}$ & lower proportion \\
\hline & no change \\
\hline higher proportion \\
\hline Proportion of in-person & decreasing \\
\hline business meetings & no change \\
\hline Real estate prices & decreasing \\
\hline & no change \\
\hline increasing
\end{tabular}
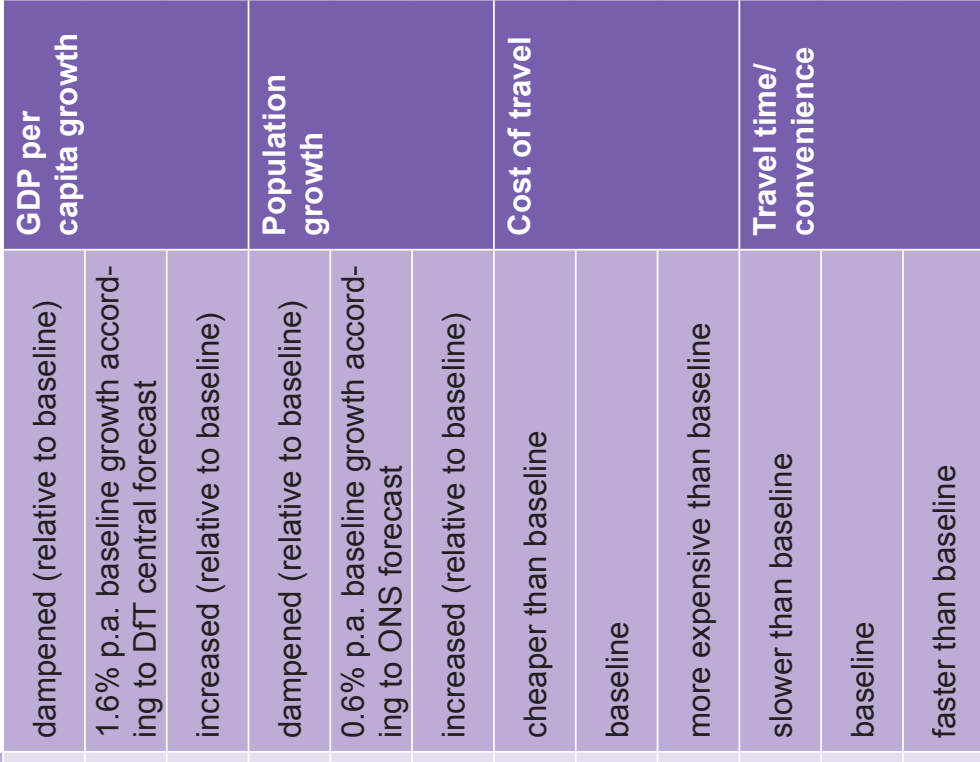

Figure A.5. Extract from the consistency matrix 
hand, high GDP growth is deemed inconsistent with decreasing real estate prices. A value of 3 suggests a neutral case, where the projections are neither highly consistent nor inconsistent.

The consistency matrix was then fed into an online tool, the RAHS platform. ${ }^{16}$ RAHS is a prototype of a web-based foresight platform that the Future Analysis Branch of the German Federal Ministry of Defence developed and funded to enhance external cooperation with industrial and scientific partners and thus to strengthen the methodological fundamentals of its own foresight work. Instead of providing a single software solution only for scenario development, it supports foresight projects with a variety of alternative foresight methods within an online environment (Brockmann 2012; Durst et al. 2012). RAHS was designed based on a comprehensive scanning of internationally applied foresight methods and tools, including the Z_punkt Foresight-Toolbox, the Joint Research Centre (JRC) FOR-LEARN Online Foresight Guide, the Foresight Horizon Scanning Centre (HSC) toolkit, the European Union research project iKnow, and compilations of future research methodologies in the Millennium Project by Glenn \& Gordon (2009) and Pillkahn (2008).

The RAHS platform was used to analyse billions of mathematically possible pairs of projections for the factors across all influencing areas and to eliminate the pairs deemed inconsistent in the consistency analysis that preceded this step. The exploratory scenario-construction toolbox in RAHS isolated clusters made up of homogeneous groups of descriptors and projections based on the consistency analysis results. (More details on the application of consistency logic and cluster analysis implemented in the RAHS platform can be found in Gausemeier et al. (1998).)
We made two changes in the use of RAHS. First, because of the high number of factors and projections, we ended up dropping several factors and projections that we judged less important to the overall results. Specifically the following factors were dropped:

- Mode share, on the basis that this could be considered explicitly during the scenario development, as a result of other factors.

- Attitudes to security, which were deemed to be less important by experts.

- Centralisation of the health system, which was impacted less by the types of technologies examined in this study.

Second, we made separate runs considering one technology at a time, and then grouped together outputs with similar characteristics. These varied in two significant ways: the projected levels of GDP growth and total amount of travel. Bearing in mind our aim to represent a spectrum of future scenarios, we chose clusters that reflected a range of GDP growth and travel. These formed the basis for the scenarios.

Table A.10 illustrates the RAHS outputs for the high-GDP clusters, for each technology, which became the basis for the Drive Ahead scenario. The number in each cell refers to the percentage of combinations that contain the projection (therefore all columns for a single factor sum to 100). The key characteristics of each cluster are defined by the factor projection with the highest values. Thus the high-GDP clusters are defined by increased population growth, lower proportions of the elderly, lower cost of travel, higher miles travelled, etc. We deleted the sixth technology, novel materials and embedded sensors, from this analysis because ultimately the experts did not find it important to future travel. 
Table A.10. High GDP clusters, by technology type

\begin{tabular}{|c|c|c|c|c|c|c|}
\hline \multirow[b]{2}{*}{ Descriptor } & \multirow[b]{2}{*}{ Projection } & \multicolumn{5}{|c|}{ High GDP clusters } \\
\hline & & AVs & $\begin{array}{c}\text { Next } \\
\text { Gen ICT }\end{array}$ & $\begin{array}{l}\text { 3D } \\
\text { printing }\end{array}$ & loT & $\begin{array}{c}\text { User } \\
\text { apps, } \\
\text { Big } \\
\text { Data }\end{array}$ \\
\hline \multirow{3}{*}{ GDP per capita growth } & Dampened (relative to baseline) & 0 & 0 & 0 & 0 & 0 \\
\hline & $1.6 \%$ p.a. baseline growth & 0 & 17 & 0 & 0 & 0 \\
\hline & Increased (relative to baseline) & 100 & 83 & 100 & 100 & 100 \\
\hline \multirow{3}{*}{ Population growth } & Dampened (relative to baseline) & 0 & 0 & 0 & 0 & 0 \\
\hline & $0.6 \%$ p.a. baseline growth & 0 & 0 & 0 & 0 & 0 \\
\hline & Increased (relative to baseline) & 100 & 100 & 100 & 100 & 100 \\
\hline \multirow{3}{*}{ Proportion of the elderly } & Lower than baseline & 100 & 100 & 96 & 100 & 97 \\
\hline & 1 in 4 baseline proportion & 0 & 0 & 0 & 0 & 0 \\
\hline & Higher than baseline & 0 & 0 & 4 & 0 & 3 \\
\hline \multirow{3}{*}{ Strength of sterling } & Lower than baseline & 13 & 0 & 4 & 57 & 12 \\
\hline & Baseline (approx $€ 1.30$ and $\$ 1.60$ ) & 16 & 17 & 13 & 9 & 12 \\
\hline & Higher than baseline & 71 & 83 & 83 & 35 & 76 \\
\hline \multirow{3}{*}{ Cost of travel } & Cheaper than baseline & 61 & 67 & 87 & 100 & 64 \\
\hline & Baseline & 39 & 17 & 13 & 0 & 36 \\
\hline & More expensive than baseline & 0 & 17 & 0 & 0 & 0 \\
\hline \multirow{3}{*}{ Travel time/ convenience } & Slower than baseline & 0 & 0 & 0 & 13 & 0 \\
\hline & Baseline & 0 & 0 & 0 & 26 & 0 \\
\hline & Faster than baseline & 100 & 100 & 100 & 61 & 100 \\
\hline \multirow{3}{*}{ Leisure time } & Decreasing & 84 & 33 & 96 & 30 & 97 \\
\hline & No change & 7 & 17 & 0 & 4 & 0 \\
\hline & Increasing & 10 & 50 & 4 & 65 & 3 \\
\hline \multirow{2}{*}{$\begin{array}{l}\text { Attitudes towards envi- } \\
\text { ronment }\end{array}$} & Less important & 13 & 17 & 48 & 26 & 39 \\
\hline & More important & 87 & 83 & 52 & 74 & 61 \\
\hline \multirow{2}{*}{ Amount of telework } & Decreasing & 100 & 33 & 96 & 17 & 97 \\
\hline & Increasing & 0 & 67 & 4 & 83 & 3 \\
\hline \multirow{2}{*}{ Commute distance } & Decreasing & 7 & 0 & 0 & 0 & 0 \\
\hline & Increasing & 94 & 100 & 100 & 100 & 100 \\
\hline \multirow{2}{*}{$\begin{array}{l}\text { London-centric develop- } \\
\text { ment }\end{array}$} & Lower proportion & 7 & 83 & 4 & 13 & 3 \\
\hline & Higher proportion & 94 & 17 & 96 & 87 & 97 \\
\hline \multirow{2}{*}{$\begin{array}{l}\text { Proportion of in-person } \\
\text { business meetings }\end{array}$} & Decreasing & 0 & 83 & 4 & 70 & 3 \\
\hline & No change & 100 & 17 & 96 & 30 & 97 \\
\hline \multirow{2}{*}{ Real estate prices } & Decreasing & 7 & 0 & 0 & 0 & 0 \\
\hline & Increasing & 94 & 100 & 100 & 100 & 100 \\
\hline \multirow{2}{*}{ Total consumption } & Decreasing & 0 & 0 & 0 & 0 & 0 \\
\hline & Increasing & 100 & 100 & 100 & 100 & 100 \\
\hline \multirow{2}{*}{ Proportion of online sales } & Decreasing & 0 & 0 & 0 & 0 & 0 \\
\hline & Increasing & 100 & 100 & 100 & 100 & 100 \\
\hline \multirow{2}{*}{ Person-to-person sales } & Decreasing & 0 & 0 & 0 & 0 & 0 \\
\hline & Increasing & 100 & 100 & 100 & 100 & 100 \\
\hline \multirow{2}{*}{$\begin{array}{l}\text { Proportion of retail in high } \\
\text { streets }\end{array}$} & Decreasing & 100 & 100 & 100 & 100 & 100 \\
\hline & Increasing & 0 & 0 & 0 & 0 & 0 \\
\hline
\end{tabular}




\begin{tabular}{|c|c|c|c|c|c|c|}
\hline \multirow[b]{2}{*}{ Descriptor } & \multirow[b]{2}{*}{ Projection } & \multicolumn{5}{|c|}{ High GDP clusters } \\
\hline & & AVs & $\begin{array}{c}\text { Next } \\
\text { Gen ICT }\end{array}$ & $\begin{array}{l}\text { 3D } \\
\text { printing }\end{array}$ & IoT & $\begin{array}{l}\text { User } \\
\text { apps, } \\
\text { Big } \\
\text { Data }\end{array}$ \\
\hline \multirow{2}{*}{$\begin{array}{l}\text { Proportion of elderly } \\
\text { people living at home }\end{array}$} & No change & 23 & 50 & 78 & 96 & 49 \\
\hline & Increasing & 77 & 50 & 22 & 4 & 52 \\
\hline \multirow{2}{*}{ Health of the nation } & Decreasing & 19 & 0 & 9 & 0 & 0 \\
\hline & Increasing & 81 & 100 & 91 & 100 & 100 \\
\hline \multirow{2}{*}{$\begin{array}{l}\text { Average frequency of } \\
\text { medical visits }\end{array}$} & Decreasing & 0 & 100 & 52 & 100 & 49 \\
\hline & Increasing & 100 & 0 & 48 & 0 & 52 \\
\hline \multirow{3}{*}{$\begin{array}{l}\text { Proportion of healthcare } \\
\text { delivered in 'non-tradi- } \\
\text { tional' settings }\end{array}$} & Decreasing & 55 & 0 & 30 & 0 & 24 \\
\hline & No change & 45 & 0 & 61 & 9 & 52 \\
\hline & Increasing & 0 & 100 & 9 & 91 & 24 \\
\hline \multirow{2}{*}{$\begin{array}{l}\text { Growth in package } \\
\text { delivery }\end{array}$} & Slight growth & 0 & 0 & 0 & 0 & 0 \\
\hline & Significant growth & 100 & 100 & 100 & 100 & 100 \\
\hline \multirow{2}{*}{ Disintermediation } & No change & 7 & 0 & 0 & 0 & 0 \\
\hline & Increasing & 94 & 100 & 100 & 100 & 100 \\
\hline \multirow{3}{*}{$\begin{array}{l}\text { Dominant warehousing } \\
\text { and distribution strategy }\end{array}$} & Emphasis on centralisation & 81 & 0 & 4 & 4 & 36 \\
\hline & No change & 0 & 0 & 0 & 0 & 0 \\
\hline & Emphasis on decentralisation & 19 & 100 & 96 & 96 & 64 \\
\hline \multirow{2}{*}{$\begin{array}{l}\text { Reshoring of manufac- } \\
\text { turing }\end{array}$} & No change & 13 & 0 & 0 & 0 & 12 \\
\hline & Increasing & 87 & 100 & 100 & 100 & 88 \\
\hline \multirow{3}{*}{ Miles travelled } & Decreasing & 0 & 0 & 0 & 0 & 0 \\
\hline & No change & 0 & 0 & 0 & 0 & 0 \\
\hline & Increasing & 100 & 100 & 100 & 100 & 100 \\
\hline
\end{tabular}

Note: The number in each cell refers to the percentage of combinations that contain the projection. Therefore all columns for a single factor sum to 100. Source: RAHS analysis.

\section{Step 5: Produce scenario narratives}

Of the many clusters produced, the research team selected three to develop further. These varied in two significant ways: the projected levels of GDP growth and total miles travelled. The Driving Ahead scenario is based around high growth in both measures, while Live Local and Digital Divide have lower (but differing) growth rates in GDP and lower miles travelled.
Drawing on the reasoning and assumptions that surfaced during the expert workshops, we developed written narratives. To further validate the scenarios, we invited experts who attended the workshops to comment on whether they found the scenario frameworks plausible, understandable and internally consistent. Although their ratings of the scenarios were generally positive, we used the critical feedback to ensure the relevance and sharpen the content of the scenarios. 
Without substantial investment, by 2035 the UK will experience severe congestion across its transport infrastructure. Innovate UK commissioned this study to explore how emerging technologies might be able to address the problem of congestion by using capacity more efficiently, supporting different mode choices, and managing or reducing travel demand.

This study included three broad phases. First, we identified six key technologies that a range of experts think may influence the effectiveness and efficiency of the transport network: autonomous vehicles, next-generation ICT connectivity, advanced manufacturing (such as 3D printing), user apps / Big Data and intelligent processing, the Internet of Things, and novel materials and embedded sensors in infrastructure. Next we developed future scenarios to examine the influence of these technologies on travel. Three scenarios were developed, based around activities that contribute to travel demand: work/business, health, retail, long-distance business and leisure travel, and freight movement. The scenarios are: Driving Ahead, based on higher-than-forecast economic growth and widespread use of autonomous vehicles; Live Local, with moderate growth and use of travel substitution due to advances in communications technology; and Digital Divide, in which technologies advance but are not evenly distributed because of rising income inequality. In the third phase of the study, we interviewed experts and policymakers about the key policy implications of the scenarios, what innovation investments would be robust across scenarios, and what are the barriers and enablers for each technology. Using these responses, we developed a strategic roadmap to inform future UK policies and investments. 